MICHELLI MACIEL

Contribuição ambiental para o planejamento da oferta futura de gás natural no Brasil

SÃo PaUlo

2018 


\section{MICHELLI MACIEL}

Contribuição ambiental para o planejamento da oferta futura de gás natural no Brasil

Dissertação apresentada à Escola Politécnica da Universidade de São Paulo para a obtenção do título de Mestre em Ciências.

Orientador:

Prof. Dr. Luiz.Alexandre Kulay 


\section{MICHELLI MACIEL}

Contribuição ambiental para o planejamento da oferta futura de gás natural no Brasil

Dissertação apresentada à Escola Politécnica da Universidade de São Paulo para a obtenção do título de Mestre em Ciências.

Área de Concentração:

Engenharia Química

Orientador:

Prof. Dr. Luiz.Alexandre Kulay

SÃo Paulo

2018 
Este exemplar foi revisado e corrigido em relação à versão original, sob responsabilidade única do autor e com a anuência de seu orientador.

São Paulo, de de

Assinatura do autor:

Assinatura do orientador:

Catalogação-na-publicação

Maciel, Michelli

Contribuição ambiental para o planejamento da oferta futura de gás natural no Brasil / M. Maciel -- versão corr. -- São Paulo, 2018.

$86 \mathrm{p}$.

Dissertação (Mestrado) - Escola Politécnica da Universidade de São Paulo. Departamento de Engenharia Química.

1.Avaliação do Ciclo de Vida,gás natural,EROI,desempenho ambiental I.Universidade de São Paulo. Escola Politécnica. Departamento de Engenharia Química II.t. 


\section{DEDICATÓRIA}

Dedico este trabalho aos meus pais Raul e Porfíria e minha avó Amélia Rosa, por toda a contribuição moral e financeira, por acreditar e se dedicar a mim, para que eu pudesse ter os melhores estudos e assim obter este título. 


\section{AGRADECIMENTOS}

Ao Prof. Dr. Luiz Alexandre Kulay pela orientação, dedicação, conversas, ensinamentos e por ser um grande exemplo.

Aos meus pais Raul e Porfíria, e irmãos por todo incentivo, ajuda e amor.

Aos amigos do GP2, Alex, Letícia, Rose, Fernando, Pini e Prof. Dr. Gil Anderi da Silva, pelos momentos de descontração e por todo auxílio prestado. A Cristina pela especial ajuda e amizade durante todo o desenvolvimento do trabalho.

A Deus pela força, e persistência para a conclusão deste trabalho. 


\section{RESUMO}

Durante as últimas três décadas, o segmento do gás natural vem mostrando avanço expressivo dado a participação na matriz energética brasileira. Esse crescimento se deve a importância da sua oferta, e um potencial de menor impacto ambiental em comparação com outros ativos energéticos de origem fóssil. Devido as essas características o Gás Natural tornou-se uma da fonte de energia mais usada. A despeito dos benefícios técnicos e econômicos o gás natural passou a ser também uma fonte estratégica de energia, principalmente em razão dos menores impactos ambientais que proporciona em comparação ao petróleo e seus derivados. Diante desse quadro o Brasil vem ampliando e disponibilizando, desse recurso em função da descoberta de novos campos em São Paulo e no litoral do Nordeste. No entanto, o mesmo não pode ser dito em relação à infraestrutura de transporte dutoviária, a malha atual de distribuição de gás refinado do país deixa de atender a uma parcela significativa da população residente nas regiões Norte, Centro-Oeste e mesmo, de municípios do interior de estados importantes do Nordeste e do Sudeste. Sendo assim, procurou-se determinar quais os benefícios e ônus, em termos de impactos ambientais acarretados pela situação atual de oferta de Gás Natural e também avaliar para a condição de suprimento futuro para este insumo. Para tal, decidiu-se adotar a Avaliação do Ciclo de Vida (ACV), que trata-se de uma ferramenta de gestão ambiental usada para avaliar impactos ambientais, associados a produtos, processos e serviços. Sua principal característica é de avaliar de forma sistêmica, levando em conta todas as etapas do seu ciclo de vida. O objetivo deste trabalho foi avaliar a contribuição ambiental para o planejamento da oferta futura de gás natural no Brasil, segundo a abordagem de ciclo de vida. Para a análise ambiental, aplicou-se o método de Avaliação de Impacto do Ciclo de Vida (AICV), Recipe midpoint e, para análise energética o método Demanda Primária de Energia foi utilizado, seguido pelo cálculo do Índice de Retorno Energético sobre o investimento (EROI). Os resultados em termos de perfil ambiental indicaram que os processos que mais contribuíram para as emissões de Gases de Efeito Estufa são os de extração e processamento do gás bruto nas Unidades de Processamento de Gás (UPGNs). As principais contribuições para Mudanças Climáticas são emissões $\mathrm{CH}_{4}$, que ocorrem durante o transporte do gás bruto ou acabado. Para a região Sul e Centro-Oeste, observou-se a influência de perdas de $\mathrm{CO}_{2}$, que ocorrem nas estações de compressão que deslocam o gás desde a Bolívia até as regiões Sul e CentroOeste do país. Em termos de Demanda Primária de Energia (PED) os resultados apontam uma concentração de consumos na forma de NRF. Pode-se observar que as perdas de $\mathrm{CH}_{4}$ com maior representatividade ocorre em sua grande maioria na extração do insumo durante a retirada do recurso fóssil das reservas. Para condição de suprimento futuro, a análise mostrou que para PED, a distância de transporte é um fator decisivo de impacto, suplantando inclusive o volume de gás processado a ser distribuído. Já no tocante a Mudanças Climáticas (CC), esses dois parâmetros serão decisivos, sendo que o maior peso para efeito de geração de impacto recairia sobre a quantidade de gás distribuído.

Palavras - chave: Avaliação do Ciclo de Vida, gás natural, EROI, desempenho ambiental. 


\begin{abstract}
During the last three decades, the natural gas field has shown considerable progress as its participation in the Brazilian energy matrix. This growth is related to the supply and demand as well as the potential of lower environmental impact compared to other fossil fuels. Therefore, considering these characteristics, the Natural Gas became one of the main sources of energy. Beside the technical and economic benefits of the natural gas, it has also become a strategic source of energy, mainly due to the smaller impacts that are provided when compared to Oil and its derivatives. In view of this situation, Brazil has expanded and making available this resource due to the discovery of new reserves in São Paulo and the Northeast Coast. However, the scenario of the pipeline transport infrastructure is different. The country's current refined gas distribution network is not serving a significant portion of the residential population in the North, Midwest and even important counties in the countryside of the Northeast and Southeast.Therefore, it was sought to determine, for the current situation, the benefits and the overall environmental impact of the Natural Gas supply and to evaluate the future condition for this input. For this, it was decided to adopt the Cycle Assessment of Life (ACV) which is an environmental management tool used to evaluate environmental impacts associated with products, processes and services. Its main characteristic is to evaluate in a systemic way, taking into account all stages of its life cycle. The goal of this work was to evaluate the environmental contribution to the planning of the future supply of the natural gas in Brazil, according to the life cycle approach. For the environmental analysis, it was used the Life Cycle Impact Assessment (AICV), Recipe midpoint and, for energy analysis, the Primary Energy Demand method was used, followed by the calculation of the Energy Return on Investment Index (EROI). The results in terms of the environmental profile indicated that the processes that most contributed to the GHG emissions are the extraction and processing of the raw gas in the Gas Processing Units (UPGNs). The main contributions to Climate Change are $\mathrm{CH}_{4}$ emissions, which occur during the transportation of the raw or finished gas. For the South and Center-West, it was observed the influence of $\mathrm{CO}_{2}$ losses, which occur in the compression stations that move the gas from Bolivia to the South and Center-West areas of the country. In terms of PED, the results indicate a concentration of consumptions as NRF. It can be observed that the most of the losses of $\mathrm{CH}_{4}$, with great relevance, occur in the extraction of the input during the withdrawal of the fossil resource from the reserves. For the future supply condition the analysis showed that, for PED, the transport distance is a decisive factor, even supplanting the volume of refined gas to be distributed for the impact profile. Regarding $\mathrm{CC}$, these two parameters will be important, and the greatest impact weight will be on the amount of gas distributed.
\end{abstract}

Keywords: Life Cycle Assessment, natural gas, EROI, environmental performance. 


\section{SUMÁRIO}

1. INTRODUÇÃO 15

$\begin{array}{lr}\text { 2. OBJETIVO } & 18\end{array}$

3. MÉTODO DE TRABALHO 19

3.1 Determinação do Estado da Arte da distribuição de gás natural no Brasil 19

3.2 Determinação do Estado da Arte da distribuição de gás natural no Brasil 20

3.2.1 Descrição da Tecnologia e coleta de dados ambientais 20

$\begin{array}{ll}\text { 3.2.2 Método de Escalonamento } & 20\end{array}$

3.2.3 Método para tratamento de perdas $\quad 22$

3.3 Diagnóstico do Desempenho Ambiental 23

3.4 Levantamento alternativos de ampliação do suprimento para atender a demanda futura 23

3.5 Elaboração do Modelo do Sistema de Produto: Situação Futura 24

3.6 Diagnóstico energético e ambiental do suprimento da demanda futura de GN do Brasil 24

4. REVISÃO DE LITERATURA 25

$\begin{array}{ll}4.1 \text { Gás Natural } & 25\end{array}$

4.2 Avaliação de Ciclo de Vida (ACV) 27

4.3 Estudos de ACV relacionados ao Gás Natural

5. MODELAGEM DO CICLO DE VIDA 33

5.1 Tecnologia de Processamento de gás Natural: aspectos gerais 33

5.2 Modelagem do Sistema de Produto 34

5.2.1 Função, Unidade Funcional (UF), Fluxo de referência (FR) 34

5.2.2 Requisitos de qualidade de dados 35

5.2.3 Definição do Sistema de Produto 35

5.2.4 Tratamento de situações de multifuncionalidade 36

5.2.5 Métodos de Avaliação de Impactos de Ciclo de Vida (AICV) 37

5.3 Premissas: Caracterizações Específicas do Sistema de produto 37

5.4 Inventário de Ciclo de Vida (ICV) 42

6. DIAGNÓSTICO DOS DESEMPENHOS ENERGÉTICO E AMBIENTAL DO SISTEMA ATUAL DE DISTRIBUIÇÃO DE GÁS NATURAL. 44

6.1 Análise Energética do suprimento Atual do gás natural do Brasil 44

6.2 Análise Ambiental do suprimento Atual do gás natural do Brasil. 45

6.3 Análise de Resultados para a região Sudeste 45

6.3.1 Mudanças Climáticas

6.3.2 - Demanda Primária de Energia 45 
6.4 Análise dos Resultados para região Nordeste $\quad 47$

6.4.1- Mudanças Climáticas $\quad 47$

6.4.2- Análise da Demanda Primária de Energia: PED 49

6.5 Análise dos Resultados para as reigões Sul e Centro-Oeste.

6.5.1- Mudanças Climáticas 49

6.5.2- Análise da Demanda Primária de Energia: PED 50

6.6 Retorno Energético de Investimento (EROI) 51

6.7 Análise de Sensibilidade. 53

7. LEVANTAMENTO DE ALTERNATIVAS DE AMPLIAÇÃO DO SUPRIMENTO PARA ATENDER A DEMANDA FUTURA DE GÁS NATUUAL.

8. ELABORAÇÃO DO MODELO DO SISTEMA DE PRODUTO DA SITUAÇÃO FUTURA

9. DIAGNÓSTICO DOS DESEMPENHOS ENERGÉTICO E AMBIENTAL DO SUPRIMENTO DA DEMANDA FUTURA DE GÁS NATURAL.

10. CONCLUSÃOO 63

11. REFERÊNCIAS BIBLIOGRÁFICAS

$\begin{array}{ll}\text { APÊNDICES } & 68\end{array}$ 


\section{LISTA DE ABREVIATURAS E SIGLAS}

ABEGÁS

ABNT

$\mathrm{ACV}$

AICV

ANP

$\mathrm{CC}$

$\mathrm{CH}_{4, \mathrm{f}}$

$\mathrm{CNI}$

CNTP

$\mathrm{CO}_{2 \text { eq }}$

$\mathrm{CO}$

EPE

EROI

FR

GASBOL

GEE

GLP

GNC

GNL

ICV

IPCC

ISO

LCA

MME

$\mathrm{MM} \mathrm{m} 3 / \mathrm{d}$

NE

NRB

NRF

NRN

PED
Associação Brasileira das Empresas Distribuidoras de Gás

Associação Brasileira de Normas Técnicas

Avaliação do Ciclo de Vida

Avaliação de Impactos Ambientais do Ciclo de Vida

Agência Nacional de Petróleo

Climate Change (Mudanças Climáticas)

Metano de origem fóssil

Confederação Nacional da Indúdtria

Condições Normais de Temperatura e Pressão

Dióxido de Carbono equivalente

Região Centro-Oeste do Brasil

Empresa de Pesquisa e Energia

Retorno Energético de Investimento

Fluxo de Referência

Gasoduto Brasil-Bolívia

Gases de Efeito Estufa

Gás Liquefeito de Petróleo

Gás Natural Comprimido

Gás Natural Liquefeito

Inventário do Ciclo de Vida

Intergovernamental Painel of Climate Change

International Organization for Standardization

Life Cycle Assessment

Ministério de Minas e Energia

Milhões de Metros Cúbicos por dia

Região Nordeste do Brasil

Biomassa Não Renovável

Fóssil Não Renovável

Nuclear Não Renovável

Demanda Primária de Energia 
PCI

PCS

$\mathrm{RB}$

RWA

RWSG

S

SE

TGB

UF

UPGN

UTG
Poder Calorífico Inferior

Poder Calorífico Superior

Biomassa Renovável

Água Renovável

Geotérmico,Solar e Eólico Renovável

Região Sul do Brasil

Região Sudeste do Brasil

Transportadora Brasileira Gasoduto Bolívia-Brasil

Unidade Funcional

Unidade de Processamento de Gás Natural

Unidade de Tratamento de Gás 


\section{LISTA DE FIGURAS}

Figura 1. Esquema da malha atual de gasoduto do Brasil

Figura 2. Balanço de Gás Natural no Brasil

Figura 3. Sistema para Gás Associado e não Associado

Figura 4. Esquema da Análise de Ciclo de Vida de um produto 28

Figura 5. Estágio do estudo de ACV 29

Figura 6. Cadeia Produtiva de Gás Natural:Upstream 33

Figura 7. Cadeia Produtiva de Gás Natural:Downstream 33

Figura 8. Esquema Simplificado das fontes de provimento de Gás Natural 36

Figura 9. Representação Esquemático do Método de Escalonamento 38 


\section{LISTA DE TABELAS}

Tabela 1. Composição média do gás natural brasileiro 26

Tabela 2. Especificações do gás natural Resolução ANP N ${ }^{\circ} 16$

Tabela 3. Uso do Método de Escalonamento para distribuição do gás natural pelo Brasil 39

Tabela 4. Distância de Transporte da Bacia $\rightarrow$ Terminal $\quad 40$

Tabela 5. Distância Relativa a transporte terrestre Terminal $\rightarrow$ UPGN $\quad 40$

Tabela 6. Distância de transportes terrestres: UPGN $\rightarrow$ Ponto de Entrega (região NE)

Tabela 7. Distância de transportes terrestres: UPGN $\rightarrow$ Ponto de Entrega (região SE) $\quad 41$

Tabela 8. Distância de transportes terrestres: UPGN BO $\rightarrow$ Ponto de Entrega (regiões S e CO) 42

Tabela 9. Impactos Energéticos expressos como PED do fornecimento de gás natural 44

Tabela 10. Impactos Energéticos da distribuição do Gás Natural para SP 46

Tabela 11. Impactos Energéticos da distribuição do Gás Natural para RJ 46

Tabela 12. Resultados de PED para distribuição de 1,0 $\mathrm{m}^{3}$ de gás natural: MG e ES 47

Tabela 13. Perfil Ambiental: Mudanças Climáticas para região NE 48

Tabela 14. Resultados de PED para distribuição de $1,0 \mathrm{~m}^{3}$ de gás natural: região NE 49

Tabela 15. Perfil do Impacto Ambiental: Mudanças Climáticas: Região S e CO 50

Tabela 16. Resultados de PED para distribuição de $1,0 \mathrm{~m}^{3}$ de gás natural: regiões $\mathrm{S}$ e $\mathrm{CO} \quad 51$

Tabela 17. EROI calculado para os diferentes estados e regiões Brasileiras 52

Tabela 18. Análise de Sensibilidade: Proporções de fornecimento de gás desde a Bolívia $\quad 54$

Tabela 19. Alternativas de ampliação futura de distribuição de gás natural para o Brasil 56

Tabela 20. Desempenhos energético e ambiental da ampliações futuras do sistema 61 


\section{INTRODUÇÃO}

Durante as últimas três décadas, o segmento do gás natural vem mostrando avanço expressivo dado a sua participação na matriz energética brasileira. Esse crescimento se deve principalmente a três fatores: (i) um aumento de oferta capaz de atender a demandas de curto e médio prazos do mercado; (ii) à gama variada de suas aplicações, e (iii) ao fato deste ativo energético apresentar potencial impacto ambiental mais baixo do que os de outros derivados fósseis (Vasconcelos et al., 2013). A julgar pelo perfil de evolução que vem demonstrando, o gás natural irá desempenhar um papel fundamental no desenvolvimento do planeta, dado que a partir dele podem ser manufaturados bens de consumo materiais (fertilizantes e químicos), e energéticos (combustíveis) necessários ao desenvolvimento das futuras gerações.

A despeito de seus benefícios técnico-econômicos o gás natural passou a ser também uma fonte estratégica de energia, principalmente em razão dos menores impactos ambientais que proporciona em comparação ao petróleo e seus derivados. A combustão de gás é praticamente isenta de óxidos de enxofre, partículas sólidas, e outros poluentes tóxicos. Além disso, este processo proporciona ainda elevados níveis de rendimento térmico (Woldeyohannes e Majid, 2011).

No caso do Brasil, as perspectivas que cercam o futuro do gás natural corroboram o quadro descrito acima. No entanto, se por um lado o país vem ampliando a disponibilidade desse recurso com a descoberta de novos campos nos litorais do estado de São Paulo, e de unidades federativas da região Nordeste, o mesmo não pode ser dito em relação à infraestrutura de transporte dutoviária. Como se verifica no esquema que consta da Figura 1, a malha atual de distribuição de gás refinado do país deixa de atender a uma parcela significativa da população residente nas regiões Norte, CentroOeste e mesmo, de municípios do interior de estados importantes do Nordeste e do Sudeste.

Mesmo com a operacionalização de novas fontes de suprimento, pouco menos da metade da demanda atual de gás do Brasil segue sendo suprida a partir de importação desde a Bolívia. Esse quadro não deve ser alterado, ao menos no curto prazo, por conta de barreiras e limitações como: (i) incertezas quanto ao volume de gás disponível sob a camada pré-sal; (ii) limitados investimentos em exploração de gás natural onshore nos últimos anos; e, (iii) prazo (elevado, em comparação às necessidades de ampliação que se fazem necessárias) para construção dos gasodutos de transporte e escoamento da produção.

O contrato que dispõe sobre o fornecimento de gás da Bolívia (BO) expira em 2019. Assim, além da necessidade de renegociação de um acordo futuro por parte dos governos envolvidos, o cenário político na Bolívia parece não favorecer investimentos em exploração de gás. Por conta disso, há sérias dúvidas quanto à continuidade deste fornecimento, particularmente, nos níveis que o mercado nacional exige hoje, e que certamente se intensificarão no futuro. 
Diante desse quadro, o gás natural liquefeito (GNL) vem ganhando espaço como alternativa parcial de suprimento de demanda interna até pelo menos o ano de 2020. No entanto, Uma barreira a continuidade de uso dessa opão para os fins a que se destina remete ao cenário, incerto e de difícil previsão, de composição dos preços desse ativo (FGV, 2014).

Figura 1. Esquema da malha atual de gasodutos do Brasil

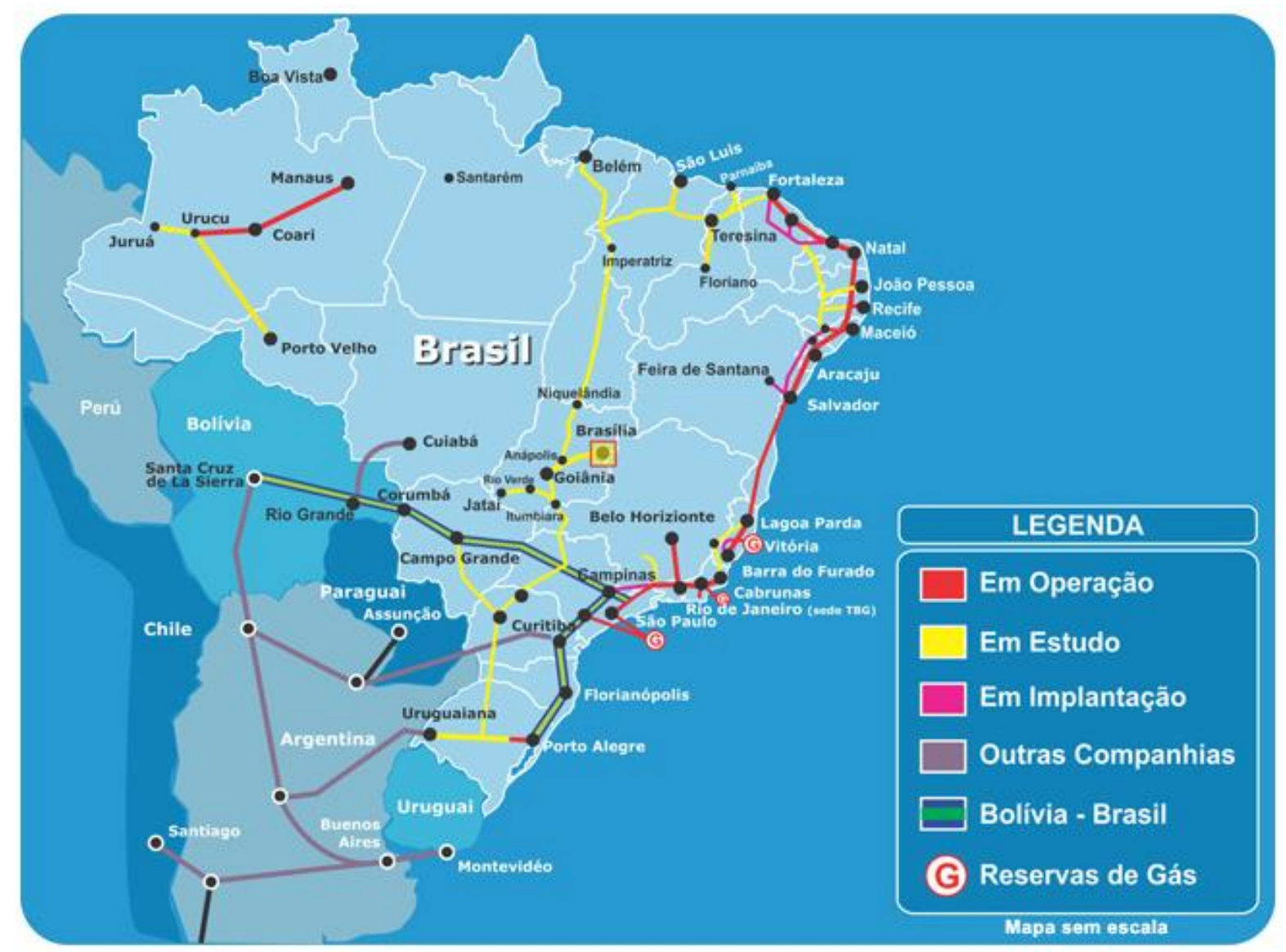

Fonte: Abegás (2015)

Uma descontinuação no fornecimento de gás boliviano exigiria a viabilização, quase que imediata e a partir das reservas nacionais, de cerca de $36 \mathrm{MMm}^{3} / \mathrm{d}$ do ativo. Portanto, o patrimônio aparentemente disponível sob a camada pré-sal passa a ser a alternativa mais viável (e talvez única) para desempenhar tal função. No entanto, ensaios prospectivos realizados pela Empresa de Pesquisa Energética (EPE) apontam que ao menos uma parte do gás originado daquela formação geológica pode não deter valores comerciais tão acessíveis quanto se imaginava anteriormente (EPE, 2014).

Dadas a dificuldade operacionais e os riscos associados a sua extração estimou-se que o gás oriundo do pré-sal viria a ser comercializado de até 15,00 US\$/ barril, um valor considerado elevado em comparação ao pratucado atualmente, de 10,00 US\$/ barril (Brasil, 2009). 
Mesmo demonstrando melhores resultados ambientais que seus equivalentes o gás natural segue sendo uma mistura de hidrocarbonetos de cadeia curta de origem não-renovável. Portanto, seu processamento e utilização estão associados ao aumento da taxa de carbono fóssil na atmosfera e, por decorrência, de seus efeitos em termos de Mudanças Climáticas (Sydney et al., 2014). Além disso, o esgotamento desse recurso natural traria reflexos econômicos e socias bastante graves já que muitas economias mundiais, particularmente do Oriente Médio e da África, além da já citada Bolívia, estão estabelecidas em função de suas reservas.

Esse quadro fez com que o governo brasileiro passasse a observar o ciclo produtivo do gás natural segundo uma ótica mais ampla, que compreende os três pilares da sustentabilidade(ambiental,social e econômico). Esta verificação se desenvolve com vistas a estimular a concepção de tecnologias capazes de que atender simultaneamente a todas essas dimensões. No entanto, ao menos dentro da vertente ambiental, as análises realizadas até o momento se concentram, apenas, em quantificar emissões de gás carbônico $\left(\mathrm{CO}_{2}\right)$ derivadas da queima do gás natural.

Uma forma analítica e organizada de ampliar esse processo, seria gerar um diagnóstico situacional das emissões das Gases de Efeito Estufa (GEE) associadas aos sistemas, atual e futuro, de suprimento da demanda de gás natural para o país. Para tanto, a técnica de Avaliação do Ciclo de Vida (ACV) desponta como uma alternativa robusta e conclusiva de identificação de impactos. Além do caráter sistêmico que pauta sua atuação, a ACV possibilita a expressão dos resultados obtidos em termos quantitativos, fazendo com que os mesmos possam ser apreciados em processos gerenciais de tomada de decisão que incluam a variável ambiental. 


\section{OBJETIVO}

O presente projeto de pesquisa se propõe a colaborar com a conjuntura introduzida na seção anterior deste documento. Assim, foram estabelecidos como objetivos gerais da presente iniciativa:

(i) Estabelecer um diagnóstico de desempenho ambiental da distribuição do sistema atual de suprimento do gás natural consumido no Brasil;

(ii) Verificar a efetividade, também na esfera ambiental, de ações voltadas a ampliação e a melhoria de performance do mesmo sistema.

Como dividendos adicionais, mas nem por isso menos importantes, da mesma ação, podem ser ainda elencados os seguintes objetivos complementares:

- Incorporar a variável ambiental a estudos futuros de viabilidade de projeto que por ventura venham a ocorrer no setor gasífero brasileiro;

- Fornecer subsídios que tornem os processos de tomada de decisão associados à área em questão mais amplos, consistentes e eficazes; e

- Orientar de maneira proativa ações de desenvolvimento naquele segmento produtivo. 


\section{MÉTODO DE TRABALHO}

O Método de Trabalho empregado para atender aos objetivos do estudo compreendeu as seguintes etapas: (i) Realização de uma revisão junto a literatura técnica para determinar o estado da arte do sistema de suprimento de gás natural no Brasil, em termos tecnológicos e de desempenho ambiental; (ii) Elaboração de modelo lógico capaz de representar as condições atuais de operação do arranjo de maneira consistente e representativa; (iii) A partir daquele quadro, diagnósticar os potenciais impactos provocados pelo sistema, em termos de consumo de recursos energéticos, e de geração de GEE causadores de Mudanças Climáticas; (iv) Levantamento de alternativas de curto e médio prazos, para ampliação do suprimento da demanda nacional de gás natural; (v) Concepção de modelo que represente, também de maneira robusta, o arranjo futuro; e (vi) Formulação de novo diagnóstico de desempenho energético e ambiental do sistema de produto, seguido de verificação da efetividade das ações que foram implementadas, a partir de comparação os resultados do cenário atual. Cada uma dessas ações será apresentada a seguir com maior nível de detalhe.

\subsection{Determinação do Estado da Arte da distribuição de gás natural no Brasil}

As pesquisas preliminares realizadas para efeito de elaboração deste estudo consistiram de identificar, selecionar, e coletar dados e informações que pudessem caracterizar o estágio atual do sistema brasileiro de suprimento de gás natural. O levantamento, realizado para o período 2012 2016, se ateve não apenas a condicionantes, requisitos e especificidades de ordens tecnológica, processual e operativa que a ele estivessem relacionadas, mas também, ao desempenho do sistema em termos energéticos e ambientais, nesse caso, restrito a impactos para Mudanças Climáticas.

Foram efetuadas consultas a portais científicos consagrados como 'Periódico Capes', 'ISI Web of science' e 'Scielo (Scientific Electronic Library Online)', a partir da aplicação simultânea de termos tais como: 'natural gas', 'fossil fuels', 'energy analysis', 'energy consumption', 'extraction', 'refining', 'sweetening', 'distribution', 'pipeline', 'environment impacts', 'life cycle assessment', 'LCA', 'air releases', 'EROI', 'ERORI', 'Greenhouse gases', 'GHG', 'methane', 'CH4', 'COO2', 'gás natural', 'extração onshoreloffshore', 'UPGN', 'TBG', 'compressão', 'distribuição', 'gasoduto', 'malha', 'ponto de entrega', 'traçado', 'consumo energético', 'emissão', 'metano', 'dióxido de carbono', 'impactos ambientais', 'Avaliação de Ciclo de Vida', 'ACV', 'PETROBRAS', 'TRANSPETRO', e 'logística'.

Como resultado dessas ações identificaram-se publicações que analisavam os desempenhos energético e ambiental do sistema brasileiro, ou de homólogos a este, junto aos seguintes periódicos: 'Journal of Cleaner Production', 'Energy', 'Energy Policy', 'Applied Energy', 'Energy and Fuels', 'Energies', 'Renewable and Sustainable Energy Reviews', 'Entropy', 'Energies', 'Environmental Science and Technology', 'Resources, Conservation and Recycling', 'Environmental Science and Technology' e 'Sience of the Total Environment'. 
No entanto, as principais fontes de dados típicos de processo procederam de relatórios e publicações técnicas disponibilizadas pela Petrobras SA, TRANSPETRO, Transportadora Brasileira Gasoduto Bolívia-Brasil SA (TGB), por enciclopédias de Engenharia Química, por produções comunicadas em conferências técnicas da área de petróleo e gás, e por produções de pós-graduação nos níveis mestrado e doutorado.

Publicações e boletins gerados pela indústria do gás natural e documentos governamentais coletados junto ao Ministério de Minas e Energia (MME) e a Agência Nacional do Petróleo, Gás Natural e Combustível (ANP), e da Confederação Nacional da Indústria (CNI) foram utilizados para caracterização das condições de demanda, de oferta e de distribuição do insumo. Além disso, informações referentes ao processo de produção de gás natural na Bolívia foram recolhidas a partir de registros técnicos oficiais do Ministério de Hidrocarburos y Energia de Bolivia.

\subsection{Determinação do Estado da Arte da distribuição de gás natural no Brasil}

A elaboração do modelo atual do sistema de distribuição de gás natural foi estruturada a partir de três atividades: (i) Descrição da tecnologia e coleta de dados; (ii) Formulação e aplicação do Método de escalonamento; e (iii) Formulação e aplicação de Método para tratamento de perdas. Tais ações são descritas a seguir em detalhes, quanto a seus conteúdos e condicionantes.

\subsubsection{Descrição da Tecnologia e coleta de dados ambientais}

A Descrição da Tecnologia consistiu no detalhamento de rotas produtivas e suas condições de operação em regime regular de funcionamento, que compõem o processamento de gás natural no Brasil. Foram levantadas características desses processos e sistemas, que permitiram descrever aqueles arranjos na forma de fluxogramas. As correntes, funções de estado, consumos de utilidades e insumos de processo que circulam entre as unidades da cadeia de produção do gás natural foram registradas naqueles esquemas obedecendo regras de balanceamento.

Seguiu-se a isso a Coleta de Dados Ambientais que teve por objetivo quantificar consumos, e emissões de recursos materiais e energéticos, advindos do ambiente para o sistema, ou que fossem deste emanados para o entorno. A coleta de dados seguiu orientações estabelecidas na norma ABNT NBR ISO 14044 (ABNT, 2009b) referentes aos estágios da Definição de Escopo, e Elaboração do Inventário do Ciclo de Vida (ICV) de um estudo de ACV.

\subsubsection{Método de Escalonamento}

A descrição da tecnologia mostrou grande disparidade em termos de disponibilidade de dados e informações entre a forma (origens do suprimento, quantidades, e mesmo, as condições de operação) como ocorre a distribuição de gás natural refinado até os pontos de entrega, e as demais etapas que compõem o sistema. 
Para preencher essa lacuna, concebeu-se um modelo aproximado e determinístico capaz de representar a atividade de distribuição de gás refinado, denominado para fins deste estudo como Método de Escalonamento. Em termos de estrutura o método baseou-se nas seguintes premissas:

a) O processo de distribuição de gás natural processado deve ser tratado unicamente no nível de estados da União;

b) A demanda de gás natural de um estado $\left(D_{L i}\right)$ será suprida primeiramente, pela oferta que está disponível na mesma unidade federativa $\left(O_{L i}\right)$, sempre que, e enquanto, esta existir. Tal situação está descrita pela equação (eq. 1):

Para: $D_{L i} \leq O_{L i}$

$$
D_{L i} \rightarrow O_{L i} \quad \text { até que, } \quad O_{L i}=D_{L i}
$$

c) Para os casos em que a demanda do estado supera sua oferta, a diferença de consumo será suprida pela disponibilidade de seus estados limítrofes $\left(O_{A j}\right)$. Caso essa também se esgote sem que $D_{L i}$ tenha sido cumprida, passa-se a consumir a $O_{A j}$ do estado limítrofe ao anterior e assim sucessivamente até que $D_{L i}$ seja atendida, assim como indicado na equação (eq. 2):

Para: $D_{L i}>O_{L i} \quad$ então, $\quad D_{L i} \rightarrow O_{L i}$ até que esta se esgote e, a seguir a isso,

$$
D_{L i}=O_{L i}+\sum_{j=1}^{k} O_{A j}
$$

Onde:

$D_{L i}$ : demanda de gás natural de certo estado (i);

$O_{L i}$ : oferta de gás natural do próprio estado (i);

$O_{A j}$ : oferta de gás natural de estados adjascentes (j);

d) A transferência de gás natural de um estado até outro ocorre continuadamente. Esse regime será interrompido apenas se: (i) $D_{L i}$ tenha sido atendida; ou, (ii) quando a oferta local tenha por ventura se esgotado $\left(O_{A j}=0\right)$;

e) O Método de Escalonamento baseia-se em critério geográfico, e o suprimento de demanda se dá sempre no sentido de Sudeste (SE) para Nordeste (NE) do Brasil;

f) As estimativas de atendimento de $D_{i}$ foram realizadas considerando-se haver consumo de gás natural em estações de compressão para transporte do produto. 


\subsubsection{Método para tratamento de perdas}

O método de tratamento de perdas baseou-se em séries históricas de dados, disponibilizadas nos boletins mensais de acompanhamento da indústria de gás natural emitidos para o ano de 2016 (MME, 2016). De acordo com aquela referência o termo 'perda' pode ser entendido no âmbito do transporte de gás, como um certo volume de produto que, muito embora tivesse sido injetado na malha de transporte, chegou a ser disponibilizado para o consumidor final. De acordo com os dados consolidados do balanço de gás natural para Brasil do ano de 2016 (Figura 2), houve um total de $4,3 \%$ de perdas do volume distribuído de gás natural refinado, dos quais exatos 3,0\% referem-se a desvios ocorridos no sistema de compressão, e o restante $(1,3 \%)$ a liberações para a atmosfera que procederam de vazamentos na própria malha de gasoduto.

Figura 2. Balanço de Gás Natural no Brasil

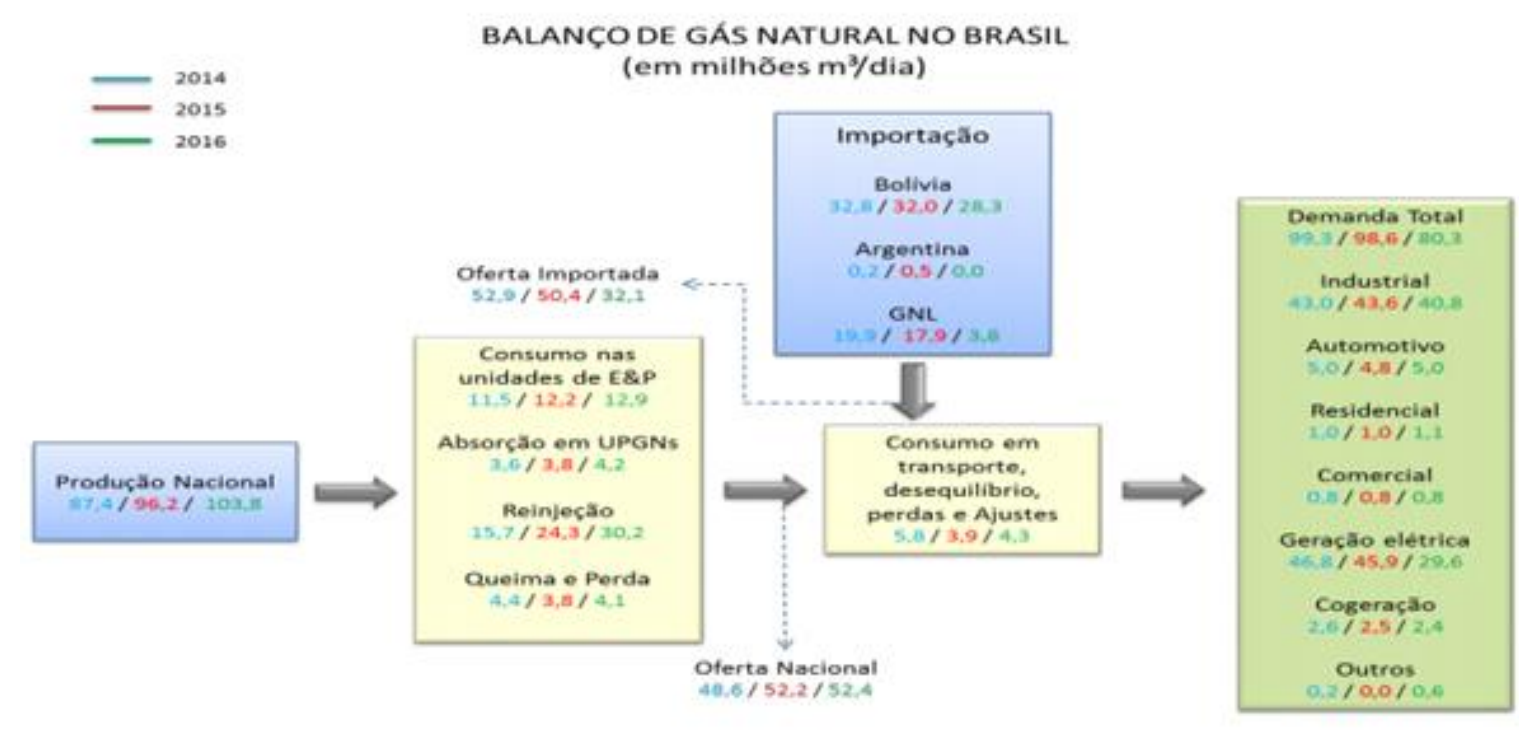

Fonte: (MME,2016)

Quanto ao tipo de gás emitido, o método supôs que o transporte do gás natural se dá, apenas, a partir da combustão completa dos hidrocarbonetos que o compõem. Por conta dessa consideração as emissões de GEE decorrentes da compressão restringem-se a perdas de $\mathrm{CO}_{2}$. Por outro lado, os lançamentos de gás devido a vazementos de linha, em estações de distribuição, ou outros acidentes nos dutos de transporte foram tratadas como sendo compostos exclusivamente por metano $\left(\mathrm{CH}_{4}\right)$.

Já o nitrogênio $\left(\mathrm{N}_{2}\right)$ presente no ar atmosférico foi considerado pelo caso presente como substância inerte. Tal simplificação pressupõe que a compressão do gás natural não gera óxidos de dinitrogênio $\left(\mathrm{N}_{2} \mathrm{O}\right)$, nem quaisquer poluentes secundários derivados de azoto, que resultem na formação de GEE. O NOx emitido durante o processo de combustão depende da composição do combustível, cada um desses parâmetros é significativo em relação à concentração final de NOx emitido. 


\subsection{Diagnóstico do Desempenho Ambiental}

Ao cumprir com sua função essencial, de proporcionar uma imagem dos efeitos energético e ambiental do sistema suprimento de gás do Brasil, este diagnóstico definiu também o status atual daquele arranjo de processo. Com isso, tornou-se ainda uma referência para efeito de comparação com cenários futuros, definidos a partir de adequações que ampliem o suprimento de gás do país.

No que se refere ao desempenho energético o diagnóstico estabeleceu a demanda total de energia primária (PED) dispendida para o processamento de $1,0 \mathrm{~m}^{3}$ de gás refinado e distribuído até o ponto de entrega. Este parâmetro foi também extratificado em termos de fontes primárias de energia. Além disso, calculou-se ainda o Retorno Energético de Investimento (EROI) com vistas a avaliar o balanço energético do combustível.

Como já fora colocado em momentos anteriores do texto, o diagnóstico ambiental ateve-se a impactos proporcionados pelo sistema em termos de Mudanças Climáticas. Essa restrição deveuse a dois fatores: (i) características do sistema em análise e dos rejeitos por ele gerados; (ii) o uso recorrente de resultados dessa categoria de impacto em ações de planejamento energético.

A revisão de literatura mostrou que, quanto a emissões de GEE, a cadeia produtiva do gás natural se concentra em $\mathrm{CO}_{2}$ e $\mathrm{CH}_{4}$. Além disso, a categoria de Mudanças Climáticas é entendida por diversos gestores como referência (em muitos casos única) de índice de performance em termos de sustentabilidade ambiental. A escolha desta para representar o desempenho ambiental do sistema decorre exatamente da associação deste fato, com um dos propósitos estabelecidos para o estudo, de considerar a variável ambiental em inicitivas que verifiquem a viabilidade de projetos realizados pelo setor gasífero brasileiro.

\subsection{Levantamento alternativos de ampliação do suprimento para atender a demanda futura}

Estabelecido o diagnóstico da situação atual do sistema, deu-se início então a um processo de busca que culminou com a formulação de um modelo capaz de representar as condições futuras de operação daquele arranjo. Esta análise partiu da coleta de informações que descrevessem em detalhes as modificações a serem implantadas no sistema para sua ampliação.

O levantamento se ateve principalmente a documentos publicados pela Petrobras SA dado que a empresa acumula as atividades de projeto, comissionamento, construção, operação e, por isso, de gestão da nova malha. De acordo com as estimativas da empresa as mudanças mais significativas na malha de suprimento (ampliação, correção de traçado, criação de entroncamentos e sistemas de 'by-pass') devem ocorrer entre os anos de 2016 e 2020.

O processo usado para identificação das alterativas levou em conta a disponibilidade de dados que retratassem os desempenhos ambientais e energéticos do modelo para condição futura em nível equivalente àquele atingido para formulação do diagnóstico da condição atual. 


\subsection{Elaboração do Modelo do Sistema de Produto: Situação Futura}

A modelagem da ampliação de rede baseou-se nas ações 3.2.1 a 3.2.3 antes descritas neste documento. A reprodução da lógica usada anteriormente confere uniformidade metodológica às análises, tornando assim comparáveis os resultados que delas foram gerados.

\subsection{Diagnóstico energético e ambiental do suprimento da demanda futura de GN do Brasil}

A formulação do desempenho energético e ambiental do sistema futuro seguiu as mesmas orientações descritas na seção 3.3, para que esses pudessem ser confrontados com seus homólogos para a situação atual. O conceito por detrás da modelagem, bem como a versatilidade dos programas computacionais usados nesta atividade, fez com que os resultados em termos de PED, EROI e impactos como Mudanas Climáticas fossem expressos por estado consumidor.

A comparação entre os dois momentos do sistema ocorreu de forma relativizada; ou seja, levando em conta os acréscimos de demanda que a ampliação do sistema irá proporcionar. Este relacionamento gera indicadores de impactos energético e ambiental $\left(\Delta R_{I E}\right.$ e $\left.\Delta R_{I A}\right)$, cujas expressões aparecem indicadas a seguir nas equações (eq. 3), e (eq. 4), respectivamente.

$$
\Delta R_{I E}=\frac{\left(\sum F_{e}-\sum A_{e}\right)}{\left(\sum F_{D}-\sum F_{A}\right)}
$$

Onde:

$\sum F_{D}$ : Oferta total de gás para a situação futura $\left(\mathrm{m}^{3}\right)$

$\sum F_{A}$ : Oferta total de gás para a situação atual $\left(\mathrm{m}^{3}\right)$

$\sum F_{e}$ : Total de Impactos Energético para a situação futura (GJ)

$\sum A_{e}$ : Total de Impactos Energético para a situação futura atual (GJ)

$$
\Delta R_{I A}=\frac{\left(\sum j_{F}-\sum j_{A}\right)}{\left(\sum F_{D}-\sum F_{A}\right)}
$$

Onde:

$\sum j_{F}$ : Total de Impacto Ambiental para a situação futura $\left(\mathrm{kg} \mathrm{CO}_{2 \text { eq }}\right)$

$\sum j_{A}$ : Total de Impacto Ambiental para a situação atual $\left(\mathrm{kg} \mathrm{CO}_{2}\right.$ eq $)$

Essa ação pretendeu que os valores das taxas de oscilação específica de impacto (por $\mathrm{m}^{3} \mathrm{de}$ gás refinado distribuído até o ponto de entrega) pudessem revelar tendências de ordem energética e ambiental, as quais, de sua parte, servissem de indicadores para planejamento e gestão do setor. 


\section{REVISÃO DE LITERATURA}

\subsection{Gás Natural}

O termo gás natural refere-se ao gás rico em hidrocarbonetos. Trata-se de um combustível fóssil gasoso encontrado em campos de petróleo e gás natural, assim como, entre camadas de carvão (Carroll, 2010). Segundo registros históricos a primeira perfuração de um poço de gás data de 1821 e teria sido realizada por William Hart em Fredonia (US). Ao longo do tempo, o gás natural passou a ser descoberto em decorrência de ações de prospecção e perfuração de poços de petróleo. Durante o século XIX, o gás era utilizado apenas em nível local como fonte de provimento de luz, dada a falta de estrutura adequada para transporte de longa distância. Após a Segunda Guerra Mundial, o uso do gás se difundiu bastante no Hemisfério Norte graças a avanços na área de engenharia que fizeram com que sua malha de distribuição fosse ampliada de forma a atender localidades mais distantes (Kidnay et al, 2011).

No estado puro, o gás natural é incolor e inodoro. Seu caráter combustível leva a geração de quantidades significativas de energia quando submetido a combustão (Speight, 2015a). Essa característica, associada a baixa emissão de poluentes, e a não consideração de estocagem para o consumo final (diminuindo custos de infraestrutura) o colocam como substituto atrativo de outros energéticos de origem fóssil. Além da aplicação trivial como combustível o gás pode ser também aproveitado em processos dos segmentos siderúrgico (como agente redutor), petroquímico (como matéria-prima não energética na produção de polímeros), e químico (como insumo essencial para a produção de adubos nitrogenados como amônia, uréia, sultato de amônio e nitrato de amônio) (Negreiros 2013).

A denominação de 'combustível limpo' usado com alguma frequência para descrever o desempenho ambiental do gás natural se deve principalmente aos tipos e quantidades de compostos tóxicos que derivam de sua queima. Ao serem comparadas com as perdas emanadas da combustão de outros fósseis, as emissões gasosas de dióxido de enxofre $\left(\mathrm{SO}_{2}\right)$, óxidos de nitrogênio $\left(\mathrm{NO}_{\mathrm{x}}\right)$, e monóxido de carbono (CO) derivadas da oxidação do gás natural são mais baixas, resultando por isso em contribuições mais discretas que as de seus congêneres para Chuva Ácida, Formação de Ozônio Troposférico e Mudanças Climáticas (BP Tecnologia do Outlook, 2015).

De acordo com a Lei Federal no 9.478/97, define-se gás natural como " a porção do petróleo que existe em fase gasosa, ou em solução no óleo, nas condições originais de reservatório, e que quando exposto às CNTP (condições normais de temperatura e pressão) seguirá em fase gasosa " (Brasil, 1997). A composição do gás natural pode variar em função de fatores tais como: classe e características do reservatório, tipo de processo de produção, e formas de acondicionamento, refino e transporte. No entanto, em qualquer dessas situações seu constituinte principal será o $\mathrm{CH}_{4}$, cuja composição varia tipicamente entre $65 \%$ e $90 \%$ v/v. As frações de contribuição de cada substância constituinte do gás brasileiro bruto aparecem indicadas na Tabela 1. 
Tabela 1. Composição média do gás natural brasileiro

\begin{tabular}{lcc}
\hline \multicolumn{1}{l}{ Componente } & Fórmula Química & Fração $(\% \mathrm{v} / \mathrm{v})$ \\
\hline Metano & $\mathrm{CH}_{4}$ & $65,0-90,0$ \\
Etano & $\mathrm{C}_{2} \mathrm{H}_{6}$ & $4,00-12,0$ \\
Propano & $\mathrm{C}_{3} \mathrm{H}_{8}$ & $2,00-6,00$ \\
Butano e pesados & $\mathrm{C}_{4} \mathrm{H}_{10}, \mathrm{C}_{5} \mathrm{H}_{12}, \mathrm{C}_{6} \mathrm{H}_{14}$ & $0,05-1,50$ \\
Nitrogênio & $\mathrm{N}_{2}$ & $0,80-11,0$ \\
Dióxido de Carbono & $\mathrm{CO}_{2}$ & $0,20-3,00$ \\
Gás sulfídrico ${ }^{(*)}$ & $\mathrm{H}_{2} \mathrm{~S}$ & $1,50-7,50$ \\
\hline
\end{tabular}

${ }^{*}$ : A faixa de variação do teor de $\mathrm{H}_{2} \mathrm{~S}$ no gás natural está expesso em unidade de concentração: $\mathrm{mg} / \mathrm{m}^{3}$ Fonte: (Vaz et al, 2008)

No que diz respeito à sua origem e composição química, o gás natural pode ser classificado como convencional e não convencional (Figura 3). O gás convencional ocorre em reservatórios profundos que são associados com petróleo (gás associado) ou que contêm pouco, ou nenhum, óleo bruto (gás não associado). Define-se como Gás Natural Associado aquele que, no reservatório, se encontra dissolvido no óleo, ou sob a forma de capa de gás. Neste caso, a produção de gás está diretamente condicionada à produção do óleo. Não havendo condições econômicas para a extração, o gás natural pode ser reinjetado ou queimado, a fim de evitar o acúmulo de combustíveis próximos aos poços de petróleo. Por conseguinte, o dito Gás Não Associado será aquele que, no reservatório, está livre do óleo, ou que detém o recurso natural em quantidades desprezíveis (Kidnay et al., 2011).

Figura 3. Sistema para gás associado e não associado no cenário de extração do gás natural.

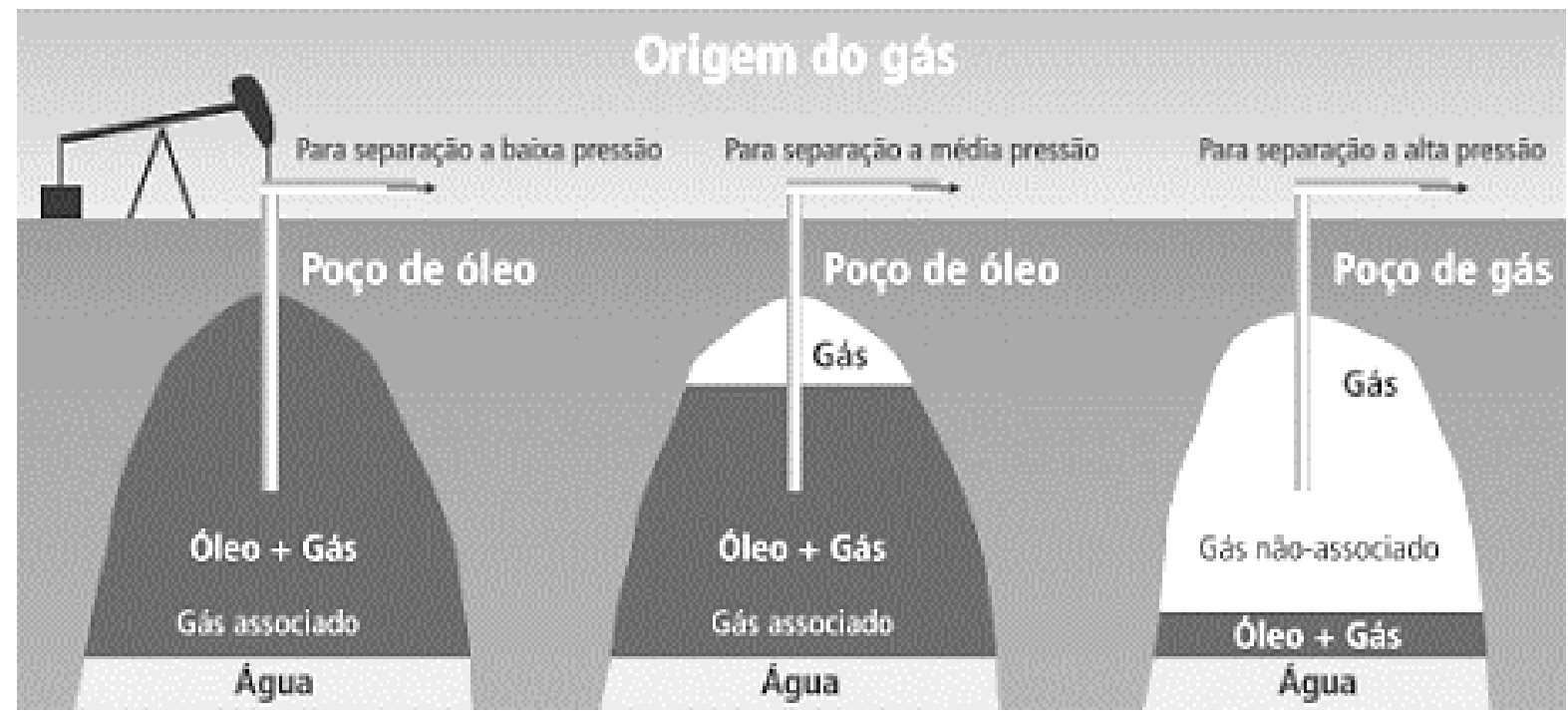

Fonte: Garcia (2005) 
No que se refere ao processamento, o gás extraído do reservatório será encaminhado para uma Unidade de Processamento de gás Natural (UPGN), cuja função principal será de ajustar teores de componentes do gás bruto até que esse esteja em condições de ser comercializado. Essa ação se dá por sucessivas operações unitárias de purificação, resfriamento, liquefação, e fracionamento do gás em termos de seus derivados. Como resultado dessas transformações são gerados o gás natural refinado, e hidrocarbonetos pesados que constituem o GNL. Para se tornar um bem de consumo, o gás natural refinado dever atender aos requisitos estabelecidos pela Resolução ANP No.16 (ANP, 2008). A Tabela 2 detalha as principais especificações a serem atendidas pelo produto.

Tabela 2. Especificações do gás natural Resolução ANP N ${ }^{\circ} 16$

\begin{tabular}{|c|c|c|c|c|}
\hline \multirow{2}{*}{ Características } & \multirow{2}{*}{ Unidade } & \multicolumn{3}{|c|}{ Limite por região ${ }^{(*)}$} \\
\hline & & $\mathrm{N}$ & $\mathrm{NE}$ & $\mathrm{CO}, \mathrm{SU}$ e $\mathrm{S}$ \\
\hline Poder Calorífico Superior (PCS) & $\mathrm{kJ} / \mathrm{m}^{3}$ & $34000-38000$ & $35000-43000$ & $35000-43000$ \\
\hline Índice de Wobbe & $\mathrm{kJ} / \mathrm{m}^{3}$ & $40500-45000$ & $46500-53500$ & $46500-53500$ \\
\hline $\mathrm{CH}_{4}$, mín. & $\% \mathrm{Mol}$ & 68,0 & 85,0 & 85,0 \\
\hline $\mathrm{C}_{2} \mathrm{H}_{6}$, máx. & $\% \mathrm{Mol}$ & 12,0 & 12,0 & 12,0 \\
\hline $\mathrm{C}_{3} \mathrm{H}_{8}$, máx. & $\% \mathrm{Mol}$ & 3,00 & 6,00 & 6,00 \\
\hline$\left(\mathrm{C}_{4} \mathrm{H}_{10}-\mathrm{C}_{6} \mathrm{H}_{14}\right)$, máx. & $\% \mathrm{Mol}$ & 1,50 & 3,00 & 3,00 \\
\hline $\mathrm{O}_{2}$, máx. & $\% \mathrm{Mol}$ & 0,80 & 0,50 & 0,5 \\
\hline Inertes $\left(\mathrm{N}_{2}+\mathrm{CO}_{2}\right)$, máx. & $\% \mathrm{Mol}$ & 18,0 & 8,00 & 6,00 \\
\hline $\mathrm{CO}_{2}$, máx. & $\% \mathrm{~mol}$ & 3,00 & 3,00 & 3,00 \\
\hline Enxofre (S) Total, máx. & $\mathrm{mg} / \mathrm{Nm}^{3}$ & 70,0 & 70,0 & 70,0 \\
\hline Gás Sulfídrico $\left(\mathrm{H}_{2} \mathrm{~S}\right)$, máx. & $\mathrm{mg} / \mathrm{Nm}^{3}$ & 10,0 & 10,0 & 10,0 \\
\hline
\end{tabular}

O Brasil é o principal importador de gás na América do Sul. Cerca de 39\% da oferta interna do produto de 2013 foi suprida com gás importado, em sua quase totalidade da Bolívia (Muñoz et al, 2014). A demanda nacional gás natural atingiu cerca de 112 milhões de $\mathrm{m}^{3}$ por dia $\left(\mathrm{MMm}^{3} / \mathrm{d}\right)$, em dezembro de 2016, valor que supera em $11 \%$ o patamar registrado no mesmo período do ano anterior (CNI, 2016).

\subsection{Avaliação de Ciclo de Vida (ACV)}

O conceito de Ciclo de Vida compreende o conjunto de estágios de um sistema antrópico necessário para que um produto, processo, ou serviço, atenda com a eficiência esperada às funções para as quais foi concebido. Em linhas gerais, esses estágios são classificados em: extração dos recursos, manufatura, uso e descarte final do produto. A conexão entre eles ocorre por meio de estágios de transporte (Silva et al., 2010). A Figura 4 descreve de maneira esquemática os estágios do Ciclo de Vida de um produto genérico. 
Por analogia (e extensão) Avaliação do Ciclo de Vida (ACV) pode então ser entendida como uma técnica de gestão desenvolvida com o intuito de fornecer um diagnóstico quantitativo do desempenho ambiental do conjunto de etapas antrópicas que devem ser cumpridas para que um produto - processo, ou serviço - cumpra com os propósitos para os quais este foi produzido (ou exercitado) (Silva, 2012).

Figura 4. Esquema da Análise de Ciclo de vida de um produto

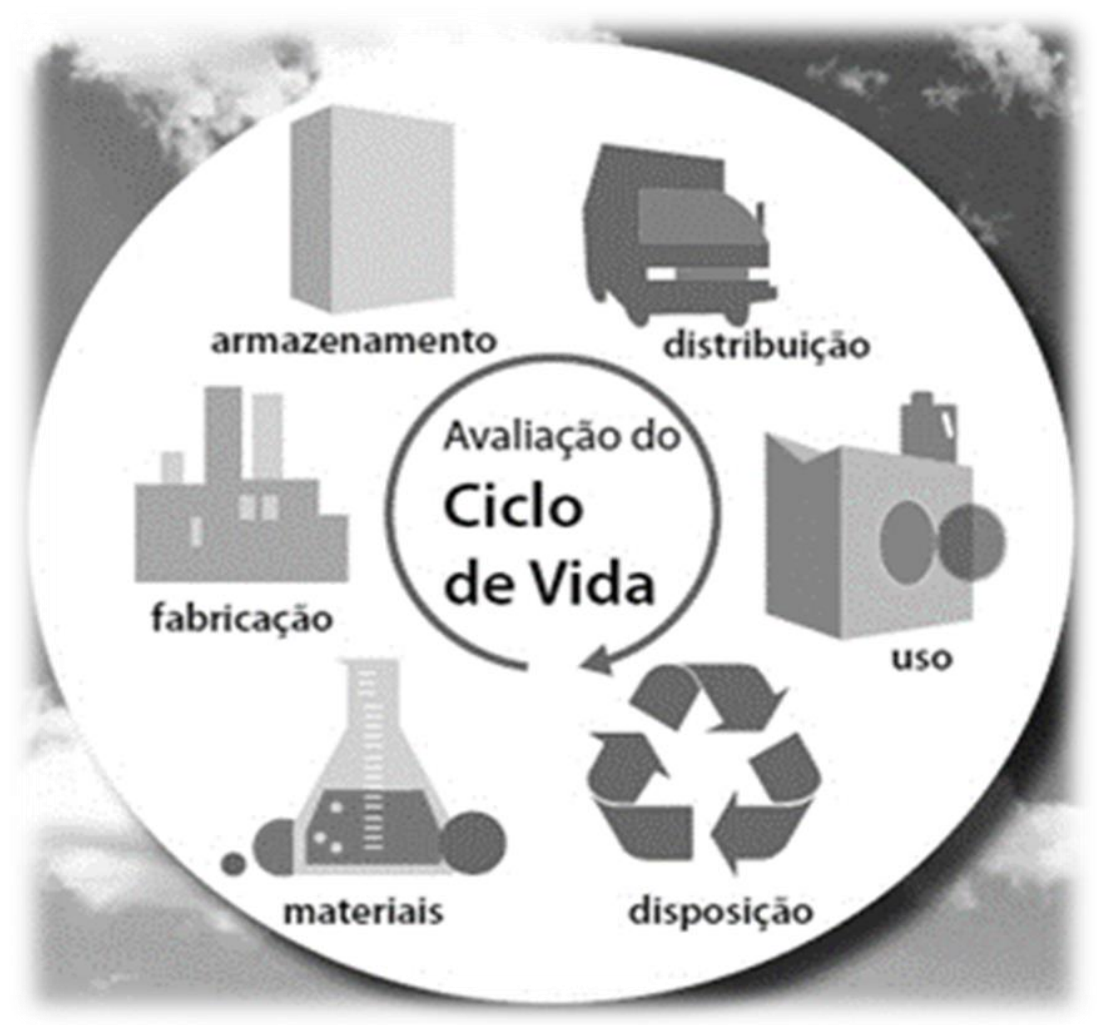

Fonte: Cervantes (2015)

De acordo com a abordagem descrita pela norma ABNT NBR ISO 14040 (ABNT, 2009a) a técnica de ACV compreende quatro etapas estruturais: Definição de Objetivo e Escopo; Análise do Inventário; Avaliação de Impactos Ambientais, e Interpretação.

A partir da representação esquemática indicada na Figura 5 pode-se perceber que todas as etapas da ACV não apenas são interdependentes, como também iterativas. Isso quer dizer que as decisões metodológicas tomadas em determinada etapa do método poderão provocar revisões de outras que a ela estão interligadas. Por outro lado, essa mesma lógica proporciona homogeneidade metodológica e permite readequações sucessivas durante o avanço do estudo (Silva e Kulay, 2006).

Na Definição de Objetivos devem ser descritos de maneira clara os objetivos do estudo, os motivos e aplicações para os quais este será desenvolvido, e o público-alvo a que seus resultados se destinam. 
Figura 5. Estágios do estudo ACV

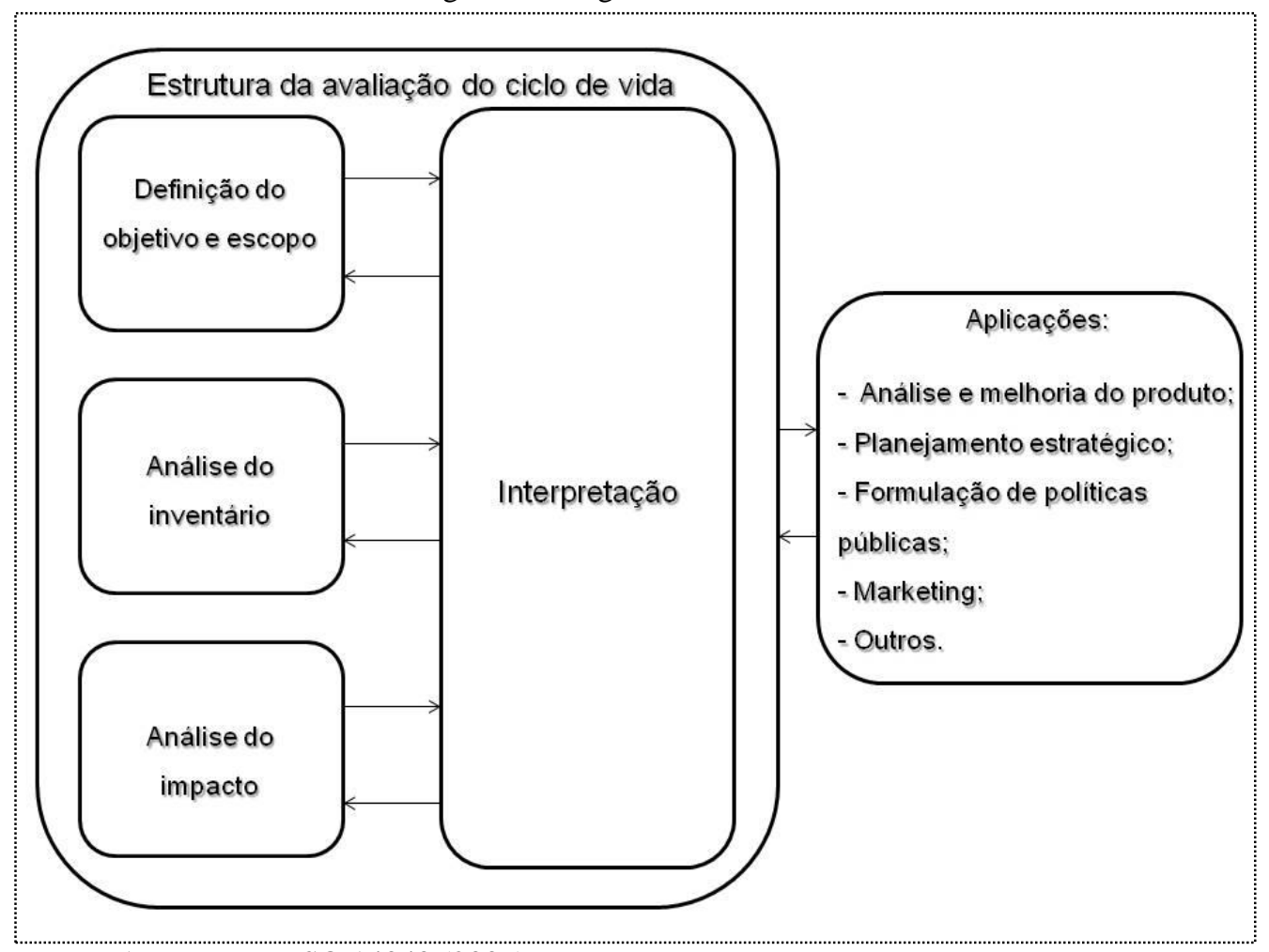

Fonte:ABNT NBR ISO 14040 (2009)

Na Definição de Escopo são estabelecidas premissas, condicionantes e orientações de caráter geral para o estudo como a função exercitada pelo objeto da análise e uma quantificação de seu exercício (Unidade Funcional, UF); as fronteiras do sistema de produto (com o meio ambiente e com outros sistemas); diretrizes orientadas para o processo de coleta de dados; tipos e qualidade dos dados; procedimentos de alocação; critérios de exclusão de dados; métodos e categorias de impacto ambiental; tratamento de incertezas; e tipo e formato do relatório (ABNT, 2009a e 2009b).

$\mathrm{Na}$ Análise de Inventário são coletados dados representativos de aspectos ambientais, ou seja, correntes materiais e de energia que circulam pelas fronteiras entre o processo em análise e o meio ambiente. Também nessa fase é usual que sejam quantificados ainda bens de consumo e seus eventuais subprodutos, fluxos intermediários - que interligam dois estágios do processo em análise -, e fluxos de produto - que serão utilizados no processo em análise, mas advêm outros processos antrópicos (Gunady et al., 2012). Os dados utilizados para essas estimativas podem ser obtidos em campo (dados primários), ou via registros ou outras fontes de literatura (dados secundários).

A coleta de dados gera um conjunto de informações em 'estado bruto'. Estes devem então ser tratados para compor o ICV, cabendo então ao praticante da ACV verificar se os requisitos de qualidade foram atendidos, aplicar balanços de massa, etc., e correlacionar os dados validados à UF (ou fluxo de referência - RF: que consiste da quantidade de produto necessária para que o mesmo cumpra com a UF definida para o estudo). Este procedimento é conhecido no jargão da técnica como tratamento dos dados. 
Dados quantitativos utilizados para efeito de comparação de materiais (ou de processos), e dados qualitativos empregados para descrição de aspectos ambientais (ou etapas não quantificáveis) podem ser selecionados a partir da aplicação dos critérios de exclusão de dados. Esses critérios permitem identificar aspectos ambientais a serem considerados em cada 'processo elementar'; ou seja, no menor nível de elaboração de um sistema de produto, para o qual será possível quantificar correntes de matéria e energia de entrada e saída (ABNT, 2009b).

Nesse instante, devem também ser incorporados critérios para tratamento de 'situações de multifuncionalidade', quando uma etapa, ou processo elementar do sistema, gera mais do que um produto. Muito embora a norma ABNT NBR ISO 14044 (ABNT, 2009b) recomende o uso dos chamados procedimentos de alocação para equacionar situações de multifuncionalidade, outras abordagens são reconhecidas e aplicadas para casos dessa natureza tais como: o Surplus Method, a Expansão de Fronteiras, ou mesmo, o uso do enfoque Consequencial (Martinho, 2014).

Em linhas gerais os procedimentos de alocação realizam uma ponderação minimamente coerente de aspectos ambientais entre os produtos gerados por um processo multifuncional. Os critérios de alocação mais comumente utilizados em estudos de ACV baseiam-se em propriedades ou características físicas (massa, ou conteúdo energético), ou mesmo, no valor comercial dos produtos gerados (Ferreira, 2012). A norma ABNT NBR ISO 14040 (2009a) recomenda evitar a alocação sempre que possível, seja através da subdivisão de certos processos ou expandindo os limites do sistema para incluir as funções adicionais relacionadas a eles (van der Voet, 2009).

A Avaliação de Impactos Ambientais do Ciclo de Vida (AICV) verifica as magnitudes e significâncias dos efeitos potenciais causados pelo ciclo de vida do produto sobre o meio ambiente e sobre o ser humano, no âmbito do atendimento da função (Martinho, 2014). Segundo a NBR ISO 14044 (ABNT, 2009b) a AICV se compõe de elementos obrigatórios e opcionais. Como elementos obrigatórios podem ser listados: (i) Seleção das categorias de impactos e respectivos indicadores; (ii) Classificação; (iii) Caracterização; e, (iv) Definição do Perfil de Impacto Ambiental. A Seleção das Categorias de Impacto baseia-se nos resultados do ICV, em especial, nos aspectos ambientais de maior relevância para o estudo. Algumas das categorias de impactos de uso mais frequentes em estudo desta natureza são: Mudança Climática; Depleção da Camada de Ozônio; Acidificação; Depleção de Recursos Abióticos; Eutrofização, Formação de Foto-oxidantes, Depleção de Recursos Hídricos e Fontes Fósseis, Transformação e Ocupação do Solo, Toxicidade Humana e Ecotoxicidade, entre outras.

Por fim, a etapa de Interpretação compreende uma confrontação dos resultados com as orientações e premissas estabelecidas para realização do estudo. Esta análise crítica se presta a combinar, resumir e discutir constatações uasadas no ICV e na AICV, de maneira iterativa com os formulados na etapa de Definição de Objetivo e Escopo (Martinho, 2014). 
As conclusões e recomendações geradas por um estudo de ACV devem refletir de maneira objetiva e consistente os resultados de suas fases executivas (Análise de inventário, Avaliação de impacto e Interpretação). Para tanto, estas não devem fugir aos Objetivos e Escopo propostos, e não podem ser baseadas em interpretações pessoais, que poderiam influenciar futuros processos de tomada de decisão para os quais os resultados da ACV dariam respaldo (Sugawara, 2012).

\subsection{Estudos de ACV relacionados ao Gás Natural}

No levantamento efetuado junto à literatura, foram identificados estudos que apresentassem como tema central a avaliação de desempenho ambiental de ações de uso do gás natural por meio de ACV. Esta revisão foi conduzida a partir de consultas realizadas junto a portais consagrados de pesquisa, casos de Science Direct, ISI - Web of Knowledge, Scielo, da biblioteca virtual de Teses e Dissertações da Universidade de São Paulo, e de bases científicas mantidas por Agências de Fomento (CAPES e FAPESP). O horizonte temporal definido para esta consulta compreendeu o período 20112015.

Donoughue et al. (2014) conduziram um estudo de ACV de eletricidade gerada a partir de gás natural em unidade termoelétrica convencional com os objetivos de identificar precursores, e reduzir a variabilidade nas estimativas das emissões de GEE durante este ciclo de vida. A análise concentrou-se em dois sistemas de geração elétrica: (i) turbina de combustão a gás natural (NGCT), e (ii) ciclo combinado (NGCC). O processo meta-analítico de "harmonização" foi empregado para alinhar diferentes limites do sistema, e parâmetros de desempenho técnico, a fim de permitir comparações entre os casos, que ocorreu no nível de impacto para Mudanças Climáticas.

Os autores perceberam que as contribuições decorrentes de NGCT variaram entre 420 e 480 $\mathrm{g} \mathrm{CO}_{2}$ eq $/ \mathrm{kWh}$, enquanto para NGCC a faixa foi mais elevada, ficando entre 570 e $750 \mathrm{gCO}_{2}$ eq $/ \mathrm{kWh}$. A harmonização da eficiência térmica provocou o maior efeito na redução da variabilidade dos resultados.

Junli et al (2015) constataram ser a ACV uma ferramenta de análise útil para estimar o consumo de energia e as emissões ambientais decorrentes de atividades econômicas. Para tanto, os autores realizaram uma ACV comparativa entre motores movidos a gás natural liquefeito (GNL) e motores a diesel. Foram identificados os processos que mais contribuem para o consumo de energia e geração de impactos ambientais durante os ciclos de vida dos sistemas em termos de Potencial de Aquecimento Global (GWP); Potencial de Acidificação (AP); Potencial de Eutrofização (EP); Potencial Fotoquímico de Criação de Ozônio (POCP); Potencial de Depleção de Ozônio (ODP); e Demanda de Energia Primária (PED).

Os resultados mostraram que no mérito energético os motores movidos GNL foram superiores em $42 \%$ àqueles movidos a diesel. Quanto aos impactos ambientais essa supremacia se manteve, sendo que a principal diferença deu-se quanto a EP, cuja redução foi de $74 \%$. A esse se seguiram respectivamente, ganhos em termos de AP (72\%), GWP (47\%) e POCP (44\%). 
Além disso, a relação custo-benefício para o ciclo de vida como um todo é também favorável para motores operados com GNL. Em ambos os casos, a etapa de uso do motor gerou os maiores impactos, especialmente, quanto a PED e POCP. Já a etapa de manufatura dos componentes trouxe contribuições mais expressivas para ODP. Por fim, os autores notaram haver maiores consumos de materiais e energia para construção do motor movido a GNL.

Robert et al (2011), se dedicaram a avaliar a Pegada de Carbono do gás natural obtido por rompimento hidráulico a partir de formações de xisto, com foco em emissões de $\mathrm{CH}_{4}$. Entre 3,6\% e $7,9 \%$ do $\mathrm{CH}_{4}$ oriundo da produção de gases de xisto escapa para a atmosfera em ventilações e vazamentos ao longo da vida útil de um poço. Tais emissões são em média $30 \%$ mais elevadas do que as associadas ao gás convencional. As maiores emissões de gases de xisto ocorrem nos momentos em que os poços são fraturados hidraulicamente, e durante a brotação após a fratura. A Pegada de Carbono para o gás de xisto mostrou-se maior do que a do gás natural convencional, ou mesmo que a do óleo, quando verificada em diferentes horizontes temporais. Em comparação ao carvão, está mostrou-se também mais elevada, neste caso em cerca de $20 \%$.

Stephen et al (2013) aplicaram ACV para avaliar impactos associados à captura de $\mathrm{CO}_{2}$ de uma usina de ciclo combinado operada a gás natural. A avaliação foi conduzida para duas taxas de absorção de $\mathrm{CO}_{2}: 80 \%$ e $90 \%$. Como agentes de absorção foram testados a monoetanolamina convencional (MEA) e solvente avançado (KS-1), em várias configurações de compressão. Os resultados mostraram reduções expressivas nas emissões de GEE para ambas as eficiências de captura. Para 90\% com MEA convencional, um decréscimo de perdas GEE de $76 \%$ foi alcançado independentemente da configuração de compressão. Também com MEA, mas para $80 \%$ de captura a redução foi de $65 \%$. O uso do solvente KS-1 proporcionou a redução de $78 \%$ nas emissões de GEE devido à diminuição da energia necessária para regeneração de $\mathrm{CO}_{2}$.

No entanto, a avaliação mostra que as operações de captura de $\mathrm{CO}_{2}$ levaram a aumento de outros impactos ambientais, como os Potenciais de Toxicidade Humana, Eutrofização Marinha, Ecotoxicidade em Água Doce, Ecotoxicidade em Água Marinha, Acidificação, Ecotoxicidade Terrestre e Formação de Oxidante Fotoquímico. Esses impactos são decorrentes da energia adicional necessária para captura de $\mathrm{CO}_{2}$, para implantação e manutenção da infraestrutura de processo, e por conta dos solventes químicos utilizados. A vantagem de usar o KS-1 é clara para a taxa de $90 \%$ de captura de $\mathrm{CO}_{2}$. 


\section{MODELAGEM DO CICLO DE VIDA}

\subsection{Tecnologia de Processamento de gás Natural: aspectos gerais}

A cadeia produtiva do gás natural pode ser dividida em duas partes. A primeira delas referese a atividades geológicas ou de campo, que estão relacionadas à obtenção do produto propriamente dito, chamada também de upstream. A segunda parte refere-se a atividades que utilizam o produto como insumo em processos diversos e são conhecidas como downstream. Constituem-se atividades de upstream: exploração, produção e processamento do gás natural (Figura 6).

Figura 6. Cadeia produtiva do gás natural: Upstream

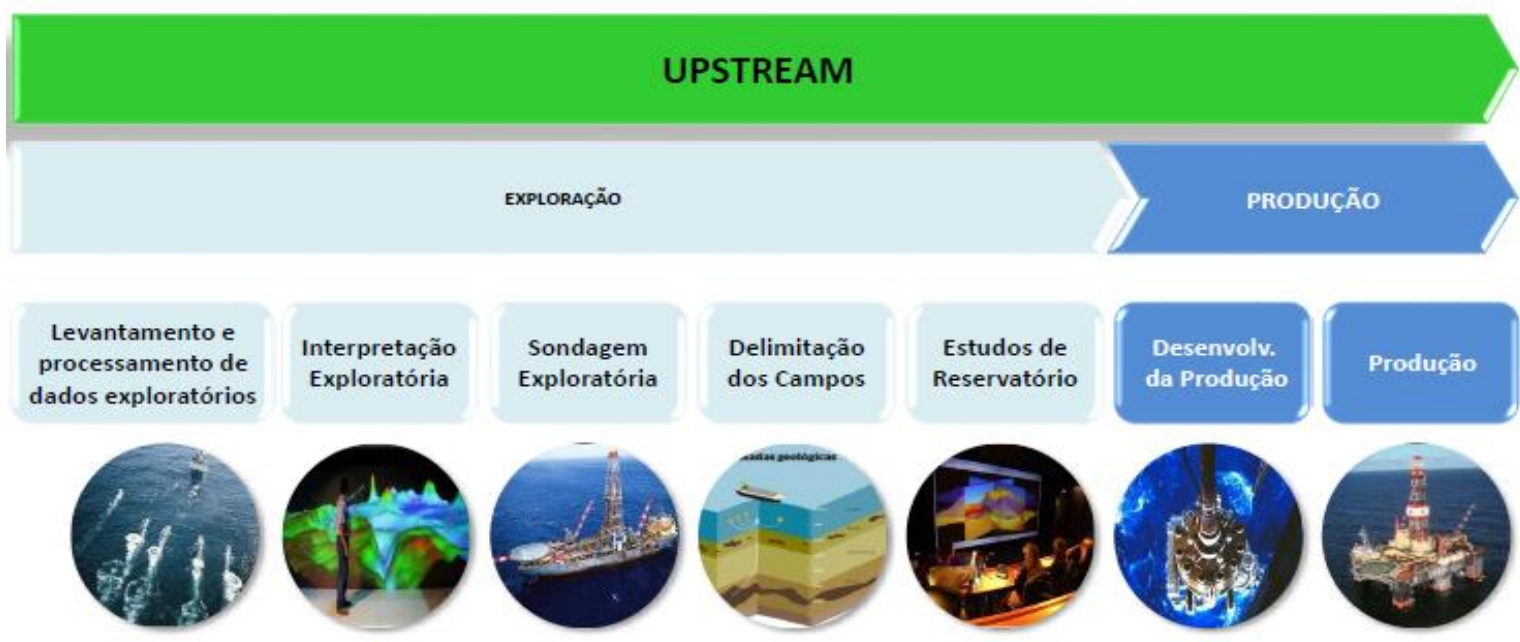

Fonte: SEBRAE (2014)

Por outro lado, são consideradas atividades de downstream aquelas que ocorrem a partir da distribuição do gás natural, que se relacionam ao fornecimento do produto acabado ao usuário final (Figura 7).

Figura 7. Cadeia produtiva do gás natural: Downstream

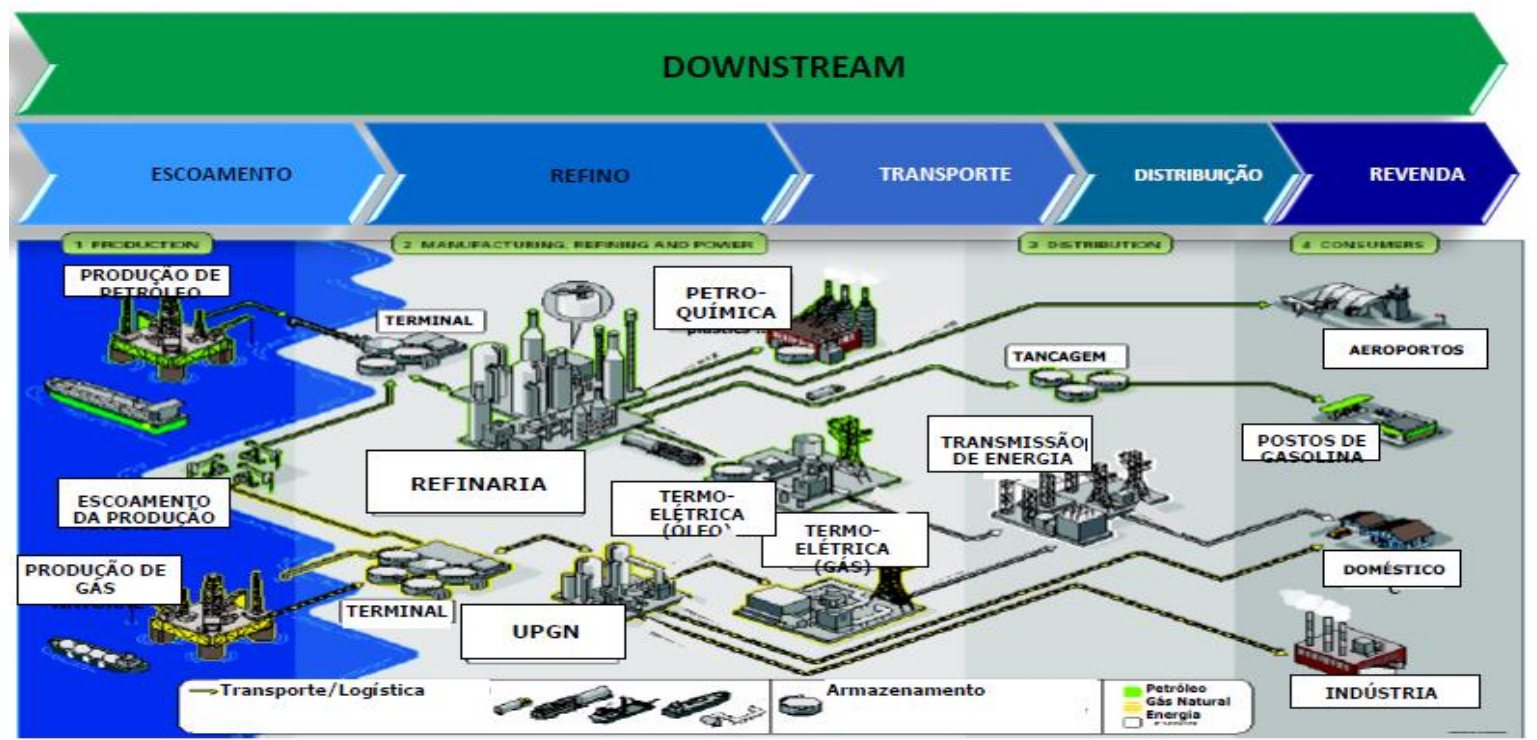

Fonte: SEBRAE (2014) 
Em linhas gerais e, segundo Tavares (2013) os processos upstream e downstream da cadeia produtiva do gás natural compreendem as seguintes etapas:

Exploração: A exploração está dividida em pesquisa e perfuração. A pesquisa identifica fatores que apontam propícios para formação de campos de gás. Um exemplo desses fatores remete a existência de rochas porosas e permeáveis, bastante propícias a receberem hidrocarbonetos $\left(\mathrm{C}_{\mathrm{x}} \mathrm{H}_{\mathrm{y}}\right)$ em seus espaços intersticiais.

Processamento: o gás natural extraído será levado através de gasodutos até as UPGNs é refinada como propósito de ser transformado em produto final. Nessas unidades de processamento as frações mais leves do gás natural $\left(\mathrm{CH}_{4} \mathrm{e}_{2} \mathrm{H}_{6}\right)$ são separadas das demais gerando o gás natural seco. As frações intermediárias $\left(\mathrm{C}_{3} \mathrm{H}_{8}\right.$ e $\left.\mathrm{C}_{4} \mathrm{H}_{10}\right)$ dão origem ao Gás Liquefeito de Petróleo (GLP), ao passo que as de cadeias mais longas $\left(\mathrm{C}_{5} \mathrm{H}_{12}\right.$ e mais pesadas) se convertem em gasolina natural.

Transporte: Das UPGNs, o gás seco pode seguir dois caminhos: ser levado diretamente até o consumidor final, ou ser distribuído até os chamados pontos de entrega, desde os quais as companhias locais se encarregam de chegar até a ponta da cadeia de consumo. O transporte do gás natural pode ocorrer por dutos (forma mais usual), via cilindros de alta pressão, como o gás natural comprimido (GNC), ou mesmo, no estado líquido na forma de gás natural liquefeito (GNL).

Distribuição: quando chega ao ponto de entrega, o gás está pronto para ser comercializado com o consumidor final. Para cumprir este último estágio de distribuição será deslocado por ramais de distribuição cujos diâmetros $(\varphi)$ podem variar entre 1,0 " $<\varphi<10$ ”.

\subsection{Modelagem do Sistema de Produto}

Este estudo compreendeu a aplicada da técnica ACV com enfoque atribucional e dentro de um escopo de aplicação do tipo 'berço-ao-portão'. Assim, além de avaliar exclusivamente os efeitos energéticos e ambientais do arranjo per se (sem ter em conta interferências de elementos externos ao sistema, como predispõe a ACV atribucional), foram consideras para efeito desta análise, apenas as etapas que compõe a cadeia de suprimentos do gás natural: desde a extração do recurso natural, até que o produto refinado chegasse ao ponto de entrega.

Quanto ao arcabouço conceitual, o estudo se baseou nas orientações e condicionantes metodológicas, descritas pela norma ABNT NBR 14044 (ABNT, 2009b). Passam a ser descritos a seguir os elementos que compõe a etapa de definição de escopo da ACV, segundo a ótica da mesma referência normativa.

\subsubsection{Função, Unidade Funcional (UF), Fluxo de referência (FR)}

A função definida para o processo objeto deste estudo é: 'produzir gás natural em condições e quantidades para que este seja capaz de suprir a demanada atual do Brasil em suas mais variadas aplicações'. 
Dado que para o caso presente foram desconsiderados estágios de pós-produção do ciclo de vida do gás natural (de uso e disposição final), a Unidade Funcional (UF) e o Fluxo de Referência (FR) tornaram-se convergentes. Portanto, definiu-se para efeito desta iniciativa um valor de UF (= FR) de 1,0 $\mathrm{m}^{3}$ gás natural refinado no limite suficiente para atender ao mercado brasileiro em todas as aplicações para os quais esse se presta.

\subsubsection{Requisitos de qualidade de dados}

Como já fora dito antes, a composição do modelo baseou-se em dados secundários obtidos de fontes técnicas referenciáveis. A esses se juntaram informações provenientes da base de dados Ecoinvent que é própria para dar sustentação a estudos de ACV. A Cobertura Temporal estabelecida para o estudo foi o ano de 2016. A Cobertura Geográfica levou em conta os processamentos realizados no estados do Rio de Janeiro, São Paulo, Espírito Santo, Bahia, Sergipe, Alagoas, Rio Grande do Norte, e Ceará. A esses se somaram ainda ações produtivas que ocorrem na Bolivia, mais especificamente nas regiões de Sabalo, San Alberto e Margarita. Por fim, a Cobertura Tecnológica observou condicionantes processuais descritas brevemente na seção 4.1 deste estudo, relativas à tecnologia média de processamento de gás natural exercitada no Brasil.

\subsubsection{Definição do Sistema de Produto}

O Sistema de Produto é composto por processos elementares que se interconectam para formar a cadeia de produção do gás natural. São eles: (i) extração em reservatórios; (ii) transporte até os terminais e UPGNs; (iii) refino; e (iv) distribuição do produto final até os pontos de entrega. Este arranjo aparece representado de maneira esquemática Figura 8.

Constam daquele esquema extrações ocorridas no Brasil, nos estados do Rio de Janeiro, São Paulo, Sergipe, Alagoas, Rio Grande do Norte, e Ceará, bem como as respectivas UPGNs e de distribuição. O modelo compreende também o estado da Bahia, por se tatar de um dos principais consumidores do ativo produzido no país, assim como ocorre com as demais unidades da federação acima citadas. A relação se completa com o Espirito Santo, que atua como centro distribuidor do gás natural processado no Rio de Janeiro para os estados da região NE.

O sistema de produto compreende também o gás processado na Bolívia junto aos campos gasiferos de Sábalo, San Alberto e Margarita. Este produto alimenta os estados de Mato Grosso, Mato Grosso do Sul na região CO do país, a região oeste do estado de São Paulo, e os estados da região S (respectivamente, Paraná, Santa Catarina e Rio Grande do Sul).

Figura 8. Esquema simplificado das fontes de proviemento de GN no Brasil 


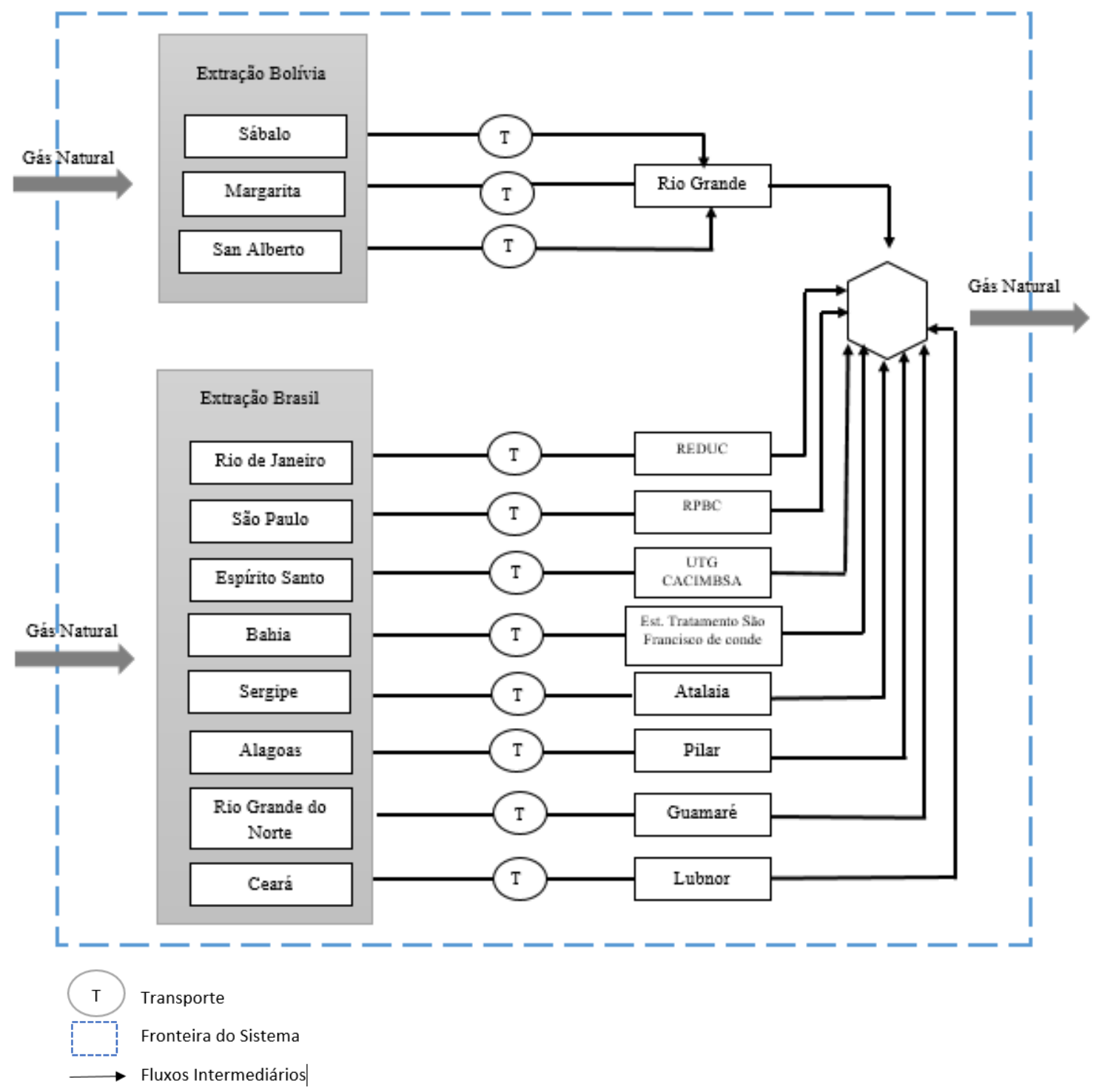

\subsubsection{Tratamento de situações de multifuncionalidade}

Tendo em vista que o volume de produção de gás natural é amplamente superior aos das demais frações derivadas do gás bruto a situação de multifuncionalidade que se caracteriza entre esses coprodutos foi tratada pelo Surplus Method (Heijungs e Suh, 2002). Por conta desse enfoque a totalidade das cargas ambientais geradas a montante do refino foi atribuída exclusivamente ao gás natural refinado.Muito embora trata-se de um contexto de multifuncionalidade, as cargas ambientais quantificadas até esse estágio do cilclo e vida,seriam atribuídas em sua totalidade,e apenas,ao produto principal sem que havesse amortecimentos.Logo nenhum impacto ambiental fica sob a responsabilidade dos demais co-produtos. Este médoto pode ser visto como uma abordagem de grande potencial,para análises preliminares de desempenho ambiental,uma vez que simplifica a execução do estudo. 


\subsubsection{Métodos de Avaliação de Impactos de Ciclo de Vida (AICV)}

Tal como também já foi apontado em momentos anteriores do texto a análise dos consumos de recursos energéticos ocorreu em termos de Demanda Priméria de Energia (PED). Para tanto optouse por utilizar o método Cumulative Energy Demand (CED) - v 1.09 (Frischknecht et al., 2007) para as categorias de impacto: Non renewable, fossil (NRF), Non renewable, nuclear (NRN), Non renewable, biomass (NRB), Renewable, wind, solar, geothermal (RWSG), Renewable, biomass (RB), e Renewable water (RWA).

A análise ambiental restringe-se ao impacto ambiental de Mudanças Climáticas (CC). Para potencializar tal efeito aplicou-se o método proposto pelo Intergovernamental Painel of Climate Change (IPCC) (IPCC, 2007). Tanto a modelagem do sistema como a avaliação dos impactos acima indicados foi realizada com auxílio da ferramenta computacional Simapro® - v. 8.3.0, que é própria para dar apoio a estudos de ACV.

\subsection{Premissas: Caracterizações Específicas do Sistema de produto}

Aparte das premissas gerais que foram indicadas antes, a modelagem do processamento de gás natural para o Brasil compreendeu também a formulação de condicionantes específicas para caracterização do modelo de sistema de produto. Estas aparecem listadas a seguir:

a) O método de escalonamento (item 3.3) foi aplicado para uma produção de $82,94 \mathrm{MMm}^{3} / \mathrm{d}$ de gás natural refinado que correspondeu à demanda média nacional de 2016 (MME 2016);

b) Foi desconsiderada para efeito desta análise a chamada área isolada, que remete a todos os estados da região N (respectivamente: Acre, Amazonas, Roraima, Rondônia, Amapá, Pará) pelo fato desta zona se auto-gerir em termo de produção e consumo de gás natural;

c) Também foram desconsiderados os estados do Piauí, Maranhão, Tocantins, Goiás, além do Distrito Federal para os quais a distribuição atual do gás natural não ocorre por gasodutos. Além de introduzir incertezas ao modelo, dada a dificuldade de obtenção de dados que reprsentassem esta forma de suprimento, o consumo acumulado de gás para esses estados não atingiu, no período em referência, mais do que 3,0\% da demanda nacional;

d) Considerou-se para efeito de escalonamento que o suprimento de gás ocorresse no sentido $\mathrm{SE} \rightarrow \mathrm{NE}$ (item 3.2.2). Esta lógica aparece representada em mais detalhes na Figura 9 e na Tabela 3. 


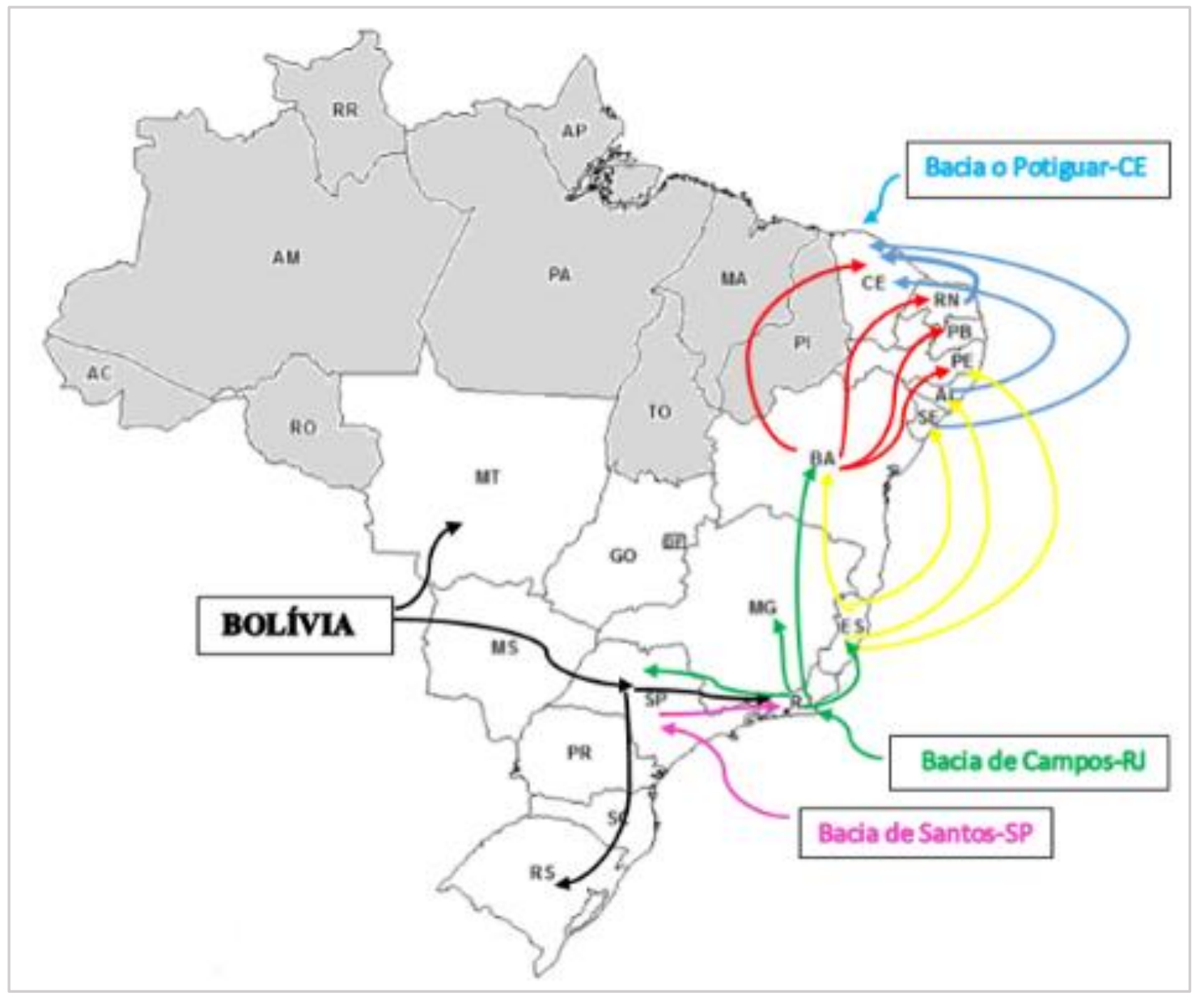

e) A Refinaria Duque de Caxias (REDUC - RJ) atua como UPGN e dela parte o gás natural refinado que, de acordo com o modelo de escalonamento, irá alimentar os estados da Bahia, Espírito Santo, Minas Gerais, São Paulo e além de parte do estado do Rio de Janeiro;

f) Refinaria Presidente Bernardes (RPBC-SP) atua como UPGN e dela procede o gás natural refinado que, também por conta do escalonamento, supre o estado de São Paulo e, a outra parcela da demanda do Rio de Janeiro;

g) A Unidade de Tratamento de Gás Cacimbas, em Linhares (ES) (UTG - Cacimbas) atua como UPGN e, de acordo com o escalonamento, a partir dela será distribuído o gás natural refindao que alimenta os estados de Alagoas, Sergipe, Bahia, Pernambuco;

h) A Unidade de Processamento do Gás Natural Candeias (BA) (UPGN - Candeias) atua como UPGN distribuindo, por conta do escalonamento, gás refinado para os estados do Rio Grande do Norte, Ceará, Paraíba e Pernambuco; 
Tabela 3. Uso do Método de Escalonamento para distribuição do gás natural pelo Brasil

\begin{tabular}{|c|c|c|c|c|c|c|c|c|c|c|c|c|c|c|c|}
\hline Localidade & $\begin{array}{l}\text { Producão } \\
\text { (MM m³/d) }\end{array}$ & $\begin{array}{l}\text { Gás disponível } \\
\left(\mathrm{MM} \mathrm{m} \mathrm{m}^{3} / \mathrm{d}\right)\end{array}$ & $\begin{array}{l}\text { Consumo } \\
\left(\mathrm{MM} \mathrm{m}^{3} / \mathrm{d}\right)\end{array}$ & $\mathrm{CE}$ & $\mathrm{RN}$ & $\mathrm{AL}$ & SE & $\mathrm{BA}$ & ES & $\mathrm{RJ}$ & SP & $\mathrm{BO}$ & $\begin{array}{c}\text { Região } \\
\text { CO }\end{array}$ & $\begin{array}{l}\text { Região } \\
\text { S }\end{array}$ & MG \\
\hline $\mathrm{CE}$ & 0,25 & 0,024 & 2,84 & 0,024 & 0,62 & 1,14 & 0,48 & 0,60 & & & & & & & \\
\hline $\mathrm{RN}$ & 1,06 & 0,62 & 2,10 & & & & & 2,11 & & & & & & & \\
\hline PB & 0,00 & 0,00 & 0,42 & & & & & 0,42 & & & & & & & \\
\hline $\mathrm{AL}$ & 1,14 & 1,14 & 0,12 & & & & & & 0,12 & & & & & & \\
\hline PE & 0,00 & 0,00 & 4,52 & & & & & 3,34 & 1,18 & & & & & & \\
\hline SE & 2,59 & 0,43 & 1,36 & & & & & & 1,36 & & & & & & \\
\hline BA & 7,45 & 6,45 & 8,74 & & & & & & 5,88 & 2,80 & & & & & \\
\hline ES & 10,6 & 8,54 & 7,19 & & & & & & & 7,19 & & & & & \\
\hline $\mathrm{RJ}$ & 45,4 & 19,3 & 20,6 & & & & & & & 8,00 & 5,59 & 9,45 & & & \\
\hline $\mathrm{MG}$ & 0,00 & 0,00 & 2,80 & & & & & & & 2,80 & & & & & \\
\hline $\mathrm{SP}$ & 15,9 & 9,92 & 14,6 & & & & & & & 0,85 & 4,33 & 9,45 & & & \\
\hline Região CO & 0,00 & 0,00 & 1,72 & & & & & & & & & 1,72 & & & \\
\hline Região S & 0,00 & 0,00 & 15,9 & & & & & & & & & 15,9 & & & \\
\hline Bolivia & & 36,5 & & & & & & & & & & & & & \\
\hline Total & 84,5 & 82,9 & 82,9 & 0,024 & 0,62 & 1,14 & 0,49 & 6,47 & 8,54 & 21,6 & 9,92 & 36,5 & & & \\
\hline
\end{tabular}


i) A Unidade de Processamento do Gás Natural Pilar, em Alagoas (UPGN - Pilar), alimenta o estado do Ceará. Este estado também terá parte de sua demanda atendida pela Unidade de Processamento do Gás Natural Atalaia, Sergipe, (UPGN - Atalaia) e pela Unidade de Processamento do Gás Natural LUBNOR lotada no próprio Ceará (UPGN - LUBNOR);

j) O gás processado na Bolívia alimenta as regiões $\mathrm{CO}$ e $\mathrm{S}$ do Brasil, além de parte do estado do Rio de Janeiro, e de São Paulo;

k) Para efeito de transporte marítimo, fez-se uso das distâncias existentes entre reservatórios na faixa costeira, terminais e UPGNs. Estas aparecem indicadas na Tabela 4.

Tabela 4. Distâncias de Transporte Bacia $\rightarrow$ Terminal

\begin{tabular}{lcc}
\hline \multicolumn{1}{c}{ Origem } & Destino & Distância (km) \\
\hline Bacia de Santos (SP) & Terminal Cabiúnas (RJ) & 125 \\
Bacia de Campos (RJ) & Terminal Cubatão (SP) & 184 \\
Parque das baleias (ES) & UTG Cacimbas (ES) & 46 \\
Bacia Sergipe/Alagoas (SE) & UPGN Atalaia (SE) & 103 \\
Bacia de Manati (BA) & UPGN Candeias (BA) & 125 \\
Bacia de Potiguar (CE) & UPGN Lubnor (CE) & 90 \\
\hline
\end{tabular}

1) No transporte terrestre considerou-se as distâncias existentes entre os terminais e refinarias, assim como encontra-se registrado na Tabela 5.

Tabela 5. Distâncias relativas a transportes terrestres Terminal $\rightarrow$ UPGN

\begin{tabular}{lcc}
\hline \multicolumn{1}{c}{ Origem } & Destino & Distância (km) \\
\hline Terminal Cubatão (SP) & RPBC (SP) & 18,4 \\
Terminal Cabiúnas (RJ) & REDUC (RJ) & 183 \\
REDUC (RJ) & Terminal Vitória (ES) & 300 \\
Terminal Vitória (ES) & Terminal Catu (BA) & 940 \\
\hline
\end{tabular}

m) As distâncias existentes entre as UPGNs e os pontos de entrega localizados na região NE também foram modeladas a partir de parâmetros reais, que constam da Tabela 6 . 
Tabela 6. Distância de transportes terrestres: UPGN $\rightarrow$ Ponto de Entrega (região NE)

\begin{tabular}{lcc}
\hline \multicolumn{1}{c}{ Origem } & Destino & Distância (km) \\
\hline UPGN Pilar (AL) & CEG (CE) & 946 \\
UPGN Candeias (BA) & CEGÁS (CE) & 1145 \\
UPGN Candeias (BA) & PBGÁS (PB) & 1135 \\
UPGN Candeias (BA) & COPERGÁS (PE) & 900 \\
UPGN Candeias (BA) & POTIGÁS (RN) & 1125,5 \\
UPGN LUBNOR (CE) & CEGÁS (CE): & 20 \\
UPGN Guamaré (RN) & CEGÁS & 418 \\
\hline
\end{tabular}

n) As distâncias existentes entre as UPGNs e os pontos de entrega localizados na região SE foram modeladas de acordo com dados indicados na Tabela 7.

Tabela 7. Distância de transportes terrestres: UPGN $\rightarrow$ Ponto de Entrega (região SE)

\begin{tabular}{lcc}
\hline \multicolumn{1}{c}{ Origem } & Destino & Distância(km) \\
\hline RPBC (SP) & COMGÁS (SP) & 100 \\
RPBC (SP) & CEGRIO (RJ) & 448 \\
REDUC (RJ) & CEGRIO (RJ) & 20 \\
REDUC (RJ) & GASMIG (MG) & 460 \\
REDUC (RJ) & BR DISTRIBUIDORA (ES) & 992 \\
REDUC (RJ) & BAHIAGÁS (BA) & 1570 \\
BR DISTRIBUIDORA (ES) & COPERGÁS (PE) & 1530 \\
BR DISTRIBUIDORA (ES) & BAHIAGÁS (BA) & 990 \\
BR DISTRIBUIDORA (ES) & SERGÁS & 1246 \\
BR DISTRIBUIDORA (ES) & ALGÁS (AL) & 1393 \\
\hline
\end{tabular}

o) Para o ramo boliviano de suprimento de gás natural foram selecionados campos com maior representatividade em termos de volume de extração: Sábalo, Margarita e San Alberto. Este desempenho foi determinado para o período 2016 (TRANSPETRO, 2016).

p) Ainda para o caso boliviano o transporte de gás refinado considerou distâncias entre os reservatórios locais e o município de Canoas (RS) que totalizam respectivamente: $3265 \mathrm{~km}$ (desde Sábalo), 3193 km (desde Margarita) e 4381 km (desde San Alberto) (YPFB, 2013; 2014; e 2015).

q) As distâncias de transporte do gás natural boliviano processado até os pontos de entrega localizados nas regiões $\mathrm{CO}$ e $\mathrm{S}$ aparecem representadas na Tabela 8. 
Tabela 8. Distância de transportes terrestres: UPGN BO $\rightarrow$ Ponto de Entrega (regiões S e CO)

\begin{tabular}{lcc}
\hline \multicolumn{1}{c}{ Origem } & Destino & Distância (km) \\
\hline Gás Boliviano & GÁS BRASILIANO (SP) & 2422 \\
\hline Gás Boliviano & COMGÁS (SP) & 2270 \\
\hline Gás Boliviano & CEGRIO (RJ) & 2997 \\
SULGÁS (RS) & \\
Gás Boliviano & COMPAGÁS (PR) & 1821 \\
& SCGÁS (SC) & \\
\hline
\end{tabular}

\subsection{Inventário de Ciclo de Vida (ICV)}

A aplicação conjunta de proposições gerais estabelecidas na etapa de definição de Escopo àquelas de caráter específico formuladas no item 5.3, relativas à tecnologia média de produção de gás natural no Brasil gerou um elenco de ICVs que retrata no nível de consumos e emissões, os desempenhos da condição atual do sistema em análise em termos energético e ambiental.

A extração do gás natural bruto pode ocorrer a partir de campos onshore, típicos a Bolívia, e offshore que compreendem o volume acumulado de gás bruto extraído no Brasil. Nesse contexto o Apêndice A.1 descreve, de maneira genérica, consumos e emissões materiais e energéticas da extração onshore das bacias de Margarita, Sábalo, San Alberto na Bolívia, além das bacias de Pilar (AL) e a Bacia do Rio Grande do Norte, localizadas na região NE do Brasil.

Já o Apêndice A.2 proporciona um exemplo de ICV para quando esta atividade (de extração de gás) é realizada em poços offshore, como acontece nos casos das bacias de Santos (SP), Campos (RJ), Parque das Baleias (ES), Campos de Manati (BA), Potiguar (CE), e de Sergipe/Alagoas (SE).

No que se refere ao transporte do gás bruto, o Apêndice A.3 faz referência a consumos e emissões derivadas do deslocamento do gás até os terminais (em alguns casos, o trajeto se estende até atingir as UPGNs). Em termos tecnológicos os processos de refino de gás (UPGNs e UTGs) foram representados por um único ICV, que está indicado no Apêndice A.4. Por fim, o Apêndice A.5 registra um exemplo de ICV para distribuição de gás processado até o ponto de entrega.

Como não poderia deixar de ser, os inventários para o suprimento da oferta futura de gás seguiram a mesma abordagem adotada para condição atual de operação do sistema. Nesses termos, o Apêndice A.6 descreve consumos e emissões de matéria e energia associado à extração onshore, para a Bacia de Parnaíba (MA). 
O Apêndice A.7 proporciona um exemplo de ICV para extrações futuras em poços offshore, como ocorrerá com a da Bacia de Pelotas, localizado no litoral do Rio Grande do Sul. Com relação ao transporte do gás bruto, o Apêndice A.8 evidencia o balanço de consumos e emissões derivadas do deslocamento do gás extraído até as UPGNs e/ou unidades de processamento.

O inventário de correntes de entrada e saída que representa as operações compreendidas no refino do gás consta do Apêndice A.9 e um modelo genérico de ICV para representar a distribuição do gás refinado até o ponto de entrega figura no Apêndice A.10. 


\section{DIAGNÓSTICO DOS DESEMPENHOS ENERGÉTICO E AMBIENTAL DO SISTEMA ATUAL DE DISTRIBUIÇÃO DE GÁS NATURAL}

\subsection{Análise Energética do suprimento Atual do gás natural do Brasil}

Os resultados indicados na Tabela 9 apontam para um valor de PED de 3035 MJ/FR. Como já se poderia supor de antemão, há uma contribuição maciça (98\%) de impactos na forma de NRF, por conta dos consumos do recurso biótico gás natural. As demais categorias de impacto mostraram aportes marginais frente àquela contribuição. Os impactos mais representativos em termos de NRF ocorreram para o estado do Rio de Janeiro (RJ), para São Paulo (SP), e para a região Sul, com 377 MJ/FR, 278 MJ/FR e 832 MJ/FR respectivamente. As operações de extração de gás contribuem de maneira significante nesse caso. Devem merecer destaque neste contexto operações realizado nas bacias lotadas no litoral do RJ, no reservatório de Sábalo (BO) que supre a região Sul do país, e nos campos também offshore da Bahia (BA), que também alimentam ES e RJ, que consomem 804 MJ/FR, 496 MJ/FR e 316 MJ/FR do recurso natural. As perdas de gás são devido às atividades de reinjeção em poços associados, uma prática trivial em plataformas offshore. Como resultado desse procedimento as perdas de gás no RJ, Sábalo e na BA atingiram respectivamente $28 \%, 18 \%$ e $11 \%$.

Tabela 9. Impactos Energéticos expressos como PED do fornecimento de gás natural

\begin{tabular}{cc}
\hline Categorias de Impacto & Total $(\mathrm{MJ} / \mathrm{FR})$ \\
NRF & 2986 \\
NRN & 4.61 \\
NRB & $1,12.10^{-3}$ \\
RB & 2,59 \\
RWSG & $2,38.10^{-2}$ \\
RWA & 41,8 \\
Total & 3035 \\
\hline
\end{tabular}

Muito embora Sábalo, Margarita e San Alberto sejam campos de extração onshore, notou-se uma perda significante de gás natural, da ordem de 13\%. Esse defcit pode ser explicado em função das práticas de perfuração exercitadas na Bolívia, que além de desprovidas de atualização tecnológica costumam enfrentar dificuldades em função da disposição geológica das camadas de gas no subsolo. 
$\mathrm{CH}_{4}$ e $\mathrm{CO}_{2}$ são precursores de impacto de $\mathrm{CC}$ da indústria de gás natural. Suas emissões se concentram no processo de extração. As perdas de $\mathrm{CO}_{2}$ podem ocorrer também a partir de desvios de processo durante o refino do gás, sendo lançadas no ar via sistema de flare (Picard et al., 2000). Esse quadro se confirmou também no caso do sistema brasileiro. A disponibilização cada 1,0 $\mathrm{m}^{3}$ de gás natural para consumo no país traz associados $299 \mathrm{~kg} \mathrm{CO}_{2 \mathrm{eq}}$ de impacto em termos de CC, sendo que cerca de $98 \%$ dessas contribuições remetem a emissões de $\mathrm{CH}_{4}$ fóssil $\left(\mathrm{CH}_{4, \mathrm{f}}\right)$ durante as etapas de extração do recurso natural. Merecem atenção nesse contexto os desempenhos registrados por RJ (1,81 kg CH$/ 4$ FR), SP (512 g CH$/ / F R)$, e ES (424 g CH$/ 4$ FR). Além disso, chamou a atenção também às performances do refino de gás nas UPGNs localizadas na Bahia e em São Paulo cujas perdas de metano foram, respectivamente, de $480 \mathrm{~g} \mathrm{CH}_{4} / \mathrm{FR}$ e $360 \mathrm{~g} \mathrm{CH}_{4} / \mathrm{FR}$.

\subsection{Análise de Resultados para a região Sudeste \\ 6.3.1 Mudanças Climáticas (CC)}

A produção de gás natural no estado de $\mathrm{SP}$ aportou $2,70 \mathrm{~kg} \mathrm{CO}_{2 \mathrm{eq}} / \mathrm{FR}$ ao total de impactos como CC. Mais de $97 \%$ dessa contribuição refere-se a emissões para o ar de $\mathrm{CH}_{4, \mathrm{f} \text {. }}$ Os principais aportes nesse caso, provêm da extração do gás (40,2 $\left.\mathrm{g} \mathrm{CH}_{4} / \mathrm{FR}\right)$, e de seu transporte até os terminais (43,2 $\left.\mathrm{g} \mathrm{CH}_{4} / \mathrm{FR}\right)$. O restante são emissões de $\mathrm{CO}_{2}$ oriundas do flare da UPGN e por compressores.

$\mathrm{O} \mathrm{RJ}$ contribuiu com outros $3,18 \mathrm{kgCO}_{2}$ eq $/$ FR por conta das operações de extração $(62,2 \mathrm{~g}$ $\mathrm{CH}_{4} / \mathrm{FR}$ ) e refino (45,2 $\left.\mathrm{kg} \mathrm{CH}_{4} / \mathrm{FR}\right)$. Os estados de MG e ES tiveram desempenhos semelhantes $\left(4,06\right.$ e $\left.3,75 \mathrm{~kg} \mathrm{CO}_{2 \text { eq }} / \mathrm{FR}\right)$. No entanto, e como já fora mencionado, essas contribuições procedem igualmente da extração do gás no RJ, que no arranjo atual da malha de distribuição está encarregado de suprir as demandas daqueles estados. As extrações do gás que atende a MG e ES receberam aportes em termos de emissão de $\mathrm{CH}_{4}$ de 95,0 e 96,4 g CH $4 / \mathrm{FR}$.

\subsubsection{Demanda Primária de Energia (PED)}

O estado de SP apresentou de PED de 21,3 MJ/FR. Impactos como NRF foram mais uma vez prevalentes nesse caso, aportando a quase totalidade do impacto (Tabela 10). As contribuições para NRF estão associadas ao suprimento da demanda do estado; no entanto, apenas cerca de $60 \%$ desse total pode ser atribuído a operações de extração e refino de gás bruto que ocorrem no estado. As parcelas restantes decorrem de ações equivalentes, mas que são operadas no RJ (24\%) e nos campos da Bolivia (16\%) que completam a oferta de gás para SP, devido ao traçado atual da malha de distribuição de gás. 
Tabela 10. Impactos Energéticos da distribuição de gás natural: SP

\begin{tabular}{cc}
\hline Categorias de Impacto & Valor (MJ) \\
NRF & 21,3 \\
NRN & $5,41.10^{-3}$ \\
NRB & $2,90.10^{-6}$ \\
RB & $3,17.10^{-3}$ \\
RWSG & $3,45.10^{-5}$ \\
RWA & $4,71.10^{-2}$ \\
TOTAL & 21,3 \\
\hline
\end{tabular}

Para o RJ a PED foi de 29,8 MJ/FR e, mais uma vez procedeu quase que integralmente de NRF (Tabela 11). Dado que o consumo do gás natural do RJ também é suprido por uma diversidade de procedências, $86 \%$ desse total de impactos origina-se de extrações locais ocorridas na Bacia de Campos, outros 8,4\% derivam da retirada de gás na Bacia de Santos, e o restante, deriva dos campos de Sábalo (BO).

Tabela 11. Impactos Energéticos de distribuição de gás natural: RJ

\begin{tabular}{cc}
\hline Categoria de Impacto & Total \\
NRF & 29,7 \\
NRN & $5,51.10^{-3}$ \\
RB & $2,57.10^{-6}$ \\
RWSG & $3,09.10^{-3}$ \\
RWA & $3,21.10^{-5}$ \\
TOTAL & $4,79.10^{-2}$ \\
\hline
\end{tabular}

Para os estados de MG e ES registraram valores semelhantes de PED (42,6 e 43,4 MJ/FR), mais uma vez concentrados em termos de NRF. Isso se explica pelo fato de o gás natural consumido nesses estados ser originário do RJ. Assim, aos consumos inerentes àquele processamento (como a reinjeção do gás nos campos offshore) devem ser somadas perdas devido aos transportes desde a REDUC até os pontos de entrega localizados em MG e ES, que necessariamente irão ampliar o volume de gás extraído. Os desempenhos de PED para esses estados estão descritos na Tabela 12. 
Tabela 12. Resultados de PED para a distribuição de $1,0 \mathrm{~m}^{3}$ de gás natural: MG e ES

\begin{tabular}{ccccc}
\hline Categorias de impacto: $\mathrm{MG}$ & Valor $(\mathrm{MJ})$ & & Categorias de impacto: ES & Valor (MJ) \\
NRF & 42,4 & NRF & 43,3 \\
NRN & $1,55.10^{-2}$ & NRN & $1,65.10^{-2}$ \\
NRB & $7,71.10^{-6}$ & NRB & $9,85.10^{-6}$ \\
RB & $7,6.10^{-3}$ & RB & $7,8.10^{-3}$ \\
RWSG & $9,04.10^{-5}$ & RWSG & $1,04.10^{-4}$ \\
RWA & $1,26.10^{-1}$ & RWA & $1,28.10^{-1}$ \\
Total & 42,6 & Total & 43,4 \\
\hline
\end{tabular}

\subsection{Análise dos Resultados para a região Nordeste \\ 6.4.1 Mudanças Climáticas (CC)}

A Tabela 13 apresenta valores de CC para os estados que compreendem a região Nordeste do Brasil. Esses resultados mostram que PE concentra as maiores contribuições para toda a região $\left(7,35 \mathrm{kgCO}_{2}\right.$ eq $\left./ \mathrm{FR}\right)$, muito embora o estado não produza gás natural. Dadas as premissas definidas para aplicação do Método de Escalonamento o gás consumido em PE é processado na BA (3,34 $\mathrm{MMm}^{3} / \mathrm{d}$ ) e no ES (1,18 $\mathrm{MM} \mathrm{m}^{3} / \mathrm{d}$ ) (Tabela 3). O impacto neste caso deve-se exatamente aos deslocamentos realizados pelo gás acabado, que percorre $900 \mathrm{~km}$ desde a UPGN - Candeias (BA) a distribuidora Pernambucana. Por vir de mais longe, a fração que chega do ES evolui por cerca de $1530 \mathrm{~km}$ dentro das tubulações até chegar ao ponto de entrega. Com isso, as operações realizadas na BA geram emissões de $126 \mathrm{~g} \mathrm{CH}_{4} / \mathrm{FR}$ na extração do gás, e 49,0 g CH$/ 4 / \mathrm{FR}$ no refino. Já a extração nos campos capixabas aporta $44,0 \mathrm{~g} \mathrm{CH}_{4} / \mathrm{FR}$.

A PB mostra $18 \%$ menos de impacto para CC do que PE. O gás que alimenta o estado é também originário da BA, mas nesse caso, o trajeto compreendido desde a UPGN - Candeias e a distribuidora localizada é menor, muito embora perfaça $1135 \mathrm{~km}$ via gasodutos. Nesse contexto o estado segue as mesmas tendências de seu vizinho: a extração acumula $106 \mathrm{~g} \mathrm{CH}_{4} / \mathrm{FR}$, aos quais se somam 68,0 $\mathrm{g} \mathrm{CH}_{4} / \mathrm{FR}$ emitidos no refino e $49,0 \mathrm{~g} \mathrm{CH}_{4} / \mathrm{FR}$ por conta dos transportes. 
Tabela 13. Perfil do Impacto Ambiental: Mudanças Climáticas: Região NE

\begin{tabular}{cc}
\hline Estado & Impactos como CC $\left(\mathrm{kg} \mathrm{CO}_{2 \text { eq }} / \mathrm{FR}\right)$ \\
$\mathrm{RN}$ & 3,58 \\
$\mathrm{CE}$ & 5,02 \\
$\mathrm{~PB}$ & 6,05 \\
$\mathrm{PE}$ & 7,35 \\
$\mathrm{AL}$ & 1,68 \\
$\mathrm{BA}$ & 1,83 \\
$\mathrm{SE}$ & 4,64 \\
\hline
\end{tabular}

AL e BA apresentam valores próximos de impacto, com destaques para a extração na BA, e para as operações de refino e transporte que ocorrem no ES a partir de onde a demanda de AL é suprida (seção 5.3 - item g). Assim, as perdas atmosféricas de $\mathrm{CH}_{4}$ que ocorrem durante a extração do gás na Bacia Parque das Baleias (ES) aportam respectivamente 11,0 $\mathrm{g} \mathrm{CH}_{4} / \mathrm{FR}$ para os impactos de $\mathrm{CC}$ associados ao atendimento de demanda de $\mathrm{AL}$, e 18,6 $\mathrm{g} \mathrm{CH}_{4} / \mathrm{FR}$ relativos ao suprimento da BA. Note-se ainda que o gás natural consumido no SE também é produzido no ES. Por conta disso, será originada uma emissão de $84,0 \mathrm{~g} \mathrm{CH}_{4} / \mathrm{FR}$, que representa $45 \%$ dos impactos de $\mathrm{CC}$ atribuídos àquela região.

Na UPGN-Cacimbas (ES) ocorrem lançamentos de $\mathrm{CH}_{4, \mathrm{f}}$ para o ar de $46,0 \mathrm{~g} \mathrm{CH}_{4} / \mathrm{FR}$ para o caso de AL (que correspondem a 68\% do impacto total atribuído ao estado), 4,52 $\mathrm{g} \mathrm{CH}_{4} / \mathrm{FR}$ para a BA $(6,2 \%)$ e 36,0 $\mathrm{g} \mathrm{CH}_{4} / \mathrm{FR}$ para $\mathrm{SE}(19 \%)$. O gás refinado que supre a BA traz também uma contribuição do RJ. Dessa forma é importante mencionar que a UPGN-REDUC aportou uma parcela de contribuição, que chega a $10,4 \mathrm{~g} \mathrm{CH}_{4} / \mathrm{FR}$ ao produto encaminhado àquele estado.

$\mathrm{O}$ gás natural consumido no RN é produzido na BA. Assim, a emissão de $\mathrm{CH}_{4, \mathrm{f}}$ associada a extração resultou em 8,16 g CH$/ / F R$ emitidos para o ar, ao que se somam outros $31,8 \mathrm{~g} \mathrm{CH}_{4} / \mathrm{FR}$ lançados por conta do refino na UPGN-Candeias (BA). Se totalizados, essas contribuições perfazem $28 \%$ do impacto de CC imputado ao RN.

$\mathrm{CE}$ apresentou 5,02 $\mathrm{kg} \mathrm{CO}_{2 \mathrm{eq}} / \mathrm{FR}$ de impacto como CC. A maior parcela do gás consumido na região é originária dos estados de $\mathrm{RN}, \mathrm{AL}, \mathrm{SE}$ e $\mathrm{BA}$ e assim, o desempenho do estado pode ser justificado por conta da distância relativamente curta entre RN e CE, se comparada dos demais trajetos. Quanto às emissões de $\mathrm{CH}_{4, \mathrm{f}}$, observou-se que a a UPGN de Pilar (AL) registra perdas 14,3 $\mathrm{g} \mathrm{CH}_{4} / \mathrm{FR}$, ao que se somam 30,0 $\mathrm{g} \mathrm{CH}_{4} / \mathrm{FR}$ emitidos a partir da extração do gás em SE, e mais 46,0 $\mathrm{g} \mathrm{CH}_{4} / \mathrm{FR}$ em função de operações na UPGN - Guamaré (RN). 


\subsubsection{Demanda Primária de Energia (PED)}

A Tabela 14 apresenta resultados da PED para os estados da região Nordeste. Também aqui as contribuições de NRF foram majoritárias. Além disso, a partir de uma comparação entre pares AL deteve o pior desempenho da região. Isso ocorre pois o suprimento de AL é de responsabilidade do ES cuja extração junto aos reservatórios totaliza 44\% de perda do recurso natural fóssil por conta de vazamentos em dutos e reinjeção nos poços associados. PB e PE, outros destaques negativos da região NE, mostraram perfil semelhante ao de AL, com defcits sobre o patrimônio de gás bruto na BA (34\%) e no ES (12\%) durante a extração.

Tabela 14. Resultados de PED para a distribuição de $1,0 \mathrm{~m}^{3}$ de gás natural: região NE

\begin{tabular}{cccccccc}
\hline $\begin{array}{c}\text { Categorias de } \\
\text { impactos }\end{array}$ & RN & CE & PB & PE & AL & BA & SE \\
\cline { 2 - 7 } NRF & 36,8 & 38,2 & 49,0 & 46,8 & 55,0 & 39,8 & 35,8 \\
NRN & $1,12.10^{-2}$ & $7,6.10^{-2}$ & $2,53.10^{-1}$ & $3,09.10^{-1}$ & $7,12.10^{-1}$ & $4,85.10^{-3}$ & $5,11.10^{-1}$ \\
NRB & $5,87.10^{-6}$ & $1,35.10^{-5}$ & $1,0.10^{-5}$ & $1,28.10^{-5}$ & $1,17.10^{-4}$ & $3,38.10^{-6}$ & $1,16.10^{-5}$ \\
RB & $5,5.10^{-3}$ & $3,12.10^{-2}$ & $1,45.10^{-1}$ & $1,78.10^{-1}$ & $3,94.10^{-1}$ & $2,2.10^{-3}$ & $2,7.10^{-1}$ \\
RWSG & $6,77.10^{-5}$ & $9,6.10^{-4}$ & $7,55.10^{-4}$ & $8,94.10^{-4}$ & $2,63.10^{-3}$ & $3,47.10^{-5}$ & $1,41.10^{-3}$ \\
RW & $9,05.10^{-2}$ & $5,25.10^{-1}$ & 2,46 & 3,02 & 6,64 & $3,58.10^{-2}$ & $1,16.10^{-1}$ \\
Total & 39,5 & 38,8 & 51,8 & 50,3 & 62,7 & 41,3 & 41,6 \\
\hline
\end{tabular}

As extrações ocorridas na BA são responsáveis pelos desempenhos demonstrados no RN e no $\mathrm{CE}$, ao passo que as condições praticadas no ES se refletem em SE. A necessidade de reinjeção de gás em poços associados, aliada a vazamentos de dutos, e perfurações que ocorrem no ES e no RJ incidem sobre a performance da BA, cuja demanda deve ser atendida por ambos os estados (Tabela 3). Observe-se, porém que, muito embora a extração de gás realizada no RJ (45,4 $\left.\mathrm{MMm}^{3} / \mathrm{d}\right)$ supere a praticada no ES $\left(10,6 \mathrm{MMm}^{3} / \mathrm{d}\right)$, as perdas de processo do sistema fluminense medido são menores que as do sistema capixaba escala relativa.

\subsection{Análise dos Resultados para as reigões Sul e Centro-Oeste \\ 6.5.1 Mudanças Climáticas (CC)}

A Tabela 15 traz dados de impactos para CC referentes às regiões Sul e Centro-Oeste. Os efeitos atribuídos à região Sul são em sua maior parte, consequências do transporte do gás natural que advêm na totalidade, dos campos da Bolívia. Em 2016 o gás consumido no Sul do Brasil atingiu $39 \%$ da importação desde aquele país. 
O deslocamento desse volume desde sua origem em Sábalo, San Alberto e Margarita se inicia com um trajeto de $557 \mathrm{~km}$ até Corumbá (MS). Essa mobilidade resulta na emissão de $151 \mathrm{~g}$ $\mathrm{CH}_{4} / \mathrm{FR}$. Já em solo brasileiro, o gás segue por $1264 \mathrm{~km}$ até Paulínia (SP) e outros 167 g CH$/ \mathrm{FR}$ são emitidos. O fato da taxa média específica de emissão de metano para o primeiro deslocamento $\left(0,27 \mathrm{~g} \mathrm{CH}_{4} / \mathrm{FR} . \mathrm{km}\right)$ ser duas vezes maior do que a do trecho subsequente $(0,13 \mathrm{~g} \mathrm{CH} / \mathrm{FR} . \mathrm{km})$ se deve ao atraso tecnológico e a carências de manutenção do sistema boliviano.

Tabela 15. Perfil do Impacto Ambiental: Mudanças Climáticas: Região S e CO

\begin{tabular}{cc}
\hline Região & $\mathrm{CC}\left(\mathrm{kg} \mathrm{CO}_{2 \text { eq }} / \mathrm{FR}\right)$ \\
\hline Sul & 6,04 \\
Centro-Oeste & 11,4 \\
\hline
\end{tabular}

Desde Paulínia até o extremo sul do estado do PR mais 193 g CH$/$ FR são emitidos. Para atingir os pontos de entrega de Santa Catarina são lançados no ar mais $208 \mathrm{~g} \mathrm{CH}_{4} / \mathrm{FR}$ e no trajeto desde o entrocamento existente no estado e o ponto final da linha de distribuição, em Canoas (RS), ocorre uma emissão adicional de $233 \mathrm{~g} \mathrm{CH}_{4} / \mathrm{FR}$. Além do $\mathrm{CH}_{4}$, figura também como precursor de impacto neste caso é o $\mathrm{CO}_{2}$. A emissão de $164 \mathrm{~g} \mathrm{CO}_{2} / \mathrm{FR}$ compreende a somatória dos lançamentos atmosféricos do gás de combustão de 19 estações de compressão existentes no trajeto do gasoduto Brasil-Bolívia (GASBOL), sendo quatro delas na Bolívia e as quinze restantes, no Brasil.

$\mathrm{O}$ atendimento da demanda do Centro-Oeste causa impactos mais expressivos do que o da região Sul. O foco dos efeitos de CC está nas operações industriais de extração e refino do gás, que juntas acumulam 57\% de participação no aporte total para a região. As cargas relativas ao transporte são pouco influenciadas pelas distâncias visto que o fornecimento de gás para MS e MT advém da Bolívia com quem esses estados fazem fronteira. No entanto, dificuldades e obstáculos físicos que existem ao longo (variações de relevo, presença de cursos de água, formações rochosas) fazem com que $138 \mathrm{~g} \mathrm{CH}_{4} / \mathrm{FR}$ sejam emitidos através do trecho Corumbá $\rightarrow$ Paulínia, que se somam aos demais 55,0 $\mathrm{g} \mathrm{CH}_{4} / \mathrm{FR}$ dos trajetos (Sabalo, Margarita e San Alberto) $\rightarrow$ Corumbá. Para atender a região o sistema de distribuição dispõem de seis estações de compressão, cujos desempenhos conjuntos com os das 10 estações de unidades bolivianas aportam mais 72,4 $\mathrm{g} \mathrm{CO}_{2} / \mathrm{FR}$ para a atmosfera.

\subsubsection{Demanda Primária de Energia (PED)}

A Tabela 16 traz valores de PED para o suprimento de demanda de gás refinado das regiões Sul e Centro-Oeste. O desempenho para os estados do Sul se justifica devido a baixa eficiência de extração e refino de gás nos campos da Bolívia mais especificamente devido a perfurações do solo e vazamentos nos gasodutos. Do total de PED atribuído à região, $42 \%$ se originam de operações realizadas em Sábalo, 31\% das que ocorrem em Margarita, e 21\% das realizadas em San Alberto. 
Para o Centro-Oeste o fenômeno se repete, inclusive em termos da ordem de geradores de impacto. No entanto, as contribuições de Sábalo, Margarita e San Alberto são respectivamente de 43\%, 32\% e $22 \%$.

Tabela 16. Resultados para CED total para a distribuição de $1,0 \mathrm{~m}^{3}$ de gás natural: $\mathrm{S}$ e CO

\begin{tabular}{ccc}
\hline Categorias de impactos & Sul (MJ) & Centro-Oeste (MJ) \\
\hline NRF & 51,1 & 44,0 \\
NRN & $1,43.10^{-2}$ & $5,53.10^{-3}$ \\
NRB & $3,46.10^{-5}$ & $1,27.10^{-5}$ \\
RB & $1,08 \mathrm{E}-02$ & $6,23.10^{-3}$ \\
RWSG & $1,04.10^{-2}$ & $1,14.10^{-4}$ \\
RW & $2,88.10^{-4}$ & $4,71.10^{-2}$ \\
Total & 51,2 & 44,1 \\
\hline
\end{tabular}

\subsection{Retorno Energético de Investimento (EROI)}

Estudos de balanço energético costumam fazer uso do indicador de Retorno Energético de Investimento (EROI) para aferir o potencial de desempenho de combustíveis. Em termos algébricos o EROI corresponde à razão entre a energia que pode ser fornecida pelo combustível ( $\left.E_{\text {disponível }}\right), e$ aquela dispendida para que este se tornasse um provedor energético ( $\mathrm{E}_{\text {consumida }}$ ). A equação (eq.4) apresenta a expressão de cálculo do EROI.

$$
E R O I=\frac{\text { Energia Disponível }}{\text { Energia Consumida }}
$$

Dado o caráter desta análise, decidiu calcular o valor do EROI associado ao sistema atual suprimento de gás natural para o Brasil. Para tanto, foram formuladas duas premissas a título de adaptação do conceito:

a) $\mathrm{E}_{\text {consumida }}$ foi representada apenas pelo consumo de ativos de origem fóssil, ou seja, por NRF;

b) A determinação desse mesmo valor ( $\left.\mathrm{E}_{\text {consumida }}\right)$ seria realizada ao longo de toda a cadeia produtiva do gás. 
Observe-se que nenhum desses ajustes contradiz o conceito original do indicador. Além de ter em conta a quase totalidade dos consumos de PED do sistema, estabelecer uma razão em termos apenas de NRF fornece uma perspectiva adicional: de verificar a taxa de fósseis que foi consumida para a produção de um combustível de mesma natureza. A extrapolação do âmbito da análise para o ciclo de vida do processamento do gás natural é uma prática recorrente em determinações dessa natureza, dado que a rigor, os consumos energéticos para a produção do bem não se limitam um único elo da cadeia de suprimentos, a despeito do quanto este esteja próximo do consumidor final.

Para o caso presente, o valor de $\mathrm{E}_{\text {disponível }}$ foi obtido a partir da ponderação entre os Poderes Caloríficos Inferiores médio do gás refinado no Brasil $\left(\mathrm{PCI}_{\mathrm{BR}}=41,4 \mathrm{MJ} / \mathrm{m}^{3}\right)$ e daquele produzido na Bolívia $\left(\mathrm{PCI}_{\mathrm{BO}}=35,1 \mathrm{MJ} / \mathrm{m}^{3}\right.$ ). Segundo Hammerschlag (2006), a aplicação do EROI pode trazer resultados conclusivos. Combustíveis de bom desempenho energético apresentam EROI > 1,0. A Tabela 17 apresenta valores de EROI individualizados por estado para aqueles que compõem as regiões SE e NE, e resultados consolidados desse índice para as regiões Sul e Centro-Oeste.

Tabela 17. EROI Calculado para diferentes estados e regiões brasileiras

\begin{tabular}{ccc}
\hline Região & NRF (MJ) & EROI \\
\hline SP & 21,6 & 1,91 \\
RJ & 29,8 & 1,17 \\
SE & 35,8 & 1,16 \\
RN & 36,9 & 1,12 \\
BA & 39,9 & 1,04 \\
MG & 42,4 & 0,98 \\
CE & 38,2 & 0,92 \\
PE & 46,8 & 0,88 \\
PB & 49,0 & 0,85 \\
ES & 43,3 & 0,81 \\
Região CO & 44,1 & 0,79 \\
Região S & 51,1 & 0,69 \\
AL & 55,0 & 0,64 \\
\hline
\end{tabular}

Uma análise desses valores indica que os suprimentos de gás natural para os estados de SP, RJ, RN, SE e BA apresentam balanços energéticos favoráveis. SP se destaca nesse âmbito por deter o maior valor de EROI de toda a série analisada. Em todos esses casos o consumo de NRF mostrouse mais significantes para o resultado final do que a presença em maior proporção do gás refinado no Brasil na mistura disponibilizada para consumo. Esse retoque deve ser feito por $\mathrm{PCI}_{\mathrm{BR}}$ supera o $\mathrm{PCI}_{\mathrm{BO}}$ em cerca de $18 \%$, oferecendo, por isso, mais energía por $\left(\mathrm{m}^{3}\right)$ de produto. 
Outra característica comum a todos os estados que atingiram elevados valores de EROI é seus suprimentos derivam de poços associados, que são próprios de produções offshore e nos quais, em geral, há maior quantidade de gás bruto. $\mathrm{O}$ suprimento para MG mostrou um perfil equilibrado, com EROI 1,0. Para esse caso, o ganho associado ao fato de a demanda local ser atendida pelo RJ acaba sendo amortecido em parte pelas perdas de produto acabado durante o transporte.

Em seguida aparece os estados do CE, PE e PB cujos desempenho foram, invariavelmente, condicionados pelas perdas ocorridas no transporte do gás refinado. Assim como aparece indicado na Tabela 3, o gás natural consumido na PB é refinado na BA, que também atende a PE, ainda que não na totalidade, dado que $26 \%$ da oferta que a esse estado é de procedencia ainda mais afastada, vindo do ES. O CE acumula os melhores resultados desse subgrupo pois, a despeito de ser suprido por gás refinado em diferentes estados, são curtas as distâncias de deslocamento até os pontos finais de entrega. A região CO é suprida por gás boliviano de poços não associados que dispõem de menor quantidade de gás natural e são típicos de processos onshore. Somado as perdas durante o transporte do produto acabado esse aspecto justifica a ligeira defasagem de seu valor de EROI em comparação ao obtido para o ES.

As regiões $\mathrm{CO}$ e $\mathrm{S}$ e o estado de $\mathrm{AL}$, que acumulam os piores índices de EROI têm todos em comum dois fatores: (i) serem supridos por gás bruto extraído de campos onshore; e (ii) deterem perdas importantes de produto acabado por conta de operações de transporte desde a UPGN até os pontos de entrega. Essas componentes elevam seus valores de NRF a patamares que desequilibram o balanço energético do combustível, tornando-o francamente desfavorável.

\subsection{Análise de Sensibilidade}

O gás importado da Bolívia exerce um papel de destaque em termos de atendimento da demanda nacional e, por decorrência, também sobre os resultados desta análise. Assim, decidiu-se realizar uma Análise de Sensibilidade da procedência desse produto, variando-se as quantidades fornecidas pelos reservatórios de Sábalo, Margarita e San Alberto a fim de aferir os efeitos que as distâncias desses centros produtores até a fronteira com o Brasil podem causar.

A Tabela 18 descreve a composição dos cenários de análise, os quais foram formulados a partir de critérios objetivos que levam em conta a disponibilidade de gás em cada região, bem como, a capacidade das respectivas UPGNs. O 'cenário A' remete à situação estabelecida para efeito de construção do modelo. O 'cenário B' supõe que o campo de San Albeto, menor dos três provedores de gás do sistema não estivesse operando em algum momento. O 'cenário C', por sua vez, trata de concentrar toda a produção boliviana em Sábalo, o maior dos campos do país. A Tabela 18 indica valores consolidados de desempenho de cada alternativa em termos de PED e CC. 
Tabela 18. Análise de Sensibilidade: Proporções de fornecimento de gás desde a Bolívia

\begin{tabular}{|c|c|c|c|c|c|}
\hline \multirow{2}{*}{ Cenários } & \multicolumn{3}{|c|}{ Localidades dos Campos de Extração BO } & \multirow{2}{*}{$\begin{array}{c}\mathrm{PED} \\
\left(\mathrm{MJ} / \mathrm{m}^{3}\right)\end{array}$} & \multirow{2}{*}{$\begin{array}{c}\mathrm{CC} \\
\left(\mathrm{kg} \mathrm{CO}_{2 \mathrm{eq}} / \mathrm{m}^{3}\right)\end{array}$} \\
\hline & Sábalo & Margarita & San Alberto & & \\
\hline $\begin{array}{c}\text { A } \\
\text { (referência) }\end{array}$ & $44,0 \%$ & $33,8 \%$ & $22,2 \%$ & 2840 & 275 \\
\hline $\mathrm{B}$ & $55,1 \%$ & $44,9 \%$ & & 2790 & 269 \\
\hline $\mathrm{C}$ & $100 \%$ & & & 2890 & 293 \\
\hline
\end{tabular}

Tomando por referência o 'cenário A' notou-se que uma descontinuação do fornecimento de gas de San Alberto (cenário B) traria redução de 1,8\% nos impactos de PED e de 2,2\% naqueles na forma de CC. Por outro lado, a concentração do fornecimento boliviano em Sábalo (cenário C) elevaria os impactos originais de PED e de CC, respectivamente em 1,7\% e 6,5\%. A despeito de as inflexões dessas tendências serem ascendente e descendente, seus valores de variação podem ser considerados pouco significativos se comparados aos do 'cenário A'. Essa constatação referenda a perpetuação do arranjo em questão para efeito das análises que se seguem. 


\section{LEVANTAMENTO DE ALTERNATIVAS DE AMPLIAÇÃO DE SUPRIMENTO PARA ATENDER A DEMANDA FUTURA DE GÁS NATURAL}

O levantamento de alternativas para ampliação da malha brasileira de distribuição de gás natural baseou-se em critérios bem definidos. São eles: (i) factibilidade da ação; (ii) grau de avanço do empreendimento; e (iii) disponibilidade de dados.

O critério de factibilidade da ação procurou identificar situações que tivesse potencial real de implantação, a despeito do grau de necessidade manifestado pela população a ser contemplada pela medida. Seguiu na mesma linha o critério de grau de avanço do empreendimento, a partir do qual pretendeu-se aferir não apenas o status de evolução das obras de ajuste da malha gasífera. Uma componente importante desse critério referiu-se a estimativa de tempo para que as medidas fossem implantadas. Nesse âmbito, o estudo se restringiu a desenvolvimentos de curto prazo, colocando como horizonte temporal o ano de 2020.

Como não poderia deixar de ser em se tratando de um estudo de $\mathrm{ACV}$, foi decisivo para a definição de futuros cenários que houvesse dados disponíveis em volume, e com qualidade suficiente para que fossem gerados modelos aprofundados, consistentes e harmonicos entre si, e com aquele formulado para que se determinasse a situação atual de operação do sistema. Para esse aspecto em específico foram extraídas informações de documentos oficiais da Petrobras SA pelos motivos operacionais apresentados na seção 3.4. deste documento. Esses parâmetros foram também confrontados com informações disponibilizadas pela ABEGÁS com o intuito de validá-los, ainda que de maneira superficial.

Como resultado desse encadeamento de ação foram estabelecidas para efeito do presente estudo, sete alternativas de ampliação/modificação da malha gasífera existente. Todas elas têm em comum o fato de atender a regiões que atualmente não recebem gás natural através de gasodutos.

A primeira alternativa é extender a malha de gasoduto de São Carlos (SP), que tem início na Bolivia, até a região Centro-Oeste abastecendo assim o Distrito Federal. Conforme ABEGÁS (2016) esta ampliação será chamado de Gasoduto Brasil Central, totalizando 2954 km de gasoduto com a capacidade de suprimento de gás de $6,00 \mathrm{MMm}^{3} / \mathrm{d}$. Como atualmente o combustível que alimenta o interior de SP provém de reservatórios bolivianos a modelagem desse ramo do sistema pressupôs a manutenção das mesmas condições de fornecimento.

A segunda alternativa compreende a construção do Gasoduto Uruguaiana no RS. Com exatos $715 \mathrm{~km}$ de extensão e capacidade de entrega de $8,00 \mathrm{MMm} 3 / \mathrm{d}$ de gás esse ramo deverá suprir a região metropolitana de Porto Alegre, além do próprio município de Uruguaiana. Além disso, tal ação poderá contribuir com o abastecimento das regiões S e SE. Isso porque, nas proximidades de Porto Alegre o gasoduto se interliga ao GASBOL. A extração do gás bruto ocorrerá na Bacia de Pelotas, localizada em Rio Grande, no extremo Sul do Rio Grande do Sul. 
A terceira alternativa tratará de suprir o agreste Alagoano. Para tanto, o gasoduto hoje em operação, que interliga a UPGN - Pilar (AL) com Penedo (AL), será ampliado a fim de abastecer o município de Arapiraca com $0,34 \mathrm{MMm}^{3} / \mathrm{d}$ de gás natural. A extração de gás seguirá ocorrendo no campo onshore de Pilar.

As alternativas 4 e 5 compreendem o uso de gás não associado obtido da Bacia de Parnaíba (MA) para atender demandas da área isolada (ver seção 5.3 - b). O cenário 4 preve uma extensão de gasodutos de $300 \mathrm{~km}$ desde o reservatório maranhense até Teresina (PI). Este ramal deverá suprir a capital do estado com $8,40 \mathrm{MMm} 3 / \mathrm{d}$ do combustível que depois será reorientado em função de necessidades e demandas regionais. O cenário 5 considera o Gasoduto do Pará, que também se origina na Bacia de Parnaíba (MA) e percorre $1360 \mathrm{~km}$ até chegar em Belém (PA) para suprir a demanda local que é de 3,50 $\mathrm{MMm}^{3} / \mathrm{d}$.

As alternativas 6 e 7 tratam mais uma vez de gás não associado, mas que neste caso será extraído nas Bacias de Sábalo, Margarita e San Alberto na Bolívia. No cenário 6 o produto refinado seguirá por $3323 \mathrm{~km}$ de gasodutos até chegar a Palmas (TO) a fim de atender a demanda da região que está orçada em 4,00 MMm³/d. Por fim, o cenário 7 compreende o Gasoduto Centro Norte, onde o gás seguirá por $4218 \mathrm{~km}$, dos campos bolivianos até Imperatriz (MA), cuja necessidade monta também 4,00 MMm³/d. Em ambos os casos o gasoduto é mais longo do que se poderia supor uma análise preliminar pois seu traçado deve necessariamente passar por Anápolis (GO) antes de alcançar seu destino final. A tabela 19 traz, de forma sintética, as alternativas de ampliação que foram propostas para atender a demanda futura de distribuição e gás natural para o Brasil.

Tabela 19. Alternativas de ampliação Futura de distribuição e gás natural para o Brasil

\begin{tabular}{|c|c|c|c|c|c|c|}
\hline Alternativas & Origem & Destino & $\begin{array}{l}\text { Extensão } \\
(\mathrm{km})\end{array}$ & $\begin{array}{c}\text { Volume } \\
\left(\mathrm{MMm}^{3} / \mathrm{d}\right)\end{array}$ & $\begin{array}{c}\mathrm{N} \circ \mathrm{de} \\
\text { Compressores }\end{array}$ & UPGN \\
\hline 1 & Bolivia & $\begin{array}{c}\text { Distrito } \\
\text { Federal (DF) }\end{array}$ & 2954 & 6,00 & 6 & $\mathrm{~N}$ \\
\hline 2 & $\begin{array}{l}\text { Rio Grande } \\
\text { (RS) }\end{array}$ & $\begin{array}{l}\text { Uruguaiana } \\
\text { (RS) }\end{array}$ & 715 & 8,00 & 3 & $\mathrm{~S}$ \\
\hline 3 & $\begin{array}{l}\text { Penedo } \\
\text { (AL) }\end{array}$ & $\begin{array}{l}\text { Arapiraca } \\
\text { (AL) }\end{array}$ & 67 & 0,34 & 1 & $\mathrm{~N}$ \\
\hline 4 & $\begin{array}{l}\text { B. de Parnaíba } \\
\text { (MA) }\end{array}$ & $\begin{array}{l}\text { Belém } \\
\text { (PA) }\end{array}$ & 1360 & 3,50 & 6 & $\mathrm{~S}$ \\
\hline 5 & $\begin{array}{l}\text { B. de Parnaíba } \\
\text { (MA) }\end{array}$ & $\begin{array}{l}\text { Teresina } \\
\text { (PI) }\end{array}$ & 300 & 8,40 & 3 & $\mathrm{~S}$ \\
\hline 6 & Bolívia & $\begin{array}{l}\text { Palmas } \\
\text { (TO) }\end{array}$ & 3323 & 4,00 & 12 & $\mathrm{~N}$ \\
\hline 7 & Bolívia & $\begin{array}{l}\text { Imperatriz } \\
\text { (MA) }\end{array}$ & 4218 & 4,00 & 12 & $\mathrm{~N}$ \\
\hline
\end{tabular}

N:não; S:sim; V:volume a ser atendido; UPGN: Unidade de processamento de gás 


\section{ELABORAÇÃO DO MODELO DO SISTEMA DE PRODUTO DA SITUAÇÃO FUTURA}

Um conjunto de informações e hipóteses suportou a elaboração do modelo de suprimento fututro de gás natural para o Brasil. No que se refere ao tratamento das perdas originadas por conta do deslocamento do gás até os pontos de entrega, o levantamento se baseou no Boletim Mensal de Acompanhamento da Indústria de Gás Natural de 2016. Assim, e tal como ocorreu com a situação atual, considerou-se um total de 4,3\% de perdas nessa operação, sendo 3,0\% corresponde ao sistema de compressão, e 1,3\% oriundas de vazamentos. Para as UPGNs admitiu-se que as perdas seriam de $8,0 \%$, ao passo que nas etapas de exploração e produção (E\&P), e nas atividades de reinjeção de gás em campos offshore, esses valores atingiriam respectivamente 12\% e 29\% (MME, 2016).

Das sete alternativas verificadas apenas uma já se encontra em operação, ao passo que as demais seguem tendo suas viabilidades técnicas sendo verificadas. Para viabilizar a alternativa 1 será realizada uma ampliação de um ramo do gasoduto que atualmente integra o GASBOL. Logo, o combustível que atenderá o DF tem origem nos campos gasíferos da Bolívia. Para percorrer a distância total prevista, serão necessários 20 compressores, sendo 14 existentes, dos quais quatro estão em território boliviano, dez no Brasil (que ligam Corumbá $\rightarrow$ São Carlos), e outros seis desde São Carlos até o DF. O Apêndice A.11 descreve esse arranjo em mais detalhes.

A alternativa 2 terá um sistema de compressão capaz de deslocar o gás bruto desde a Bacia de Pelotas até a Refinaria de Rio Grande, onde este será tratado. Depois, outros três compressores serão necessários para distribuir o combustível, até o ponto de entrega que atende o município de Uruguaiana (Apêndice A.12).

A alternativa 3 também se propõe a ampliar uma linha existente de gasoduto para atender a certa demanda de gás. No caso presente a tubulação que suprirá o município de Arapiraca será expandida em $67 \mathrm{~km}$ a partir de Penedo. O sistema contará com um sistema de compressão para realizar o deslocamento do gás bruto até a UPGN Pilar, e de outro compressor para atender o município de Arapiacara (Apêndice A.13).

O estado do Maranhão é destaque na exploração de gás natural em onshore, dado o modelo operacional utilizado na região que combina gás natural e energia. Os cenários 4 e 5 estão foram estudados dentro dessa perspectiva, ou seja suprir centros como Teresina e Belém com o gás natural extraído na Bacia de Parnaíba, localizada em Santo Antônio dos Lopes (MA). Para o cenário 4 será necessária a construção de $1360 \mathrm{~km}$ de gasodutos ligando o reservatório Belém. O transporte será feito com um sistema de compressão que deslocará o combustível bruto por $50 \mathrm{~km}$ desde o campo de extração até a Unidade de Tratamento de Gás, também localizada em Santo Antônio dos Lopes. 
O gás natural processado seguirá por mais $530 \mathrm{~km}$ com o auxílio de dois compressores que o levarão até Açailândia (MA) para daí ser encaminhado ao ponto de entrega. O trajeto compreende 774 km e deverá utilizar três sistemas de compressão (Apêndice A.14).

Conforme o Apêndice A.15 serão necessários 300 km de gasodutos para ligar a Bacia de Parnaíba até a capital piauiense. Assim, o transporte de gás no cenário 5 será feito com a instalação de um sistema de compressão que deslocará o combustível bruto por $50 \mathrm{~km}$ desde o reservatório até a Unidade de Tratamento de Gás em Santo Antônio dos Lopes. Já o gás refinado avançará por mais $250 \mathrm{~km}$, nesse caso com o auxílio de dois compressores que o farão chegar ao ponto de entrega no estado do Piauí.

Assim como já fora discutido o cenário 6 verifica o traçado que irá abastecer Palmas a partir de uma ramificação do Gasoduto GASBOL. Nesse trajeto o gasoduto passa pelo interior de São Paulo e por Anápolis. Para vencer os acidentes e perdas de carga do deslocamento o sistema conta com 12 compressores desde São Carlos até o Tocantins. Por fim, o ramo objeto de análise pelo cenário 7 se propõe a suprir Imperatriz a partir da mesma origem na Bolívia. O gasoduto ligará Anápolis ao Maranhão e para esse transporte serão necessários 6 compressores, além dos outros seis sistemas que deslocarão o gás desde São Carlos ao município goiano.Os Apêndices A.16 e A.17 trazem mais detalhes sobre os arranjos de processo tratados nas alternativas 6 e 7 . 


\section{DIAGNÓSTICO DOS DESEMPENHOS ENERGÉTICO E AMBIENTAL DO SUPRIMENTO DA DEMANDA FUTURA DE GÁS NATURAL}

Por se tratar de um ensaio de projeção os diagnósticos energético e ambiental do sistema futuro de suprimento de gás para o Brasil foram estabelecidos sempre tendo como referência a condição atual do mesmo arranjo. Assim, como já se havia adiantado na seção 3.6 deste documento, as análises foram conduzidas a partir de estimativas relativizadas, medidas em função das variações de produção que a condição futura pode proporcionar ao sistema a partir da implementação de cada alternativa. Portanto, antes de estimar valor, o propósito dessas verificações é identificar tendências.

Além desse esclarecimento, um breve preâmbulo de caráter operativo-ambiental deve ser realizado a título de faciliar a interpretação dos resultados obtidos. Tal como já foi discutido durante a descrição do processo (seção 4.1) em sistemas com extração onshore, como é o caso de todas as alternativas analisadas, não há necessidade de reinjeção de gás. Assim, o foco principal de consumo de PED concentra-se invariavelmente no transporte do gás refinado desde a UPGN até o ponto de entrega, por conta de: (i) vazamentos em tubulações e outros elementos que compõem as linhas de distribuição; e (ii) o processo de recompressão, que faz uso de parte do gás como força motriz para o impulsionamento do fluído até a estação de compressão seguinte. Em termos quantitativos, tais efeitos remetem, respectivamente, a 1,3\% e 3,0\% de perdas de produto acabado. Note-se ainda que a própria UPGN também impõe perdas ao sistema, da ordem de 8,0\% (Capítulo 8). Muito embora ocorrendo no trecho final da cadeia de produção, essas perdas poderão ser compensadas apenas, por ações realizadas na porção inicial daquele ciclo produtivo, por meio da retirada de um excedente de gás bruto.

Olhando a questão sob o ponto de vista de CC, perdas por vazamento são mais impactantes, em termos específicos, do que o consumo de gás para compressão. Isso porque, que o primeiro dos efeitos proporciona o lançamento atmosférico de $\mathrm{CH}_{4, \mathrm{f}}$, (Fator de Impacto, $\mathrm{FI}=25 \mathrm{~kg} \mathrm{CO} \mathrm{eq}_{2} / \mathrm{kg}$ ), ao passo que o outro ocorre na forma de $\mathrm{CO}_{2}$, que por ser ser padrão da categoria de $\mathrm{CC}$, apresenta $\mathrm{FI}=1.0 \mathrm{~kg} \mathrm{CO} \mathrm{eq}_{\mathrm{eq}} / \mathrm{kg}$.

A Tabela 20 apresenta os resultados dos desempenhos energético e ambiental do sistema futuro de suprimento de gás natural para o Brasil em termos discretizados, ou seja, tendo em conta a implantação de cada alternativa de expansão em separado. Essa abordagem, inclusive, motivou a criação de cenários.

Uma análise desses valores indicou haver sempre acréscimo de impacto em decorrência das ações de ampliação. Esse achado, que se origina do fato de os indicadores de desempenho serem positivos $\left(\Delta R_{I E}>0\right.$ e $\left.\Delta R_{I A}>0\right)$, não chega a ser surpreendente, dado o porte dos empreendimentos, e o fato de as propostas de ampliação não terem sido submetidas a uma análsie de fundo ambiental de abrangência sistêmica para efeito de sua aprovação. 
No primeiro momento, chamam a atenção os $\Delta R_{I E}$ de $\mathrm{C} 2$ e $\mathrm{C} 5$, respectivamente, de 44.34 e $43.75 \mathrm{MJ} /\left(\mathrm{MM} \mathrm{m}^{3} / \mathrm{dia}\right)$. O desempenho de C2 é ligeiramente pior que o de seu homólogo, muito embora essa alternativa distribua diariamente 5,0\% a mais de gás do que C5. Observando em mais detalhes as características desses cenários (Tabela 19) notam-se semelhanças entre eles, tanto no número de compressores, como na existência de uma UPGN própria para suprir cada demanda. No entanto, em C2 o gás desloca-se por $715 \mathrm{~km}$ desde Rio Grande até Uruguaiana, ao passo que em C5, o trajeto da Bacia de Parnaíba até Teresina compreende $300 \mathrm{~km}$. Esse quadro sugere que a distância de transporte seja mais determinante para efeito de impactos gerados como PED do que o volume transportado. A confrontação daqueles resultados com os valores obtidos para $\mathrm{C} 1$ apenas ratifica essa conclusão. A distribuição $6,00 \mathrm{MMm}^{3} / \mathrm{d}$ de gás refinado desde a Bolivia até o DF acumulou $\Delta R_{I E}=45.78 \mathrm{MJ} /\left(\mathrm{MM} \mathrm{m}^{3} / \mathrm{d}\right)$ ao valer-se de seis compressores para suplantar um deslocamento de $2954 \mathrm{~km}$. Ou seja: a distribuição de um volume em cerca de $25 \%$ menor do que os praticados por $\mathrm{C} 2$ e C5, ao longo, porém, de uma distância que corresponde, respectivamente, a quatro e a dez vezes as daquelas distribuições faz com que os impactos em termos de PED superem os dos mesmos cenários em 3,2 e 4,6\% respectivamente.

Os cenários C6 e C7 seguem a mesma tendência. Nesses casos, muito embora a demanda local a ser atendida seja de $4,00 \mathrm{MMm}^{3} / \mathrm{d}$ (portanto, perto de $50 \%$ mais baixa do que as necessidades para C2 e C5), os valores de $\Delta R_{I E}$ estão entre os mais elevados de toda a série analizada. De acordo com os valores da Tabela 19, os subministros de gás refinado desde a Bolívia até Palmas (C6) e até Imperatriz (C7) predispõem deslocamentos de 3323 e 4218 km, utilizando para tanto, doze estações de compressão.

No outro extremo do conjunto de resultados estariam C4 e, na condição limite, C3. Essas ampliações se caracterizam por distribuir volumes menores de gás por deslocamentos curtos. Ainda que os 3,50 $\mathrm{MMm}^{3} / \mathrm{d}$ de $\mathrm{C} 4$ se aproximem do patamar praticado por $\mathrm{C} 6$ e $\mathrm{C} 7$, o fato do trecho Bacia de Parnaíba $\rightarrow$ Belém ser de $1360 \mathrm{~km}$ fez com que $\Delta R_{I E}^{C 4}$ fosse, dos mais baixos de todo o conjunto, se assemelhando inclusive, e em muito, ao resultado obtido em $\Delta R_{I E}{ }^{C 2}$, o qual foi conseguido para uma distância em cerca de $91 \%$ menor, mas transportando 2,3 vezes mais gás refinado.

Por fim, deve-se destacar a situação de $\mathrm{C} 3$, cujo $\Delta R_{I E}{ }^{C 3}$ mostrou-se potencialmente nulo. Nesse caso, além de os volume de gás e distância de transporte serem discretos, o sistema de ligação entre Penedo e Arapiraca não necessita de UPGN própria e conta apenas com um único compressor, que aliás é de menor porte se comparado aos dos demais, consumindo portanto e inevitavelmente menos gás do que aqueles para ultrapassar os $67 \mathrm{~km}$ de trecho quase linear entre as duas localidades. 
Tabela 20. Desempenhos energético e ambiental das ampliações futuras do sistema

\begin{tabular}{|c|c|c|c|c|c|c|c|}
\hline Canório & $\left(\sum F_{D}-\sum F_{A}\right)$ & $\sum F_{e}$ & $F_{e}-\sum$ & $\Delta R_{I E}$ & $\sum j_{F}$ & $\sum j_{F}-\sum j_{A}$ & $\Delta R_{I A}$ \\
\hline & $\left(\mathrm{MM} \mathrm{m}^{3} / \mathrm{dia}\right)$ & $(\mathrm{GJ})$ & $(\mathrm{MJ})$ & {$\left[\mathrm{MJ} /\left(\mathrm{MM} \mathrm{m}^{3} / \mathrm{dia}\right)\right]$} & $\left(\mathrm{kg} \mathrm{CO}_{2 \text { eq }}\right)$ & $\left(\mathrm{kg} \mathrm{CO}_{2 \text { eq }}\right)$ & {$\left[\mathrm{kg} \mathrm{CO}_{2 \mathrm{eq}} /\left(\mathrm{MM} \mathrm{m}^{3} / \mathrm{dia}\right)\right]$} \\
\hline $\mathrm{C} 1$ & 6,00 & 3.31 & 275 & 45.78 & 326 & 27.2 & 4.53 \\
\hline $\mathrm{C} 2$ & 8,00 & 3.39 & 355 & 44.34 & 349 & 50.3 & 6.29 \\
\hline $\mathrm{C} 3$ & 0,34 & 3.03 & 0.0 & 0.0 & 299 & 0.0 & 0.0 \\
\hline $\mathrm{C} 4$ & 3,50 & 3.19 & 155 & 44.29 & 316 & 17.2 & 4.92 \\
\hline $\mathrm{C} 5$ & 8,40 & 3.40 & 367 & 43.75 & 336 & 36.8 & 4.38 \\
\hline C6 & 4,00 & 3.22 & 183 & 45.74 & 319 & 20.2 & 5.05 \\
\hline $\mathrm{C} 7$ & 4,00 & 3.22 & 185 & 46.29 & 320 & 21.6 & 5.39 \\
\hline
\end{tabular}


Ao olhar os mesmos perfis agora em termos de $\mathrm{CC}$, nota-se uma digressão com respeito às tendências evidenciadas a partir da análise energética. Para essa dimensão o cenário C 2 mostrou a pior taxa de impacto para cada $\mathrm{MMm}^{3}$ adicionado ao sistema diariamente, distante inclusive, em em cerca de 44\% daquele acumulado para C5, cujo volume distribuído é semelhante. Conclui-se a partir desses resultados que para CC, o binômio volume de gás - distância de deslocamento exerce um papel fundamental na geração de impacto, com mais peso para o primeiro. Além disso, a taxa de perdas por vazamento (de 1,3\% do volume de gás descartado durante o transporte) será também mais significante do que aquela decorrente da compressão $(3,0 \%)$ para o cômputo geral de impacto, por ocorrem em termos de $\mathrm{CH}_{4, \mathrm{f}}$.

Em uma escala hierarquica decrescente, seguem-se ao desempenho de $\mathrm{C} 2$, aqueles obtidos por C6 e C7. Como já se havia apontado, muito embora essas distribuições ocorram ao longo de distâncias de quatro a seis vezes mais elevadas, tais cenários tem a missão de transportar não mais do que $50 \%$ do volume praticado em $\mathrm{C} 2$, atingindo assim, respectivamente perto de $80 \%$ e $86 \%$ de seu patamar de desempenho.

As performances de $\mathrm{C} 1$ e $\mathrm{C} 4$ também corroboram esta leitura, comprovando-a, no entanto, por diferença. Nesses casos, observam-se condições opostas estabelecidas em C2, respectivamente com volumes transportados mais baixos e distâncias maiores do que os daquela referência. Como resultados desses arranjos os resultados de $\Delta R_{I A}{ }^{C l}$ e $\Delta R_{I A}{ }^{C 4}$ mostraram ser dos mais discretos dentre todos aqueles verificados pelo estudo. $\mathrm{O}$ quandro ratifica a confirma a necessidade de prevalência do volume transportado sobre a distância na magnificação de impactos como CC.

Mais uma vez neste caso, C3 apresentou um desempenho virtualmente nulo, sugerindo que também para Mudanças Climáticas os efeitos do atendimento de baixas demandas que se situassem a curtas distâncias seriam desprezíveis. 


\section{CONCLUSÃO}

Este trabalho se propôs a verificar impactos ambientais e consumos energéticos associados da distribuição do gás natural consumido no Brasil, para a situação presente e para as condições futuras. Para tanto, modelos teóricos, que representassem de maneira consistente cada situação, foram construídos a partir de dados secundários disponíveis na literatura, formada em sua maioria por documentos oficiais. Os impactos energéticos foram quantificados em termos de Demanda Primária de Energia (PED), ao passo que o perfil ambiental foi firmado em termos de contribuições para Mundanças Climáticas (CC).

Tendo em vista as características e especificidades do sistema de produto os resultados obtidos em termos de PED para a primeira proposta do trabalho, indicam haver uma concentração de consumos na forma de NRF. Essa leitura já era esperada dadas as características do sistema. Pode-se observar que as perdas de $\mathrm{CH}_{4}$ com maior representatividade, ocorre em sua grande maioria na extração do insumo durante a retirada do recurso fóssil das reservas. Outro fator que contribuinte para a perda do gás metano é a atividade de reinjeção do gás em poços associados em plataformas offshore.

Em termos do Perfil Ambiental, os processos que mais contribuíram para as emissões de GEE são extração e processamento do gás bruto nas Unidades de Processamento de Gás (UPGNs). As principais contribuições para Mudanças Climáticas são emissões $\mathrm{CH}_{4}$, que ocorrem durante o transporte do gás bruto ou acabado, por conta de vazamentos em juntas de tubulações, em selos e superfícies rotativas e nos componentes e acessórios de linhas e outros equipamentos. Ao analisar os resultados para a região Sul e Centro-Oeste, observou-se a influência de perdas de $\mathrm{CO}_{2}$, que ocorrem nas estações de compressão que deslocam o gás desde a Bolívia até as regiões Sul e Centrooeste do país.

Uma forma adicional de verificar a efetividade energética da cadeia de processamento de gás natural foi avaliar seu valor de Índice de Retorno Energético sobre o investimento (EROI). Pode-se concluir que os estados de Minas Gerais, Espírito Santo, Ceará, Paraíba, Pernanbuco, Alagoas, além das regiões Sul e Centro Oste apresentam maior dispêndio de energia de origem não renovável do que aquela que pode proporcionar o gás natural em condições de comercialização. Essa constatação encontra respaldo nos longos deslocamentos que o combustível percorre. $\mathrm{O}$ sistema de extração também influenciou nos valores obtidos, visto que ao comparar processos de extração em terra e no mar, aqueles que integram o primeiro grupo requerem maiores consumos do recurso natural, por se concentrar em reservas não associadas onde a disponibilidade de gás é menor.

Diante dessa quandro foram analisadas ações de expánsão da malha gasífera nacional que estivessem concluídas e operando até 2020. A aplicação de critérios de seleção que se baseassem em (i) factibilidade da ação; (ii) grau de avanço do empreendimento; e (iii) disponibilidade de dados fez com que fossem selecionadas para de nova verificação energético-ambiental sete alternativas. 
Esses arranjos produtivos foram também modelados a partir de dados secundários. A incorporação de cada ampliação a malha existente gerou um cenário específico de análise, cujas desempenhos nas formas de PED e CC voltaram a ser medidos e interpretados.

A análise sugeriu que, em termos de PED, a distância de transporte é um fator decisivo de impacto, suplantando inclusive o volume de gás refinado a ser distribuído. Já no tocante a CC, esses dois parâmetros serão decisivos, sendo que o maior peso para efeito de geração de impacto recairia sobre a quantidade de gás distribuído.

Exceuando-se as performences virtualmente nulas obtidas pelo cenário $\mathrm{C} 3$, que considera o transporte 0,34 $\mathrm{MMm}^{3} / \mathrm{d}$ de gás desde Penedo até Arapirada (ambos municípios de Aloagoas), por uma distância de $67 \mathrm{~km}$, com apenas um compressor e desobrigando da existência de UPGN para isso, os melhores resultados para a entrega de cada $\mathrm{MMm}^{3}$ diário adicional ao sistema nacional foram obtidos para o cenário C5. Nesse caso, exatos 8,40 $\mathrm{MMm}^{3} / \mathrm{d}$ são transportados desde a Bacia de Parnaíba (MA) até Teresina (PI) por $300 \mathrm{~km}$, consumindo 43,75 MJ e gerando 4,38 $\mathrm{kg} \mathrm{CO}_{2}$ eq.

A tecnica de Avaliação de Ciclo de Vida cumpriu de forma adequado com o papel que dela se espera, de verificar os efeitos proprocionados por esses sistemas antrópicos sobre o ambiente de maneira quantitativa e abragente a ponto de fornecer subsídios para futuras ações de gestão a serem tomadas no mesmo âmbito, para as quais a variável ambiental venha a ser por ventura relacionada. 


\section{REFERÊNCIAS BIBLIOGRÁFICAS}

ABNT. Associação Brasileira de Normas Técnicas. ABNT NBR ISO 14001:2004: Sistemas da gestão ambiental - Requisitos com orientações para uso. São Paulo: ABNT, 2004. 27p.

NBR ISO 14040: Gestão ambiental - Avaliação do ciclo de vida - Princípios e estrutura. São Paulo: ABNT, 2009a. 21p.

NBR ISO 14044: Gestão ambiental - Avaliação do ciclo de vida - Requisitos e orientações. São Paulo: ABNT, 2009b. 46p.

ANP. Agência Nacional de Petróleo, Gás Natural e Biocombustíveis. Anuário Estatístico de Petróleo, Gás Natural e Biocombustíveis. 2016. ISSN 1983-5884. 232 pp.

ABEGÁS - Associação Brasileira das Empresas Distribuidoras de Gás Canalizadohttp://www.abegas.org.br

BP Technology Outlook, 2015. Technology Choices for a Secure, Affordable and Sustainable Energy Future. In: BP p.l.C. London, United Kingdom.

BRASIL. Câmara dos Deputados. Os Desafios do pre-Sal. Cadernos de Altos estudos - v5. 2009. CDU 665.6(81). ISBN 978-85-7325-607-7. 76p.

BRASIL. Lei No 9.478, de 6 de agosto de 1997,. Disponível em https://www. planalto.gov.br/ ccivil_03/leis/19478.htm.

CARROL, JJ., 2010. Acid Gas Injection and Carbon Dioxide Sequestration. John Wiley \& Sons Inc., Scrivener publishing LLC., Massachusetts, USA.

CNI. Confederação Nacional da Indústria. Gás natural liquefeito: cenários globais e oportunidades para a indústria brasileira. Brasília: CNI, 2016. CDU: 665.6/.7.169 p.

DONOUGHUE, PR. ; HEATH, GA. ; DOLAN, SL. ; VORUM, M- Life Cycle Greenhouse Gas Emissions of Electricity Generated from Conventionally Produced Natural Gas - Journal of Industrial Ecology, February 2014, Vol.18(1), pp.125-144.

EPE Plano Decenal de Expansão da Malha de Transporte Dutoviário - PEMAT 2022 - Empresa de Pesquisa Energética (2014)

FGV Energia,novembro 2014; - ano 1;n॰2;ISSN 2358-5277-GÁS NATURAL

FERREIRA, V. C. M. Análise da fundamentação da avaliação do ciclo de vida consequencial. Dissertação (Mestrado) - Escola Politécnica, Universidade de São Paulo, São Paulo, 73 p. 2012

FRISCHKNECHT, R. et al 2007. Implementation of Life Cycle Impact Assessment Methods: Data v2.0. Ecoinvent report No. 3, Swiss Centre for Life Cycle Inventories, Dübendorf, CH. 2007.

GARCIA, CB (coord.) Gás Natural: benefícios ambientais no Estado da Bahia. Companhia de Gás da Bahia - Bahiagas. (2005). CDU - 622.324.5. 132p. 
GUNADY MGA. et al. Evaluating The Global Warming Potential Of The Fresh Produce Supply Chain For Strawberries, Romaine/Cos Lettuces (Lactuca Sativa), And Button Mushrooms (In Print: Agaricus Bisporus) In Western Australia Using Life Cycle Assessment (LCA). Journal Of Cleaner Production, v. 28, p. 81-87, 2012.

HAMMRSCHLAG, R Ethanol'sEnergy Return on Investment: A Survey of the Literature 1990Present.Environmental Science \& Technology, v.40, n.6,p. 1744-1750,fev 2006.

HEIJUNGS R, SUH S (2002). The Computational structure of Life Cycle Assessment. Kluwer Academic Publishers, Dordrecht

JUNLI ,SHI ; LI, TAO ; PENG, SHITONG ;LIU, ZHICHAO ; ZHANG, HONGCHAO ; JIANG, QIUHONG - Comparative Life Cycle Assessment of remanufactured liquefied natural gas and diesel engines in China - Journal of Cleaner Production, 15 August 2015, Vol.101, pp.129-136.

KIDNAY, A.J., Parrish, W.R., McCartney, D.G., 2011. Fundamentals of Natural Gas Processing, second ed. CRC Press, Taylor and Francis Group, LLC

MARTINHO, H. M. Avaliação da efetividade de arranjos tecnológicos e processuais na melhoria do desempenho ambiental da produção de fosfato bi cálcico. Dissertação (Mestrado). Escola Politécnica da Universidade de São Paulo. USP, São Paulo, 156p. 2014.

MOUTINHO DOS SANTOS, E. Capítulo 7: Aspectos técnicos e ambientais da exploração de petróleo. In: Textos-Energia que transforma (Kitta Eitler, Vania Lins, org.). Rio de Janeiro: Fundação Roberto Marinho, 2012, p. 54-71.

MME - Ministério de Minas e Energia. (2015) Boletim Mensal de Acompanhamento da Indústria de Gás Natural - n0 109. Março 2016. Secretária de Petróleo, Gás Natural e Combustíveis Renováveis. Brasília. Consultado em: http://www.mme.gov.br

MUÑOZ CPF et al (2014) Cadernos FGV Energia Gás natural (2014): 1 (2). Fundação Getúlio Vargas FGV. Rio de Janeiro, 2014. 80p. ISSN 2358-5277

Negreiros A.R., Considerações sobre o mercado da Indústria do Gás Natural no Brasil-SIMPOI 2013Universidade Estadual do Norte Fluminense.

PICARD, D. et al. Fugitive Emissions from Oil and Natural Gas Activities: Background paper. In: IPCC, Energy Sector - Good Practice Guidance and Uncertainty Management in National Greenhouse Gas Inventories. Revised Good Practice Guidance and Uncertainty Management in National Greenhouse Gas Inventories (Good Practice Guidance 2000). Genebra: IPCC, 2000.

ROBERT HOWARTH, ; RENEE SANTORO, ; ANTHONY INGRAFFEA, - Methane and the greenhouse-gasfootprint of natural gas from shale formations - Climatic Change, 2011, Vol.106(4), pp.679690

SANTOS, W.G. Minicurso Processamento de Gás Natural, UFPETRO, maio 2012

SEBRAE - Programa Petróleo e Gás: Informações para e Empresas fornecedoras de Bens e Serviços, novembro 2014.

SILVA, G. A.; KULAY, L. A. Avaliação do ciclo de vida. In: Vilela Junior, A.; Demajorovic, J. "Modelos de ferramentas de gestão ambiental: desafios e perspectivas para organizações". São Paulo. Ed Senac, 2006 
SILVA, G. A.; KULAY, L. A. Avaliação do Ciclo de Vida. In: Vilela Jr., A.; Demajorovic, J. (Org.). Modelos e ferramentas de Gestão Ambiental: Desafios e perspectivas para as organizações. $2^{\mathrm{a}}$ ed. revista e ampliada. São Paulo: Editora Senac, 2010. p. 325-348.

SPEIGHT, J.G., 2015a. Liquid fuels from natural gas. In: Lee, S., Speight, J.G., Loyalka, S.K. (Eds.), Handbook of Alternative Fuel Technologies, second ed. Taylor and Francis Group, LLC, CRC Press, pp. $157 \mathrm{e} 178$.

FADEYI S.; ARAFAT H.A., MOHAMMAD R.M.- Life cycle assessment of natural gas combined cycle integrated with $\mathrm{CO}_{2}$ post combustion capture using chemical solvente- International Journal of Greenhouse Gas Control, November 2013, Vol.19, pp.441-452

SYDNEY, E. B., et al. Economic processe to produce biohydrogen and volatile fatty acids by a mixed culture using vinasse from sugarcane ethanol industry as nutrient source. Biosource technology, v. 159, p. 380-386, 2014

SUGAWARA, E. T. Comparação dos desempenhos ambientais do B5 etílico de soja e de óleo diesel, por meio da avaliação do ciclo de vida (ACV). Dissertação (Mestrado) - Escola Politécnica, Universidade de São Paulo, São Paulo, 242 p., 2012

TAVARES, M. Os Desafios do Mercado Brasileiro de Gás Natural. Interesse Nacional. São Paulo. v. 6, n. 22. 22-31. Jul./Set. 2013.

VAN DER VOET, E et al. Allocation Issues in LCA Methodology: A Case Study of Corn Stover-Based Fuel Ethanol. International Journal of Life Cycle Assessment. 14, 529-539, 2009.

VASCONCELOS, C. D; LOURENÇO, S. R.; GRACIAS, C. D. A. Network flows modeling applied to the natural gas pipeline in Brazil. Journal of Natural Gas Science and Engineering, n. 14, 2013. 211-224.

VEROBA, R.; STEWART, E., Fundamentals of Gas Sweetening, Proceedings of the Laurance Reid Gas Conditioning Conference, Norman, OK. 2003, 1.

VAZ, C.E.M.; MAIA, J.L.P.M; SANTOS, W.G. Tecnologia da Indústria do Gás Natural, $1^{\text {a }}$ edição, Blucher, 2008.

WOLDEYOHANNES, A.D., MAJID, M.A.A., 2011. Simulation model for natural gas transmission pipeline network system. Simulation Modelling Practice and Theory 19, 196e212. Elsevier http://www.sciencedirect.com/science/article/pii/S1569190X10001279. 


\section{APÊNDICES}




\section{A.1- Inventário de Extração Onshore de Gás Natural}

\section{Corrente}

Natural gas, unprocessed SÁBALO, at
extraction/BO U
extraction/BO U
Quantidade Unidade

Produto

\begin{tabular}{|c|c|c|}
\hline 1.0 & $\mathrm{~m}^{3}$ & $\begin{array}{l}\text { Extração de gás natural no Campo de Sábalo- } \\
\text { Bolívia }\end{array}$ \\
\hline
\end{tabular}

Recursos Naturais obtidos da Biosfera

$1.0 \quad \mathrm{~m}^{3}$

Electricity, medium voltage, production $\mathrm{BO}$, at grid/BO U

Natural gas SÁBALO, at production/BO U

Esfera tecnológicas: Materiais e Combustíveis

\begin{tabular}{|c|c|c|c|}
\hline \multicolumn{4}{|c|}{ Saídas } \\
\hline \multicolumn{4}{|c|}{ Emissões Atmosféricas } \\
\hline Methane, fossil & 0,00882 & $\mathrm{~kg}$ & \\
\hline \multicolumn{4}{|c|}{ Emissões para água } \\
\hline 4-Methyl-2-pentanone & $1,33 \mathrm{E}-08$ & $\mathrm{~kg}$ & \\
\hline Acetone & $3,17 \mathrm{E}-08$ & $\mathrm{~kg}$ & \\
\hline Acidity, unspecified & $6,67 \mathrm{E}-07$ & $\mathrm{~kg}$ & \\
\hline Aluminium & 0,0000584 & $\mathrm{~kg}$ & \\
\hline Ammonium, ion & 0,0000391 & $\mathrm{~kg}$ & \\
\hline Antimony & $3,57 \mathrm{E}-08$ & $\mathrm{~kg}$ & \\
\hline Arsenic & $7,01 \mathrm{E}-07$ & $\mathrm{~kg}$ & \\
\hline Barium & 0,000903 & $\mathrm{~kg}$ & \\
\hline Benzene & 0,00000532 & $\mathrm{~kg}$ & \\
\hline Benzene, ethyl- & 2,99E-07 & $\mathrm{kg}$ & \\
\hline Beryllium & $3,18 \mathrm{E}-08$ & $\mathrm{~kg}$ & \\
\hline BOD5, Biological Oxygen Demand & 0,000552 & $\mathrm{~kg}$ & \\
\hline Boron & 0,00000996 & $\mathrm{~kg}$ & \\
\hline Bromine & 0,00068 & $\mathrm{~kg}$ & \\
\hline Cadmium & $1,02 \mathrm{E}-07$ & $\mathrm{~kg}$ & \\
\hline Calcium, ion & 0,0102 & $\mathrm{~kg}$ & \\
\hline Chloride & 0,115 & $\mathrm{~kg}$ & \\
\hline Chromium & 0,00000161 & $\mathrm{~kg}$ & \\
\hline Cobalt & 7,03E-08 & $\mathrm{kg}$ & \\
\hline COD, Chemical Oxygen Demand & 0,000913 & $\mathrm{~kg}$ & \\
\hline Copper & 4,48E-07 & $\mathrm{kg}$ & \\
\hline Cyanide & $2,29 \mathrm{E}-10$ & $\mathrm{~kg}$ & \\
\hline Fluoride & 1,11E-09 & $\mathrm{kg}$ & \\
\hline Iron & 0,000184 & $\mathrm{~kg}$ & \\
\hline Lead & 0,00000101 & $\mathrm{~kg}$ & \\
\hline Lead-210 & 0,000918 & $\mathrm{kBq}$ & \\
\hline Lithium & 0,00341 & $\mathrm{~kg}$ & \\
\hline Magnesium & 0,00199 & $\mathrm{~kg}$ & \\
\hline Manganese & 0,00000322 & $\mathrm{~kg}$ & \\
\hline Mercury & $6,23 \mathrm{E}-10$ & $\mathrm{~kg}$ & \\
\hline Molybdenum & $7,29 \mathrm{E}-08$ & $\mathrm{~kg}$ & \\
\hline m-Xylene & $9,61 \mathrm{E}-08$ & $\mathrm{~kg}$ & \\
\hline Nickel & $5,55 \mathrm{E}-07$ & $\mathrm{~kg}$ & \\
\hline
\end{tabular}




\begin{tabular}{|c|c|c|}
\hline Oils, unspecified & 0,0000609 & $\mathrm{~kg}$ \\
\hline o-Xylene & 0,00000007 & $\mathrm{~kg}$ \\
\hline Phenol & 0,00000142 & $\mathrm{~kg}$ \\
\hline Radium-226 & 0,0042 & $\mathrm{kBq}$ \\
\hline Radium-228 & 0,00591 & $\mathrm{kBq}$ \\
\hline Selenium & 7,05E-09 & $\mathrm{kg}$ \\
\hline Silver & 0,00000665 & $\mathrm{~kg}$ \\
\hline Sodium, ion & 0,0323 & $\mathrm{~kg}$ \\
\hline Suspended solids, unspecified & 0,141 & $\mathrm{~kg}$ \\
\hline Strontium & 0,000173 & $\mathrm{~kg}$ \\
\hline Sulfate & 0,000234 & $\mathrm{~kg}$ \\
\hline Sulfur & 0,00000841 & $\mathrm{~kg}$ \\
\hline Thallium & $7,54 \mathrm{E}-09$ & $\mathrm{~kg}$ \\
\hline Tin & 3,49E-07 & $\mathrm{kg}$ \\
\hline Titanium & $5,48 \mathrm{E}-07$ & $\mathrm{~kg}$ \\
\hline Toluene & 0,00000503 & $\mathrm{~kg}$ \\
\hline Vanadium & $8,62 \mathrm{E}-08$ & $\mathrm{~kg}$ \\
\hline Xylene & 0,00000254 & $\mathrm{~kg}$ \\
\hline Zinc & 0,00000157 & $\mathrm{~kg}$ \\
\hline
\end{tabular}




\section{A.2- Inventário de Extração Offshore de Gás Natural}

\begin{tabular}{lccc}
\hline \multicolumn{1}{c}{ Corrente } & Quantidade & Unidade & Observações \\
\hline \multicolumn{2}{c}{ Produto } & & \\
\hline $\begin{array}{l}\text { Natural gas, unprocessed SÃO PAULO, } \\
\text { from extraction/ BR U }\end{array}$ & 4,73 & $\mathrm{~m}^{3}$ & Extração de gás natural na Bacia de Santos \\
\hline Natural Gas Reinjetado, SP & 2,35 & $\mathrm{~m}^{3}$ & \\
\hline Natural gas electricity production, SP & 0,055 & $\mathrm{~m}^{3}$ & \\
\hline & \multicolumn{2}{c}{ Entradas } \\
\hline
\end{tabular}

\section{Entradas}

Recursos Naturais obtidos da Biosfera

Gas, natural $/ \mathrm{m}^{3}$

$5,79 \quad \mathrm{~m}^{3}$

Esfera tecnológicas: Materiais e Combustíveis

Electricity, medium voltage, at grid/BR U

Natural Gas BR from reinjection- SP

$0,136 \quad \mathrm{kWh}$

2,35 $\mathrm{m}^{3}$

\section{Saídas}

Emissões Atmosféricas

$\mathrm{P}=$ perda de gás natural por conta de ações $\mathrm{P} \& \mathrm{D}=12,43 \%$

Methane, fossil

0,693

$\mathrm{kg}$

Perdas totais como $\mathrm{P} \& \mathrm{D}=1,005 \mathrm{~m}^{3}$

\begin{tabular}{|c|c|c|c|}
\hline \multirow[t]{3}{*}{ Mictilante, Iossit } & \multirow[t]{3}{*}{0,093} & \multirow[t]{3}{*}{ kg } & \multirow{3}{*}{$\begin{array}{l}\text { Densidade do gás }=0,78 \mathrm{~kg} / \mathrm{m}^{3} \\
\text { Teor de } \mathrm{CH}_{4}=88,32 \% \\
\mathrm{E}_{\mathrm{CH} 4}=1,005 * 0,78 * 0,8832=0,693 \mathrm{~kg}\end{array}$} \\
\hline & & & \\
\hline & & & \\
\hline \multicolumn{4}{|c|}{ Emissões para água } \\
\hline 4-Methyl-2-pentanone & $1,33 \mathrm{E}-08$ & $\mathrm{~kg}$ & \\
\hline Acetone & $3,17 \mathrm{E}-08$ & $\mathrm{~kg}$ & \\
\hline Acidity, unspecified & $6,67 \mathrm{E}-07$ & $\mathrm{~kg}$ & \\
\hline Aluminium & 0,0000584 & $\mathrm{~kg}$ & \\
\hline Ammonium, ion & 0,0000391 & $\mathrm{~kg}$ & \\
\hline Antimony & $3,57 \mathrm{E}-08$ & $\mathrm{~kg}$ & \\
\hline Arsenic & 7,01E-07 & $\mathrm{kg}$ & \\
\hline Barium & 0,000903 & $\mathrm{~kg}$ & \\
\hline Benzene & $5,32 \mathrm{E}-06$ & $\mathrm{~kg}$ & \\
\hline Benzene, ethyl- & 2,99E-07 & $\mathrm{kg}$ & \\
\hline Beryllium & $3,18 \mathrm{E}-08$ & $\mathrm{~kg}$ & \\
\hline $\mathrm{BOD}_{5}$, Biological Oxygen Demand & 0,000552 & $\mathrm{~kg}$ & \\
\hline Boron & $9,96 \mathrm{E}-06$ & $\mathrm{~kg}$ & \\
\hline Bromine & 0,00068 & $\mathrm{~kg}$ & \\
\hline Cadmium & $1,02 \mathrm{E}-07$ & $\mathrm{~kg}$ & \\
\hline Calcium, ion & 0,0102 & $\mathrm{~kg}$ & \\
\hline Chloride & 0,115 & $\mathrm{~kg}$ & \\
\hline Chromium & $1,61 \mathrm{E}-06$ & $\mathrm{~kg}$ & \\
\hline Cobalt & $7,03 \mathrm{E}-08$ & $\mathrm{~kg}$ & \\
\hline COD, Chemical Oxygen Demand & 0,000913 & $\mathrm{~kg}$ & \\
\hline Copper & $4,48 \mathrm{E}-07$ & $\mathrm{~kg}$ & \\
\hline Cyanide & $2,29 \mathrm{E}-10$ & $\mathrm{~kg}$ & \\
\hline Fluoride & $1,11 \mathrm{E}-09$ & $\mathrm{~kg}$ & \\
\hline Iron & 0,000184 & $\mathrm{~kg}$ & \\
\hline Lead & 1,01E-06 & $\mathrm{kg}$ & \\
\hline Lead-210 & 0,000918 & $\mathrm{kBq}$ & \\
\hline Lithium & 0,00341 & $\mathrm{~kg}$ & \\
\hline
\end{tabular}




\begin{tabular}{|c|c|c|}
\hline Magnesium & 0,00199 & $\mathrm{~kg}$ \\
\hline Manganese & $3,22 \mathrm{E}-06$ & $\mathrm{~kg}$ \\
\hline Mercury & $6,23 \mathrm{E}-10$ & $\mathrm{~kg}$ \\
\hline Molybdenum & $7,29 \mathrm{E}-08$ & $\mathrm{~kg}$ \\
\hline m-Xylene & 9,61E-08 & $\mathrm{kg}$ \\
\hline Nickel & $5,55 \mathrm{E}-07$ & $\mathrm{~kg}$ \\
\hline Oils, unspecified & 0,0000609 & $\mathrm{~kg}$ \\
\hline o-Xylene & 7E-08 & $\mathrm{kg}$ \\
\hline Phenol & $1,42 \mathrm{E}-06$ & $\mathrm{~kg}$ \\
\hline Radium-226 & 0,0042 & $\mathrm{kBq}$ \\
\hline Radium-228 & 0,00591 & $\mathrm{kBq}$ \\
\hline Selenium & 7,05E-09 & $\mathrm{kg}$ \\
\hline Silver & $6,65 \mathrm{E}-06$ & $\mathrm{~kg}$ \\
\hline Sodium, ion & 0,0323 & $\mathrm{~kg}$ \\
\hline Suspended solids, unspecified & 0,141 & $\mathrm{~kg}$ \\
\hline Strontium & 0,000173 & $\mathrm{~kg}$ \\
\hline Sulfate & 0,000234 & $\mathrm{~kg}$ \\
\hline Sulfur & $8,41 \mathrm{E}-06$ & $\mathrm{~kg}$ \\
\hline Thallium & 7,54E-09 & $\mathrm{kg}$ \\
\hline Tin & 3,49E-07 & $\mathrm{kg}$ \\
\hline Titanium & $5,48 \mathrm{E}-07$ & $\mathrm{~kg}$ \\
\hline Toluene & 5,03E-06 & $\mathrm{kg}$ \\
\hline Vanadium & $8,62 \mathrm{E}-08$ & $\mathrm{~kg}$ \\
\hline Xylene & $2,54 \mathrm{E}-06$ & $\mathrm{~kg}$ \\
\hline Zinc & $1,57 \mathrm{E}-06$ & $\mathrm{~kg}$ \\
\hline
\end{tabular}




\begin{tabular}{|c|c|c|c|c|c|}
\hline \multicolumn{6}{|c|}{ A.3- Inventário de Transporte do Gás Natural não processado } \\
\hline Corrente & Quantidade & Unidade & Observaçõe & & \\
\hline \multicolumn{6}{|c|}{ Produto } \\
\hline \multirow{3}{*}{$\begin{array}{l}\text { Natural gas, unprocessed SÃO PAULO, } \\
\text { at transportation/ BR U }\end{array}$} & \multirow{3}{*}{1.0} & \multirow{3}{*}{$\mathrm{m}^{3}$} & \multicolumn{3}{|c|}{ Composição do gás natural bruto da bacia de Santos: } \\
\hline & & & $88,32 \% \mathrm{CH}_{4}$ & $6,06 \% \mathrm{C}_{2} \mathrm{H}_{6}$ & $3,07 \% \mathrm{C}_{3} \mathrm{H}_{8}$ \\
\hline & & & $0,7 \% \mathrm{C}_{4} \mathrm{H}_{10}$ & $0,15 \% \mathrm{CO}_{2}$ & $0,68 \% \mathrm{~N}_{2}$ \\
\hline \multicolumn{6}{|c|}{ Entradas } \\
\hline \multicolumn{6}{|c|}{ Esfera tecnológicas: Materiais e Combustíveis } \\
\hline \multirow{3}{*}{$\begin{array}{l}\text { Transport, natural gas, offshore pipeline, } \\
\text { long distance/BR U }\end{array}$} & \multirow{3}{*}{0,149} & \multirow{3}{*}{ t.km } & \multicolumn{3}{|c|}{$\mathrm{T}=1,037 \mathrm{~m}^{3 *} 0,78^{*} 184 \mathrm{~km}=0,149 \mathrm{tkm}$} \\
\hline & & & $\mathrm{L}=184 \mathrm{~km}$ & Densidade $\mathrm{d}$ & $\mathrm{I}_{4}=0,78 \mathrm{~kg} / \mathrm{m}^{3}$ \\
\hline & & & \multicolumn{3}{|c|}{$\begin{array}{l}\text { Como } \mathrm{L}=184 \mathrm{~km} \text {, considerou-se uma perda relativa de } \\
\mathrm{P}=3,68 \%\end{array}$} \\
\hline $\begin{array}{l}\text { Natural gas, unprocessed SÃO PAULO, } \\
\text { from extraction/ BR U }\end{array}$ & 1,037 & \multicolumn{4}{|c|}{ - } \\
\hline \multicolumn{6}{|c|}{ Saídas } \\
\hline \multicolumn{6}{|c|}{ Emissões Atmosféricas } \\
\hline Methane & 0,025 & $\mathrm{~kg}$ & & $\mathrm{E}_{\mathrm{CH} 4}=0,036$ & $78 * 0,8832=0,02535 \mathrm{~kg}$ \\
\hline Carbon dioxide, fossil & $4,31 \mathrm{E}-04$ & $\mathrm{~kg}$ & & $\mathrm{E}_{\mathrm{CO} 2}=0,036$ & $78 * 0,0015=4,306 \mathrm{E}-04 \mathrm{~kg}$ \\
\hline
\end{tabular}

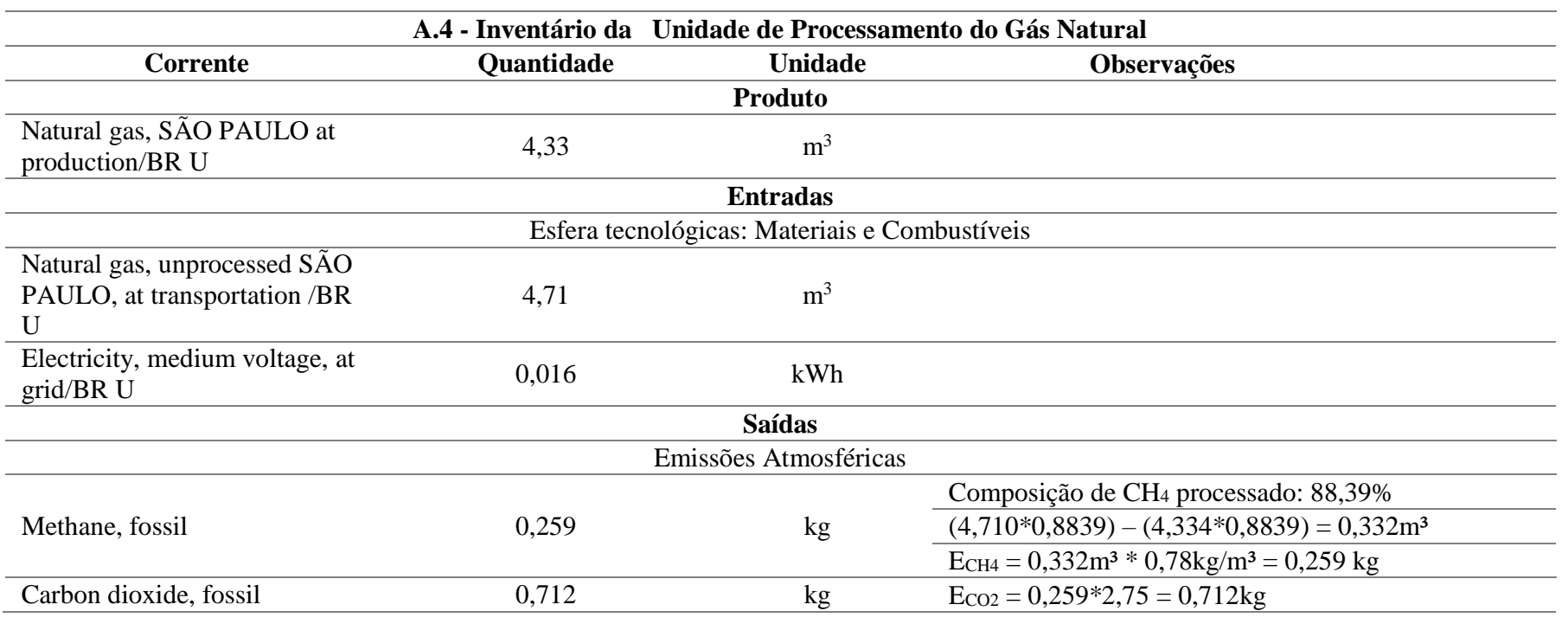




\begin{tabular}{|c|c|c|c|c|}
\hline \multicolumn{5}{|c|}{ A.5 - Inventário do Gás Natural Processado e transportado } \\
\hline Corrente & Quantidade & Unidade & Observa & \\
\hline \multicolumn{5}{|c|}{ Produto } \\
\hline \multirow{4}{*}{$\begin{array}{l}\text { Natural Gas at production } \\
\text { transportation from SÃO PAULO to } \\
\text { SP }\end{array}$} & \multirow{4}{*}{1.0} & \multirow{4}{*}{$\mathrm{m}^{3}$} & \multicolumn{2}{|c|}{$\begin{array}{l}\text { Composição do gás natural processado em } \\
\text { RPBC }\end{array}$} \\
\hline & & & $88,32 \% \mathrm{CH}_{4}$ & $6,06 \% \mathrm{C}_{2} \mathrm{H}_{6}$ \\
\hline & & & $3,07 \% \mathrm{C}_{3} \mathrm{H}_{8}$ & $0,70 \% \mathrm{C}_{4} \mathrm{H}_{10}$ \\
\hline & & & $0,15 \% \quad \mathrm{CO}_{2}$ & $0,68 \% \mathrm{~N}_{2}$ \\
\hline \multicolumn{5}{|c|}{ Entradas } \\
\hline \multicolumn{5}{|c|}{ Esfera tecnológicas: Materiais e Combustíveis } \\
\hline $\begin{array}{l}\text { Natural gas, SÃO PAULO at } \\
\text { production/BR U }\end{array}$ & 1,01 & $\mathrm{~m}^{3}$ & $\begin{array}{l}\text { Para } \mathrm{L}=100 \mathrm{k} \\
\mathrm{P}=1,00 \%\end{array}$ & -se uma perda \\
\hline \multirow[t]{2}{*}{$\begin{array}{l}\text { Transport, natural gas, onshore } \\
\text { pipeline, long distance/BR U }\end{array}$} & \multirow[t]{2}{*}{0,079} & \multirow[t]{2}{*}{ t.km } & \multicolumn{2}{|c|}{$\begin{array}{l}\mathrm{T}=1,01 \mathrm{~m}^{3} *(0,78 / 1000) * 100 \mathrm{~km} \\
\mathrm{~T}=0,079 \mathrm{tkm}\end{array}$} \\
\hline & & & \multicolumn{2}{|c|}{ Densidade do $\mathrm{CH}_{4}=0,78 \mathrm{~kg} / \mathrm{m}^{3}$} \\
\hline \multicolumn{5}{|c|}{ Saídas } \\
\hline \multicolumn{5}{|c|}{ Emissões Atmosféricas } \\
\hline Methane, fossil & 0,00689 & $\mathrm{~kg}$ & $\mathrm{E}_{\mathrm{CH} 4}=0,01 * 0$ & $=6,89 \mathrm{E}-3$ \\
\hline Carbon dioxide, fossil & $5,30 \mathrm{E}-05$ & $\mathrm{~kg}$ & $\mathrm{E}_{\mathrm{CO} 2}=0,01 * 0$ & $=5,30 \mathrm{E}-5$ \\
\hline
\end{tabular}

\section{A.6- Inventário de Extração Onshore de Gás Natural da Alternativa- 4}

\begin{tabular}{|c|c|c|c|}
\hline Corrente & Quantidade & Unidade & Observações \\
\hline \multicolumn{4}{|c|}{ Produto } \\
\hline $\begin{array}{l}\text { Natural gas, unprocessed MARANHÃO, } \\
\text { from extraction/ BR U }\end{array}$ & 3,99 & $\mathrm{~m} 3$ & $\begin{array}{l}\text { Extração de Gás Natural na Bacia de } \\
\text { Parnaíba ,MA }\end{array}$ \\
\hline \multicolumn{4}{|c|}{ Entradas } \\
\hline \multicolumn{4}{|c|}{ Recursos Naturais } \\
\hline Gas, natural/m3 & 1 & $\mathrm{~m} 3$ & \\
\hline \multicolumn{4}{|c|}{ Recursos Antrópicos } \\
\hline Electricity, medium voltage, at grid/BR U & 0,06673 & $\mathrm{kWh}$ & Grid Brasil \\
\hline \multicolumn{4}{|c|}{ Saídas } \\
\hline \multicolumn{4}{|c|}{ Emissõs Atmosféricas } \\
\hline Methane, fossil & 0,329 & $\mathrm{~kg}$ & $\begin{array}{l}12,43 \% \text { de perda de gás natural que } \\
\text { corresponde a ações } \mathrm{P} \& \mathrm{D}\end{array}$ \\
\hline & & & $\begin{array}{l}\text { Perda P\&D = } \\
0,4972 \mathrm{~m}^{3}\end{array}$ \\
\hline & & & Densid. $=0,78 \mathrm{~kg} / \mathrm{m}^{3}$ \\
\hline & & & $\begin{array}{l}\text { Comp.CH4 no MA } \\
=85 \%\end{array}$ \\
\hline & & & $\begin{array}{l}\mathrm{CH} 4=0,4972 * 0,78 * 0,85 \\
=0,329 \mathrm{~kg}\end{array}$ \\
\hline \multicolumn{4}{|c|}{ Emissões para a água } \\
\hline 4-Methyl-2-pentanone & $1,3 \mathrm{E}-08$ & $\mathrm{~kg}$ & \\
\hline Acetone & 3,2E-08 & $\mathrm{kg}$ & \\
\hline Acidity, unspecified & 6,7E-07 & $\mathrm{kg}$ & \\
\hline Aluminium & $5,8 \mathrm{E}-05$ & $\mathrm{~kg}$ & \\
\hline Ammonium, ion & $3,9 \mathrm{E}-05$ & $\mathrm{~kg}$ & \\
\hline Antimony & $3,6 \mathrm{E}-08$ & $\mathrm{~kg}$ & \\
\hline
\end{tabular}




\begin{tabular}{|c|c|c|}
\hline Arsenic & $7 \mathrm{E}-07$ & $\mathrm{~kg}$ \\
\hline Barium & 0,0009 & $\mathrm{~kg}$ \\
\hline Benzene & $5,3 \mathrm{E}-06$ & $\mathrm{~kg}$ \\
\hline Benzene, ethyl- & 3E-07 & $\mathrm{kg}$ \\
\hline Beryllium & $3,2 \mathrm{E}-08$ & $\mathrm{~kg}$ \\
\hline BOD5, Biological Oxygen Demand & 0,00055 & $\mathrm{~kg}$ \\
\hline Boron & $1 \mathrm{E}-05$ & $\mathrm{~kg}$ \\
\hline Bromine & 0,00068 & $\mathrm{~kg}$ \\
\hline Cadmium & 1E-07 & $\mathrm{kg}$ \\
\hline Calcium, ion & 0,0102 & $\mathrm{~kg}$ \\
\hline Chloride & 0,115 & $\mathrm{~kg}$ \\
\hline Chromium & $1,6 \mathrm{E}-06$ & $\mathrm{~kg}$ \\
\hline Cobalt & 7E-08 & $\mathrm{kg}$ \\
\hline COD, Chemical Oxygen Demand & 0,00091 & $\mathrm{~kg}$ \\
\hline Copper & $4,5 \mathrm{E}-07$ & $\mathrm{~kg}$ \\
\hline Cyanide & $2,3 \mathrm{E}-10$ & $\mathrm{~kg}$ \\
\hline Fluoride & $1,1 \mathrm{E}-09$ & $\mathrm{~kg}$ \\
\hline Iron & 0,00018 & $\mathrm{~kg}$ \\
\hline Lead & 1E-06 & $\mathrm{kg}$ \\
\hline Lead-210 & 0,00092 & $\mathrm{kBq}$ \\
\hline Lithium & 0,00341 & $\mathrm{~kg}$ \\
\hline Magnesium & 0,00199 & $\mathrm{~kg}$ \\
\hline Manganese & $3,2 \mathrm{E}-06$ & $\mathrm{~kg}$ \\
\hline Mercury & $6,2 \mathrm{E}-10$ & $\mathrm{~kg}$ \\
\hline Molybdenum & $7,3 \mathrm{E}-08$ & $\mathrm{~kg}$ \\
\hline m-Xylene & $9,6 \mathrm{E}-08$ & $\mathrm{~kg}$ \\
\hline Nickel & $5,6 \mathrm{E}-07$ & $\mathrm{~kg}$ \\
\hline Oils, unspecified & $6,1 \mathrm{E}-05$ & $\mathrm{~kg}$ \\
\hline o-Xylene & 7E-08 & $\mathrm{kg}$ \\
\hline Phenol & $1,4 \mathrm{E}-06$ & $\mathrm{~kg}$ \\
\hline Radium-226 & 0,0042 & $\mathrm{kBq}$ \\
\hline Radium-228 & 0,00591 & $\mathrm{kBq}$ \\
\hline Selenium & 7,1E-09 & $\mathrm{kg}$ \\
\hline Silver & $6,7 \mathrm{E}-06$ & $\mathrm{~kg}$ \\
\hline Sodium, ion & 0,0323 & $\mathrm{~kg}$ \\
\hline Suspended solids, unspecified & 0,141 & $\mathrm{~kg}$ \\
\hline Strontium & 0,00017 & $\mathrm{~kg}$ \\
\hline Sulfate & 0,00023 & $\mathrm{~kg}$ \\
\hline Sulfur & $8,4 \mathrm{E}-06$ & $\mathrm{~kg}$ \\
\hline Thallium & $7,5 \mathrm{E}-09$ & $\mathrm{~kg}$ \\
\hline Tin & $3,5 \mathrm{E}-07$ & $\mathrm{~kg}$ \\
\hline Titanium & $5,5 \mathrm{E}-07$ & $\mathrm{~kg}$ \\
\hline Toluene & 5E-06 & $\mathrm{kg}$ \\
\hline Vanadium & $8,6 \mathrm{E}-08$ & $\mathrm{~kg}$ \\
\hline Xylene & $2,5 \mathrm{E}-06$ & $\mathrm{~kg}$ \\
\hline Zinc & $1,6 \mathrm{E}-06$ & $\mathrm{~kg}$ \\
\hline
\end{tabular}




\section{A.7- Inventário de Extração Offshore de Gás Natural da}

Alternativa-2

\begin{tabular}{|c|c|c|c|}
\hline Corrente & Quantidade & Unidade & Observações \\
\hline \multicolumn{4}{|c|}{ Produto } \\
\hline $\begin{array}{l}\text { Natural gas, unprocessed PELOTAS RS, at } \\
\text { extraction/BR U }\end{array}$ & 9,075 & $\mathrm{~m} 3$ & \\
\hline Natural Gas Reinjetado, RS & 2,654 & $\mathrm{~m} 3$ & \\
\hline Natural gas electricity production, RS & 0,1315372 & $\mathrm{~m} 3$ & \\
\hline \multicolumn{4}{|c|}{ Entradas } \\
\hline \multicolumn{4}{|c|}{ Recursos Naturais } \\
\hline Gas, natural/m3 & 9,122 & $\mathrm{~m} 3$ & \\
\hline \multicolumn{4}{|c|}{ Recursos Antrópicos } \\
\hline Electricity, medium voltage, at grid/BR U & 0,485 & $\mathrm{kWh}$ & \\
\hline Natural Gas BR from reinjection- RJ & 2,654 & $\mathrm{~m} 3$ & \\
\hline \multicolumn{4}{|l|}{ 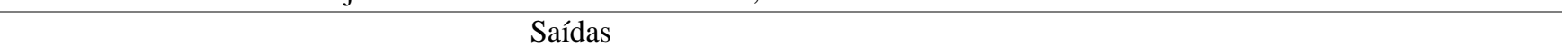 } \\
\hline \multicolumn{4}{|c|}{ Emissões Atmosféricas } \\
\hline Methane, fossil & 0,7911 & $\mathrm{~kg}$ & $\begin{array}{l}\text { Corresponde a } 12,43 \% \text { de perda de gás } \\
\text { natural por conta de ações P\&D }\end{array}$ \\
\hline & & & Perda E\&P =1,134m³ \\
\hline & & & Densid $=0,78 \mathrm{~kg} / \mathrm{m}^{3}$ \\
\hline & & & Comp.CH4 no RJ=89,44\% \\
\hline & & & $\mathrm{CH} 4=1,134 * 0,78 * 0,8944=0,7911 \mathrm{~kg}$ \\
\hline \multicolumn{4}{|c|}{ Emissões para a água } \\
\hline 4-Methyl-2-pentanone & $1,33 \mathrm{E}-08$ & $\mathrm{~kg}$ & \\
\hline Acetone & $3,17 \mathrm{E}-08$ & $\mathrm{~kg}$ & \\
\hline Acidity, unspecified & 0,000000667 & $\mathrm{~kg}$ & \\
\hline Aluminium & 0,0000584 & $\mathrm{~kg}$ & \\
\hline Ammonium, ion & 0,0000391 & $\mathrm{~kg}$ & \\
\hline Antimony & $3,57 \mathrm{E}-08$ & $\mathrm{~kg}$ & \\
\hline Arsenic & 0,000000701 & $\mathrm{~kg}$ & \\
\hline Barium & 0,000903 & $\mathrm{~kg}$ & \\
\hline Benzene & 0,00000532 & $\mathrm{~kg}$ & \\
\hline Benzene, ethyl- & 0,000000299 & $\mathrm{~kg}$ & \\
\hline Beryllium & $3,18 \mathrm{E}-08$ & $\mathrm{~kg}$ & \\
\hline BOD5, Biological Oxygen Demand & 0,000552 & $\mathrm{~kg}$ & \\
\hline Boron & 0,00000996 & $\mathrm{~kg}$ & \\
\hline Bromine & 0,00068 & $\mathrm{~kg}$ & \\
\hline Cadmium & 0,000000102 & $\mathrm{~kg}$ & \\
\hline Calcium, ion & 0,0102 & $\mathrm{~kg}$ & \\
\hline Chloride & 0,115 & $\mathrm{~kg}$ & \\
\hline Chromium & 0,00000161 & $\mathrm{~kg}$ & \\
\hline Cobalt & $7,03 \mathrm{E}-08$ & $\mathrm{~kg}$ & \\
\hline COD, Chemical Oxygen Demand & 0,000913 & $\mathrm{~kg}$ & \\
\hline Copper & 0,000000448 & $\mathrm{~kg}$ & \\
\hline Cyanide & $2,29 \mathrm{E}-10$ & $\mathrm{~kg}$ & \\
\hline Fluoride & $1,11 \mathrm{E}-09$ & $\mathrm{~kg}$ & \\
\hline Iron & 0,000184 & $\mathrm{~kg}$ & \\
\hline Lead & 0,00000101 & $\mathrm{~kg}$ & \\
\hline
\end{tabular}




\begin{tabular}{|c|c|c|}
\hline Lead-210 & 0,000918 & $\mathrm{kBq}$ \\
\hline Lithium & 0,00341 & $\mathrm{~kg}$ \\
\hline Magnesium & 0,00199 & $\mathrm{~kg}$ \\
\hline Manganese & 0,00000322 & $\mathrm{~kg}$ \\
\hline Mercury & $6,23 \mathrm{E}-10$ & $\mathrm{~kg}$ \\
\hline Molybdenum & 7,29E-08 & $\mathrm{kg}$ \\
\hline m-Xylene & $9,61 \mathrm{E}-08$ & $\mathrm{~kg}$ \\
\hline Nickel & 0,000000555 & $\mathrm{~kg}$ \\
\hline Oils, unspecified & 0,0000609 & $\mathrm{~kg}$ \\
\hline o-Xylene & 0,00000007 & $\mathrm{~kg}$ \\
\hline Phenol & 0,00000142 & $\mathrm{~kg}$ \\
\hline Radium-226 & 0,0042 & $\mathrm{kBq}$ \\
\hline Radium-228 & 0,00591 & $\mathrm{kBq}$ \\
\hline Selenium & 7,05E-09 & $\mathrm{kg}$ \\
\hline Silver & 0,00000665 & $\mathrm{~kg}$ \\
\hline Sodium, ion & 0,0323 & $\mathrm{~kg}$ \\
\hline Suspended solids, unspecified & 0,141 & $\mathrm{~kg}$ \\
\hline Strontium & 0,000173 & $\mathrm{~kg}$ \\
\hline Sulfate & 0,000234 & $\mathrm{~kg}$ \\
\hline Sulfur & 0,00000841 & $\mathrm{~kg}$ \\
\hline Thallium & 7,54E-09 & $\mathrm{kg}$ \\
\hline Tin & 0,000000349 & $\mathrm{~kg}$ \\
\hline Titanium & 0,000000548 & $\mathrm{~kg}$ \\
\hline Toluene & 0,00000503 & $\mathrm{~kg}$ \\
\hline Vanadium & $8,62 \mathrm{E}-08$ & $\mathrm{~kg}$ \\
\hline Xylene & 0,00000254 & $\mathrm{~kg}$ \\
\hline Zinc & 0,00000157 & $\mathrm{~kg}$ \\
\hline
\end{tabular}




\begin{tabular}{|c|c|c|c|}
\hline \multicolumn{4}{|c|}{ A.8 - Inventário de Transporte do Gás Natural não Processado da Alternativa- 4} \\
\hline Corrente & Quantidade & Unidade & Observações \\
\hline \multicolumn{4}{|c|}{ Produto } \\
\hline \multirow{4}{*}{$\begin{array}{l}\text { Natural gas, unprocessed MARANHÃO, at } \\
\text { transportation/ BR U }\end{array}$} & & & $85 \% \quad \mathrm{CH} 4 \quad 3,0 \% \quad \mathrm{C} 02$ \\
\hline & & & $12 \% \mathrm{C} 2 \mathrm{H} 6$ \\
\hline & & & $3,0 \% \mathrm{C} 4 \mathrm{H} 10$ \\
\hline & Entradas & & \\
\hline \multicolumn{4}{|c|}{ Esfera Tecnológicas: Materiais e Combustíveis } \\
\hline \multirow[t]{4}{*}{$\begin{array}{l}\text { Transport, natural gas, onshore pipeline, long } \\
\text { distance/BR U }\end{array}$} & 0,0627 & tkm & $\mathrm{L}=55 \mathrm{~km}$ \\
\hline & & & densidade do $\mathrm{CH} 4=0,78 \mathrm{~kg} / \mathrm{m} 3$ \\
\hline & & & $\begin{array}{l}\text { Para } L=55 \mathrm{~km} \text { foi considerado } \\
\text { perda de } 0,33 \%\end{array}$ \\
\hline & & & $(55 / 500) * 3 \%=0,33 \%$ \\
\hline \multirow{3}{*}{$\begin{array}{l}\text { Natural gas, unprocessed MARANHÃO, from } \\
\text { extraction/ BR U }\end{array}$} & 4 & $\mathrm{~m} 3$ & \\
\hline & \multicolumn{3}{|c|}{ Emissões Atmosféricas } \\
\hline & 0,0021879 & $\mathrm{~kg}$ & $0,0033 * 0,78 * 0,85=2,1879 \mathrm{E}-3$ \\
\hline Methane, fossil & 0,0016692 & $\mathrm{~kg}$ & $\begin{array}{l}\text { CH4 }(p)= \\
0,002144 * 0,78=0,0016692 \mathrm{~kg}\end{array}$ \\
\hline Carbon dioxide, fossil & 0,00007722 & $\mathrm{~kg}$ & $0,0033 * 0,78 * 0,03=7,722 \mathrm{E}-5$ \\
\hline
\end{tabular}

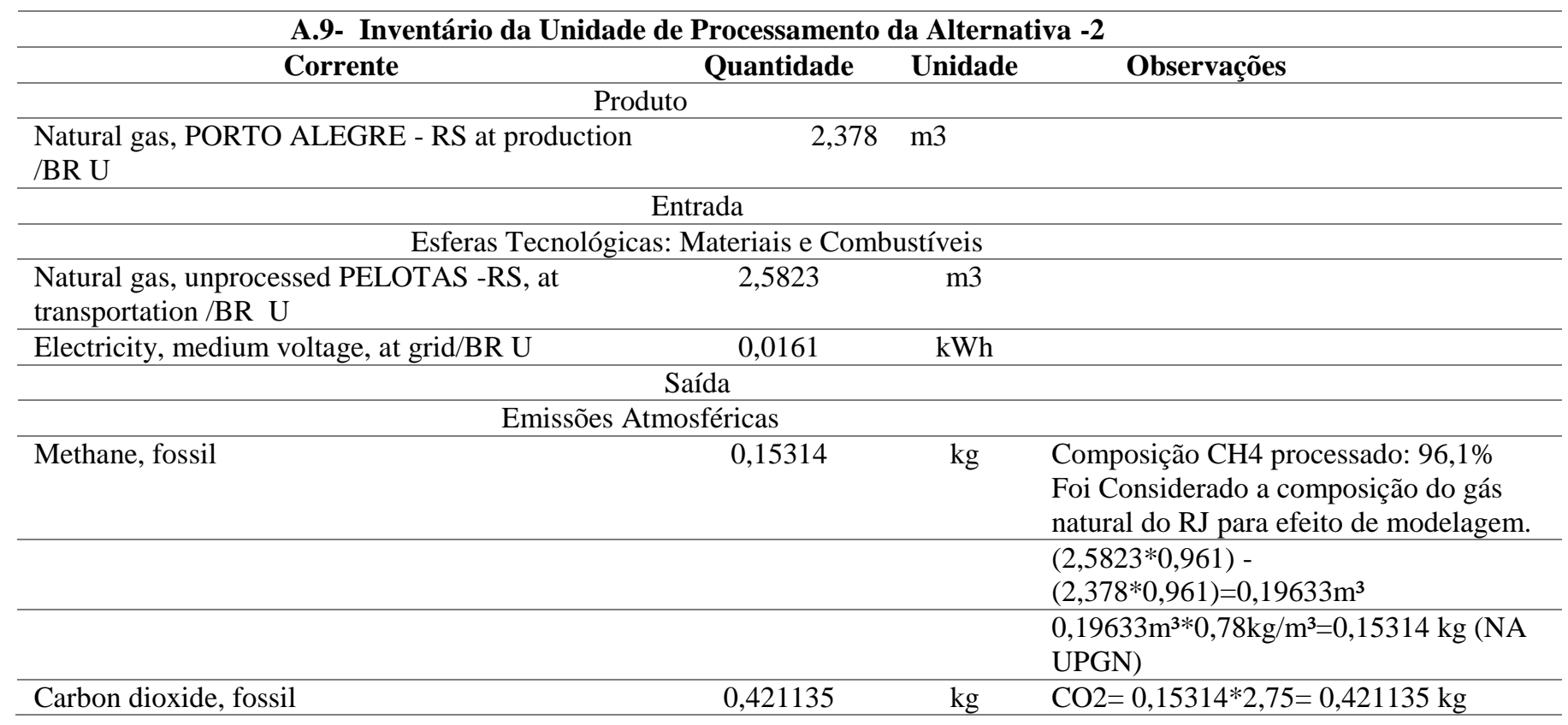




\section{A.10- Inventário do Gás Natural Processado e Transportado a Alternativa -6}

\begin{tabular}{|c|c|c|c|}
\hline Corrente & Quantidade & Unidade & Observações \\
\hline \multicolumn{4}{|c|}{ Produto } \\
\hline \multirow{6}{*}{$\begin{array}{l}\text { Natural Gas at production } \\
\text { transportation from } \\
\text { ANÁPOLIS-GO to } \\
\text { PALMAS }\end{array}$} & 4,029 & $\mathrm{~m} 3$ & Composição GÁS NATURAL -BO: \\
\hline & & & C4H10. $003 \%$ \\
\hline & & & C2H6: $5,58 \%$ \\
\hline & & & С3H8: $0,97 \%$ \\
\hline & \multicolumn{3}{|c|}{ Entradas } \\
\hline & \multicolumn{3}{|c|}{ Esfera Tecnológicas:Materiais e Combustíveis } \\
\hline \multirow{2}{*}{$\begin{array}{l}\text { Natural Gas at production } \\
\text { transportation from SÃO } \\
\text { CARLOS-SP to } \\
\text { ANÁPOLIS-GO }\end{array}$} & \multirow{2}{*}{4,071} & \multirow[t]{2}{*}{$\mathrm{m} 3$} & Para $\mathrm{L}=722 \mathrm{~km}$ a perda será de $4,332 \%$ \\
\hline & & & Distância SÃO CARLOS-SP to ANÁPOLIS-GO \\
\hline \multirow{2}{*}{$\begin{array}{l}\text { Transport, natural gas, } \\
\text { onshore pipeline, long } \\
\text { distance/BR U }\end{array}$} & \multirow[t]{2}{*}{0,58755} & \multirow[t]{2}{*}{ tkm } & $\mathrm{T}=1,04332 \mathrm{~m} 3 *(0,78 / 1000) * 722 \mathrm{~km}=0,58755 \mathrm{tkm}$ \\
\hline & & & Densidade do $\mathrm{CH} 4=0,78 \mathrm{~kg} / \mathrm{m} 3$ \\
\hline \multicolumn{4}{|c|}{ Emissões Atmosféricas } \\
\hline Methane & 0,031 & $\mathrm{~kg}$ & $0,04332 * 0,78 * 0,918=0,0310$ \\
\hline Methane, fossil & 0,009984 & $\mathrm{~kg}$ & $\mathrm{CH} 4(\mathrm{p})=0,0128 * 0,78=0,009984$ \\
\hline Carbon dioxide, fossil & $2,70317 \mathrm{E}-05$ & $\mathrm{~kg}$ & $0,04332 * 0,78 * 0,0008=2,703168 \mathrm{E}-5$ \\
\hline \multirow[t]{2}{*}{ Carbon dioxide, fossil } & 0,00008167 & $\mathrm{~kg}$ & Foi considerado ao longo de $772 \mathrm{~km} 3$ compressores: \\
\hline & & & $\mathrm{CO} 2=0,0297 * 2,75=0,08167 \mathrm{~g}$ ou $(8,167 \mathrm{E}-5 \mathrm{~kg})$ \\
\hline
\end{tabular}




\section{A.11 - Alternativa-1}

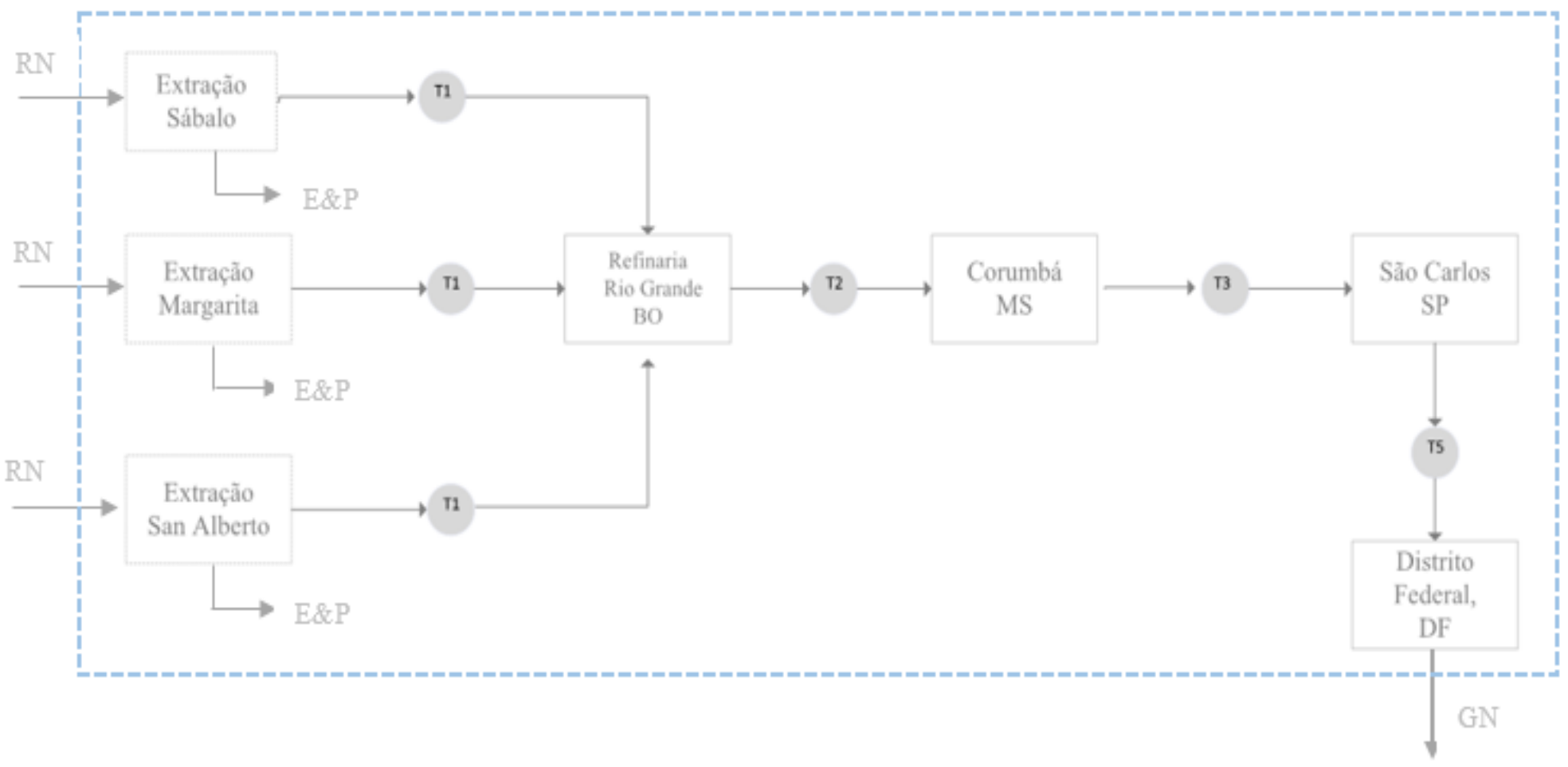

T Transporte

$\longrightarrow$ Fluxos Intermediários

Fronteira do Sistema

6 compressores de São Carlos a DF

4 compressores do Campo de Extração a Refinaria Rio Grande

10 compressores da Refinaria Rio Grande a São Carlos

RN :Recurso Natural

GN: Gás Natural 
A.12 - Alternativa-2

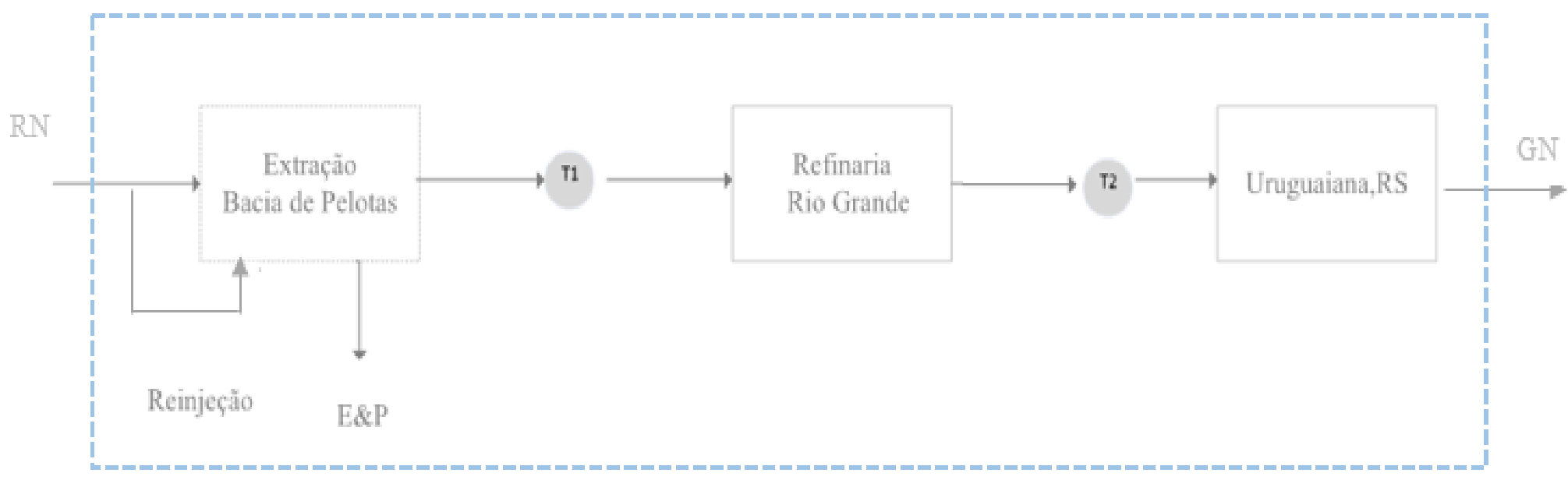

T Transporte

Fluxos Intermediários

Fronteira do Sistema

1 compressor do Campo de Extração a Refinaria Rio Grande

3 compressores da Refinaria Rio Grande a Uruguaiana

$\mathrm{RN}$ :Recurso Natural

GN: Gás Natural 


\section{A.14 - Alternativa-4}

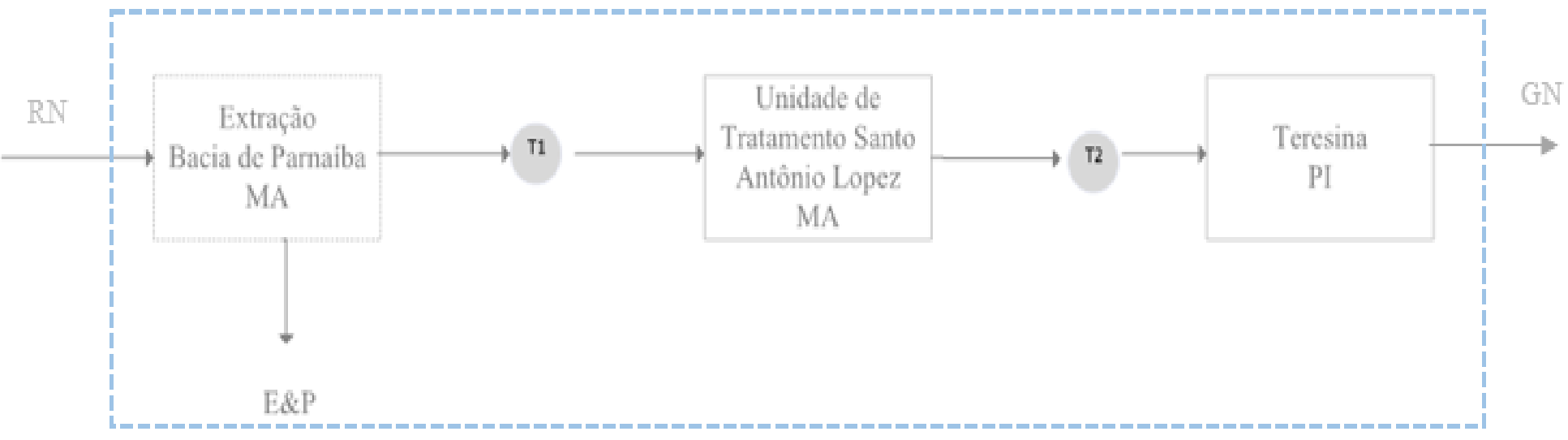

T Transporte

$\longrightarrow$ Fluxos Intermediários

Fronteira do Sistema

1 compressor do Campo de Extração a Unidade de Tratamento Santo Antônio Lopez, MA

2 compressores da Unidade de Tratamento Santo Antônio Lopez, MA até Teresina, PI

RN :Recurso Natural

GN: Gás Natural 


\section{A.15 - Alternativa-5}

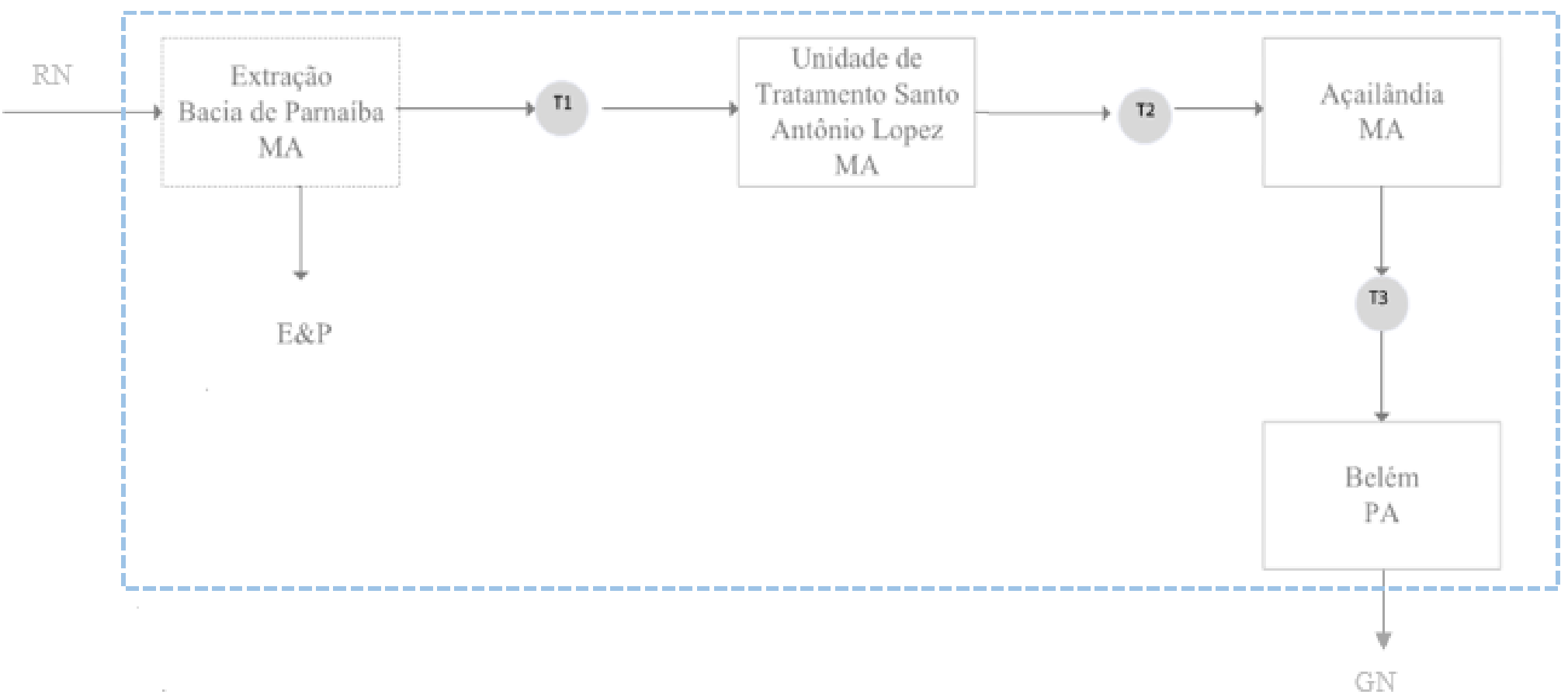

T Transporte

\begin{tabular}{ll}
$\longrightarrow$ & Fluxos Intermediários \\
\hdashline & Fronteira do Sistema
\end{tabular}

1 compressor do Campo de Extração a Unidade de Tratamento Santo Antônio Lopez, MA

2 compressores da Unidade de Tratamento Santo Antônio Lopez, MA até Açailândia, MA

3 compressores de Açailândia, MA até Belém, PA

RN :Recurso Natural

GN: Gás Natural 


\section{A.16 - Alternativa-6}

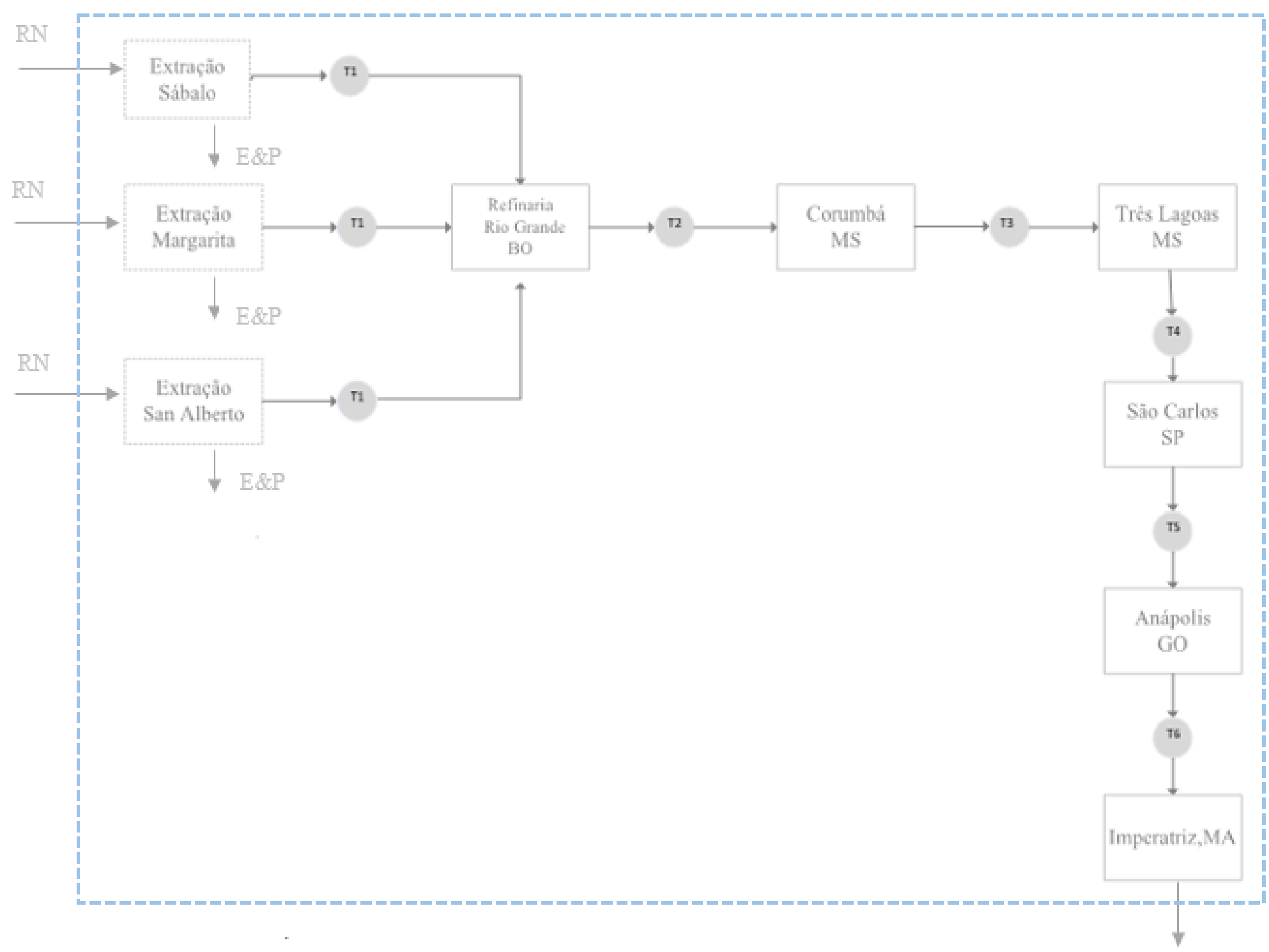

T Transporte

Fluxos Intermediários

Fronteira do Sistema

4 compressores do Campo de Extração a Refinaria Rio Grande, BO

10 compressores da Refinaria Rio Grande a São Carlos

12 compressores de São Carlos a Imperatriz, MA

$\mathrm{RN}:$ Recurso Natural

GN: Gás Natural 
